University of Tennessee Health Science Center UTHSC Digital Commons

\title{
Mrp4 Is a Crucial Regulator of Testosterone Biosynthesis
}

Jessica Ann Morgan

University of Tennessee Health Science Center

Follow this and additional works at: https://dc.uthsc.edu/dissertations

Part of the Amino Acids, Peptides, and Proteins Commons, and the Medical Cell Biology Commons

\section{Recommended Citation}

Morgan, Jessica Ann , "Mrp4 Is a Crucial Regulator of Testosterone Biosynthesis" (2012). Theses and Dissertations (ETD). Paper 182. http://dx.doi.org/10.21007/etd.cghs.2012.0217.

This Dissertation is brought to you for free and open access by the College of Graduate Health Sciences at UTHSC Digital Commons. It has been accepted for inclusion in Theses and Dissertations (ETD) by an authorized administrator of UTHSC Digital Commons. For more information, please contact jwelch30@uthsc.edu. 


\title{
Mrp4 Is a Crucial Regulator of Testosterone Biosynthesis
}

\begin{abstract}
The physiological role of multidrug resistance protein 4 (Mrp4) in the testes is unknown. It was discovered that Mrp4 is expressed primarily in mouse and human Leydig cells; however, there is no current evidence that Mrp4 regulates testosterone biosynthesis. The role of Mrp4 was investigated in Leydig cells where testosterone production is regulated by cAMP, an intracellular second messenger formed when the luteinizing hormone (LH) receptor (Lhr) is activated. As Mrp4 regulates cAMP, we compared testosterone levels in our Mrp4 WT and KO mice. Prepubertal KO mice had significantly reduced testicular testosterone, impaired gametogenesis, and disrupted cAMP homeostasis, resulting in decreased expression of genes involved in testosterone biosynthesis. Testosterone production was also impaired in adult KO mice but testicular morphology was normal. In vitro culture of primary KO Leydig cells stimulated with LH revealed decreased intracellular CAMP concentrations and attenuated cAMPresponse element binding protein (CREB) phosphorylation of downstream targets, notably several genes directly involved in testosterone biosynthesis. However, chemical inhibition of Mrp4 in WT Leydig cells revealed a substantial elevation in intracellular cAMP concentration but paradoxically reduced testosterone production. The reduced testosterone production was related to decreased immunoreactive StAR expression, the rate limiting step in testosterone biosynthesis. Future analysis will focus on the mechanism controlling cAMP concentrations under these conditions, with a primary focus on cAMP regulation by phosphodiesterases (PDEs). Continued assessment of our KO animals revealed prepubertal animals had reduced systemic testosterone concentrations while adult mice had normal circulating levels. The difference is pre-pubertal KO mice have increased Cyp2b10, a known testosterone metabolizing enzyme, expression and catalytic activity due to disrupted testicular testosterone production. Therefore, defective testicular testosterone production deregulates hepatic Cyp-mediated testosterone metabolism to disrupt gametogenesis. The findings presented here have important implications for understanding the side effects of therapeutics that disrupt Mrp4 function and can alter androgen production.
\end{abstract}

\section{Document Type}

Dissertation

Degree Name

Doctor of Philosophy (PhD)

Program

Biomedical Sciences

Research Advisor

John D. Schuetz, Ph.D.

Keywords

cAMP, testosterone, Mrp4, Leydig cell

\section{Subject Categories}

Amino Acids, Peptides, and Proteins | Chemicals and Drugs | Medical Cell Biology | Medical Sciences | Medicine and Health Sciences 
Mrp4 Is a Crucial Regulator of Testos te rone Biosynthesis

\author{
A Dissertation \\ Presented for \\ The Graduate Studies Council \\ The University of Tennessee \\ Health Science Center
}

In Partial Fulfillment

Of the Requirements for the Degree

Doctor of Philosophy

From The University of Tennessee

By

Jessica Ann Morgan

December 2012 
Chapters 2-5 (C) 2012 by The American Society for Biochemistry and Molecular Biology, Inc.

All other material (C) 2012 by Jessica Ann Morgan.

All rights reserved. 


\section{DEDICATION}

This work is dedicated to my parents, Debbie and Spud Morgan, whose selfless love and steadfast encouragement over the course of a lifetime carried me to this moment. 


\section{ACKNOWLEDGEMENTS}

It is a most difficult task to pay respect to those people who, throughout the years, have aided me on this continued journey. Nonetheless, I will give it my all. First and foremost, with the greatest sincerity, I would like to thank my mentor Dr. John Schuetz. During these years, John's continued support and belief in this project drove me on days when I felt unsure of purpose or direction. I am grateful for the countless hours of guidance and motivation he has provided both professionally and personally. His daily dedication to his work is an inspiration to constantly strive for a higher level.

I am also indebted to my committee members: Dr. Linda Hendershot, Dr. Susan Senogles, Dr. Brian Sorrentino and Dr. Beatriz Sosa-Pineda. Their scientific inquiries have molded this work, and I am happy to present it to them as a complete story. Their support and positive attitudes always made committee meetings a little less frightening.

I am grateful to all members of the Schuetz lab, both past and present. I have learned and grown tremendously being surrounded by a group that is constantly abuzz with excitement about science. They have not only helped to me to develop in my career but also provided a second family in which I can depend on. In particular, I would like to thank Dr. Masashi Adachi for laying the groundwork for this project as well as teaching me how to use chopsticks properly. Dr. Yao Wang has been such a supportive force for me, and her contribution to this work is extensive and greatly appreciated. Additionally, I would like to thank Dr. Erin Schuetz for her constructive comments and suggestions on this project. Both she and her lab members were a tremendous resource, always willing to assist whenever asked.

It is hard to convey how much I owe to the two 'Grizz girls', Dr. Yu Fukuda and Dr. Louise Treanor. They are the epitome of true friendship, and I feel honored to call them as such. Their faith in my process has never wavered, and they know there isn't a problem that can't be fixed with a little laughter and a lot of excellent food.

This work would not be possible without the animal expertise and assistance of Ginger Redd. Her knowledge and skill level is one that I can only hope to aspire to. Her infectious laughter and positive outlook always made tedious experiments go by quickly. I am thankful not only for the multiple skills I learned but also for the friendship she has so generously provided over the years.

There are so many others who have contributed to this work that I am most thankful for. I am indebted to the ARC staff for taking care of my mice. As my entire project depends on these animals, their assistance with day to day care cannot be overlooked. No testosterone measurements would ever have taken place without the permission of the gentlemen in radiation safety, Warner Turner, Donnie Swift and Jennings Payne. They allowed unlimited access to the gamma counter without question or hesitation and provided comic relief along with an occasional Snickers. I would like to especially thank Kellie Turner for her continued friendship and support although she is 
across the pond and half a world away. Ramon Klein-Geltink and Annette Patterson have shared in the ups and down, and their kindness is most appreciated.

My family has never wavered in their belief that this day would arrive, and for that unrelenting faith, thank you will never be enough.

Finally, although he will never read these words or know the end to this story, I am eternally grateful to my cousin, Michael Bynum. His certainty in my success, both personally and professionally, was something he never let me forget. I only hope I am the person he believed me to be, and that he can be proud of where I have been and where I am yet to go. 


\begin{abstract}
The physiological role of multidrug resistance protein 4 (Mrp4) in the testes is unknown. It was discovered that Mrp4 is expressed primarily in mouse and human Leydig cells; however, there is no current evidence that Mrp4 regulates testosterone biosynthesis. The role of Mrp4 was investigated in Leydig cells where testosterone production is regulated by cAMP, an intracellular second messenger formed when the luteinizing hormone $(\mathrm{LH})$ receptor $(\mathrm{Lhr})$ is activated. As Mrp4 regulates cAMP, we compared testosterone levels in our Mrp4 WT and KO mice. Pre-pubertal KO mice had significantly reduced testicular testosterone, impaired gametogenesis, and disrupted cAMP homeostasis, resulting in decreased expression of genes involved in testosterone biosynthesis. Testosterone production was also impaired in adult $\mathrm{KO}$ mice but testicular morphology was normal. In vitro culture of primary KO Leydig cells stimulated with LH revealed decreased intracellular cAMP concentrations and attenuated cAMP-response element binding protein (CREB) phosphorylation of downstream targets, notably several genes directly involved in testosterone biosynthesis. However, chemical inhibition of Mrp4 in WT Leydig cells revealed a substantial elevation in intracellular cAMP concentration but paradoxically reduced testosterone production. The reduced testosterone production was related to decreased immunoreactive StAR expression, the rate limiting step in testosterone biosynthesis. Future analysis will focus on the mechanism controlling cAMP concentrations under these conditions, with a primary focus on cAMP regulation by phosphodiesterases (PDEs).

Continued assessment of our $\mathrm{KO}$ animals revealed pre-pubertal animals had reduced systemic testosterone concentrations while adult mice had normal circulating levels. The difference is pre-pubertal KO mice have increased Cyp2b10, a known testosterone metabolizing enzyme, expression and catalytic activity due to disrupted testicular testosterone production. Therefore, defective testicular testosterone production deregulates hepatic Cyp-mediated testosterone metabolism to disrupt gametogenesis. The findings presented here have important implications for understanding the side effects of therapeutics that disrupt Mrp4 function and can alter androgen production.
\end{abstract}




\section{TABLE OF CONTENTS}

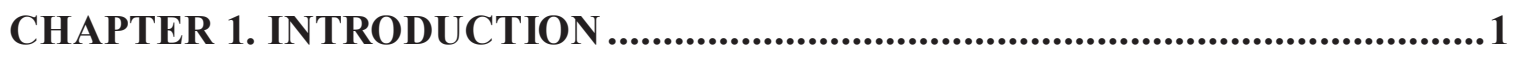

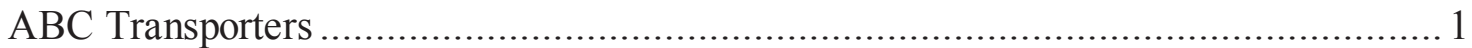

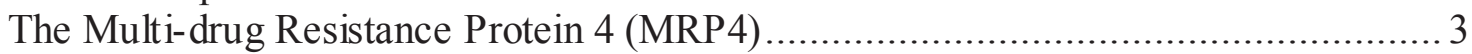

Development of the Mrp4 KO mouse .............................................................. 3

Understanding the pharmacological role of Mrp4 through the KO mouse mode1......5

The relationship between Mrp4 and cAMP ...................................................... 5

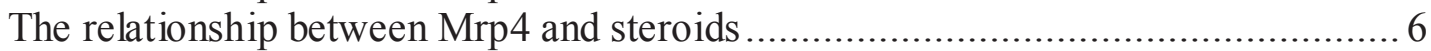

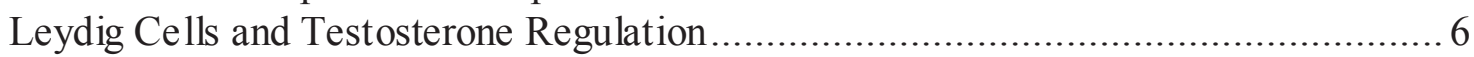

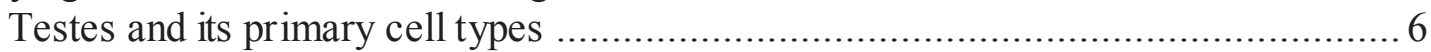

Testosterone biosynthes is in the Leydig cells ................................................... 7

Testosterone maintains testic ular homeostas is ..................................................... 7

Testosterone is a critical regulator of multiple physiological processes .................. 10

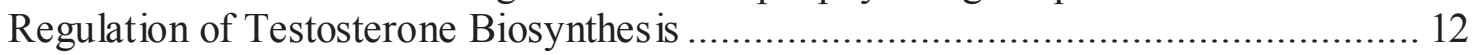

Functional StAR and $\mathrm{Pbr}$ are necessary for testosterone synthes is ........................ 12

Cyclic AMP regulates multiple processes in the testosterone synthesis pathway .... 13

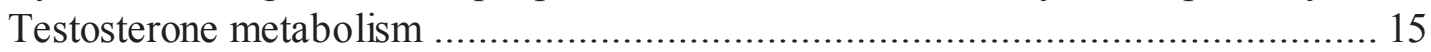

\section{CHAPTER 2. THE ABSENCE OF MRP4 IN LEYDIG CELLS RESULTS IN REDUCED INTRATESTICULAR TESTOSTERONE CONCENTRATION .........18}

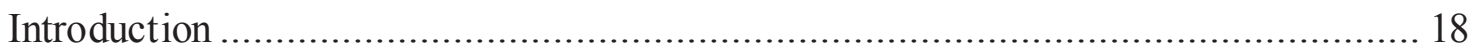

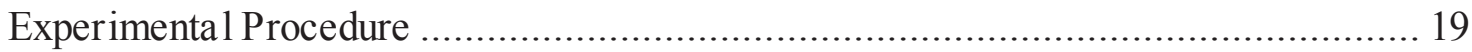

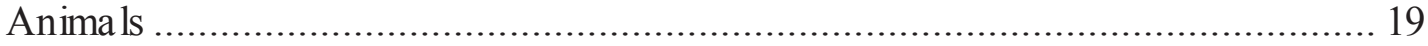

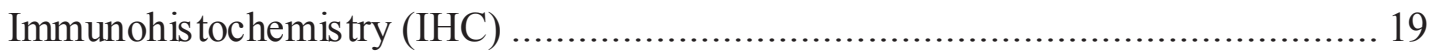

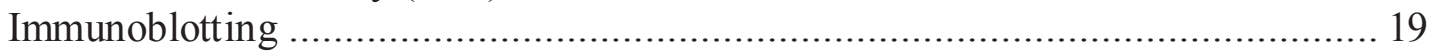

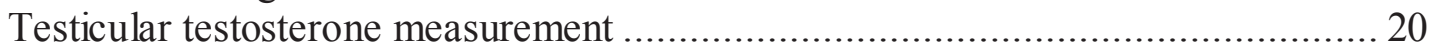

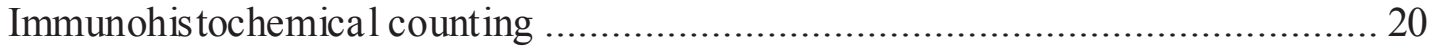

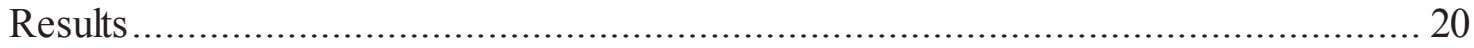

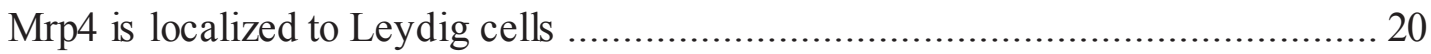

The absence of Mrp4 in Leydig cells does not affect general reproductive

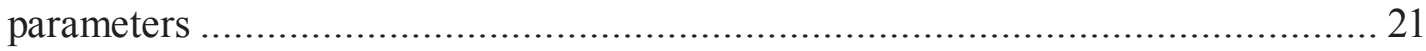

Pre-pubertal Mrp4 KO mice are deficient in testicular testosterone....................... 21

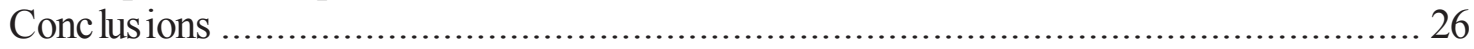

\section{CHAPTER 3. TESTICULAR TESOSTERONE BIOSYNTHESIS IS \\ IMPAIRED IN MRP4 KO MICE..........................................................................28}

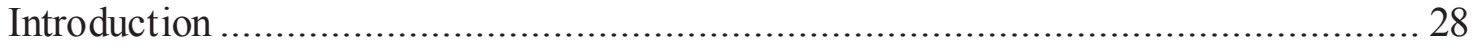

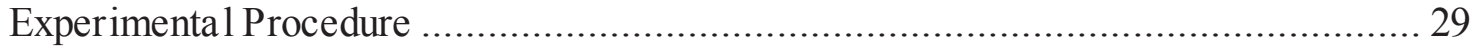

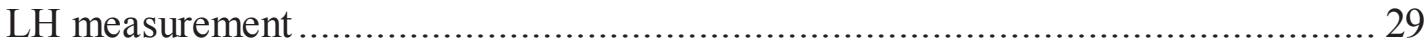

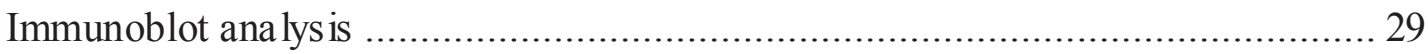

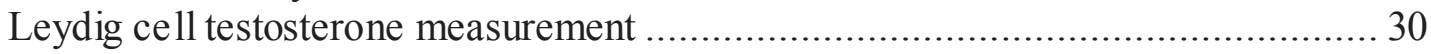

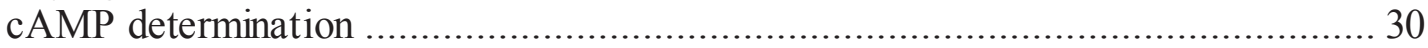

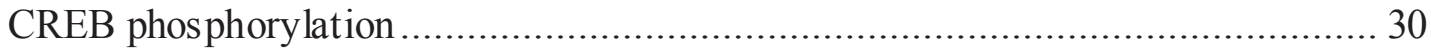

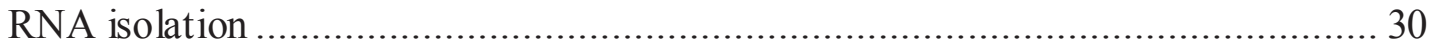




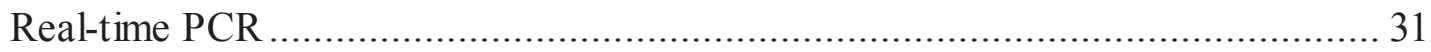

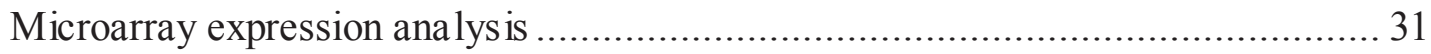

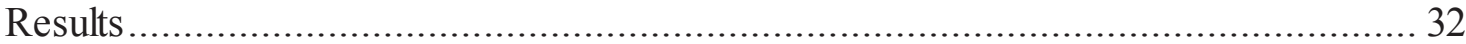

Expression of Lhr, but not LH concentration, is decreased in Mrp4 KO mice ........ 32

Cyclic AMP concentration is drastically diminished in Mrp4 KO Leydig cells ...... 32

CREB activation, a cAMP dependent phenomenon, and downstream target gene

expression are reduced in Mrp4 KO Leydig cells ................................................ 36

Genes directly involved in testosterone biosynthesis are downregulated in Mrp4

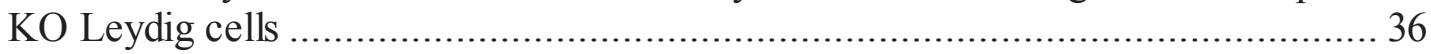

Acute Mrp4 inhibition results in elevated intracellular cAMP concentrations......... 42

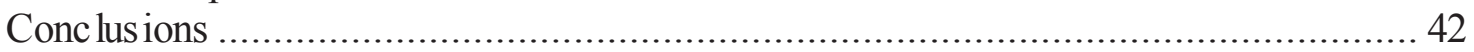

\section{CHAPTER 4. ADULT MRP4 KO MICE MAINTAIN A TESTICULAR TESTOSTERONE DEFICIENCY WHILE POSSESSING NORMAL TESTES

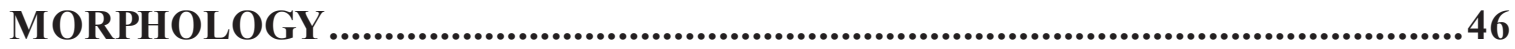

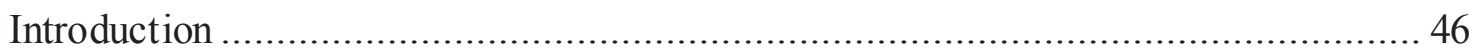

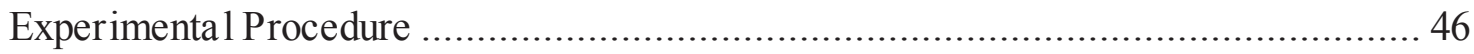

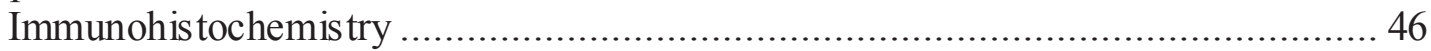

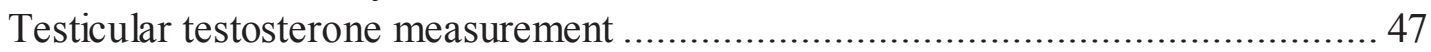

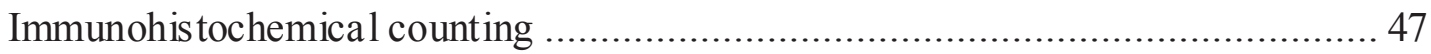

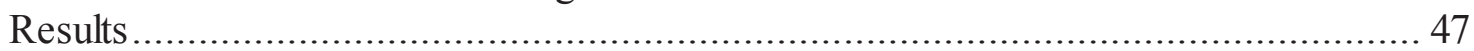

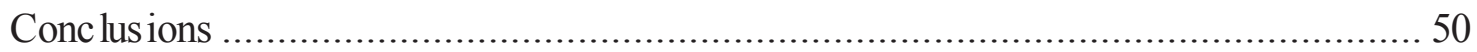

\section{CHAPTER 5. DECREASED SERUM TESTOSTERONE IN PRE-PUBERTAL MRP4 KO MICE RESULTS FROM INCREASED METABOLISM ......................51}

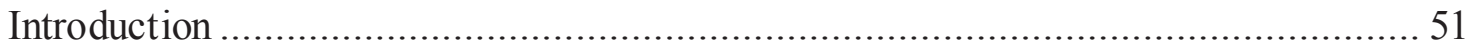

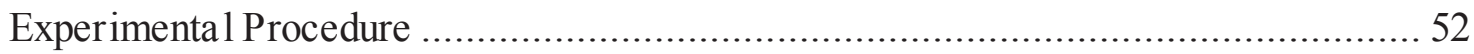

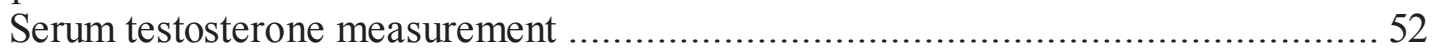

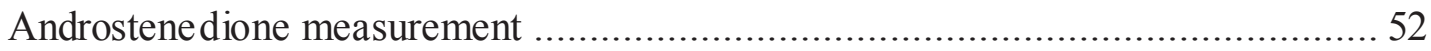

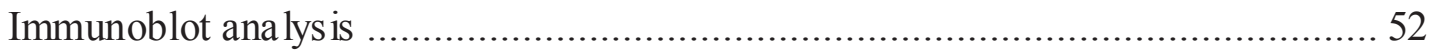

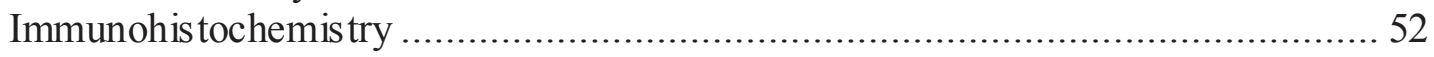

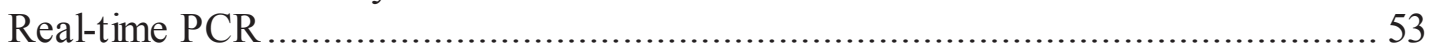

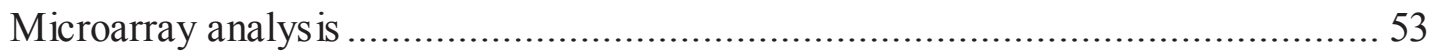

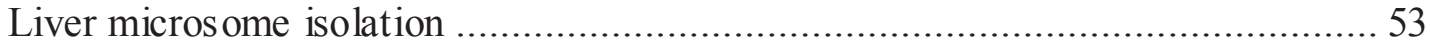

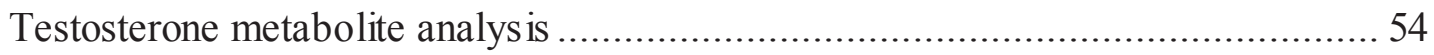

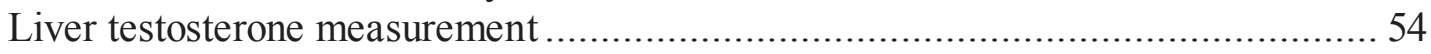

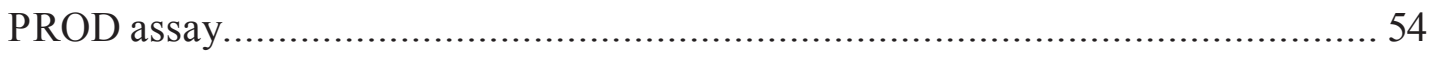

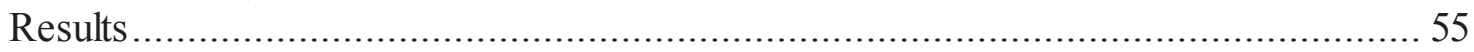

Serum testosterone concentration is drastically reduced in pre-pubertal Mpr4 KO mice but is restored with age .............................................................................. 55

Additional $\mathrm{ABC}$ transporters expressed in the testes are not unregulated in the

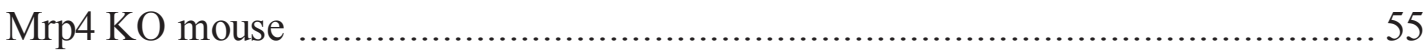

Decreased serum testosterone in pre-pubertal Mrp4 $\mathrm{KO}$ mice is a result of

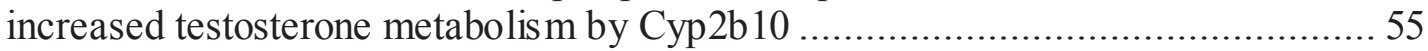

Elevated Cyp2b10 expression is not a result of general CAR activation..................60 60

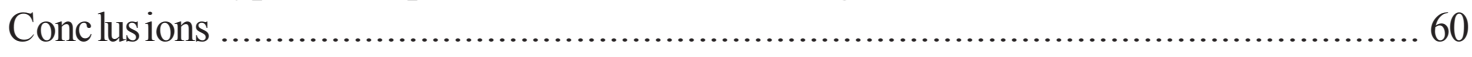




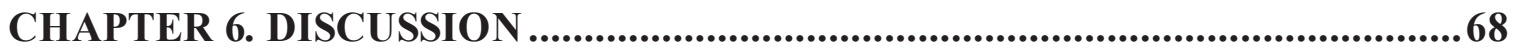

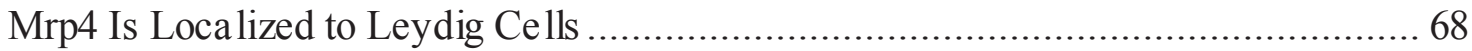

Mrp4 KO Mice Have an Inherent Deficiency in Testicular Testosterone

Concentration

Cyclic AMP Is the Regulatory Factor Controlling Decreased Testosterone

Synthes is in the Mrp4 KO Mouse

Increased Cyp2b10 Expression and Activity Results in Decreased Serum

Testosterone in Pre-pubertal Mrp4 KO Mice 72

Genetic Variants Highlight the Importance of Proper Functioning Mrp4 73

Future Directions

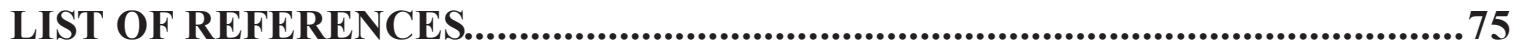

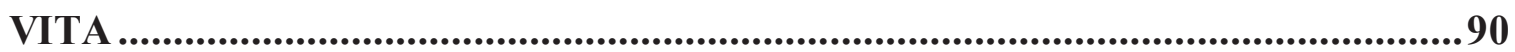




\section{LIST OF FIGURES}

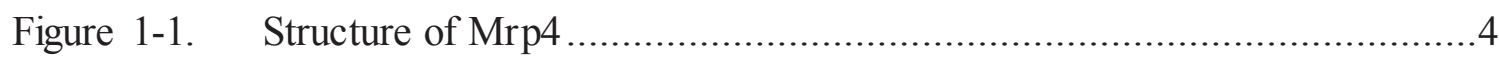

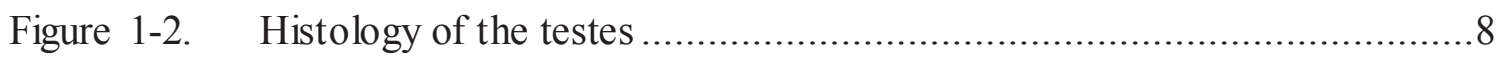

Figure 1-3. Testosterone biosynthes is pathway.............................................

Figure 1-4. The balance between steroid biosynthesis and inactivation................... 16

Figure 2-1. Mrp4 is expressed in Leydig cells ......................................... 22

Figure 2-2. Mrp4 KO mice display normal reproductive parameters .....................23

Figure 2-3. Mrp4 protein expression increases with age....................................24

Figure 2-4. Pre-pubertal Mrp4 KO mice are deficient in testicular testosterone....... 25

Figure 2-5. Pre-pubertal Mrp4 KO mice exhibit impaired testicular morphology .....27

Figure 3-1. Luteinizing hormone receptor expression, but not LH concentration, is altered in Mrp4 $\mathrm{KO}$ mice .................................. 33

Figure 3-2. Cholesterol biosynthesis genes are reduced in Mrp4 KO mice but serum cholesterol concentrations are unchanged between genotypes .....34

Figure 3-3. Cyclic AMP concentration is decreased in Mrp4 KO Leydig cells .........35

Figure 3-4. CREB phosphorylation and cAMP regulated genes are downregulated

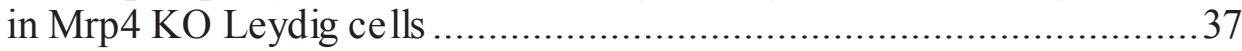

Figure 3-5. Steroid biosynthesis and related genes have a distinct expression pattern in Mrp4 WT and KO mice....

Figure 3-6. Genes involved directly in testosterone biosynthesis are downregulated in Mrp4 KO Leydig cells

Figure 3-7. Cultured Leydig cells exhibit properties observed in vivo.

Figure 3-8. Acute inhibition of Mrp4 results in increased intracellular cAMP concentration but downregulated Lhr and StAR protein expression .......44

Figure 3-9. Alternate $\mathrm{ABC}$ transporters are not upregulated upon LH stimulation.... 45

Figure 4-1. Testicular testosterone is decreased in adult Mrp4 KO mice 48 
Figure 4-2. Testicular deficiencies are absent in the adult Mrp4 KO mouse

Figure 5-1. Serum testosterone concentration is decreased in the pre-pubertal Mrp4 KO mouse but normalizes with age

Figure 5-2. Protein expression of cholesterol importers are not decreased in Mrp4

$\mathrm{KO}$ adrenal glands

Figure 5-3. Pre-pubertal Mrp4 KO mice exhibit impaired prostate morphology while adult $\mathrm{KO}$ mice are normal

Figure 5-4. Alternate ABC and steroid transporters are not upregulated in Mrp4 $\mathrm{KO}$ mice

Figure 5-5. Cyp2b10 RNA expression is upregulated in pre-pubertal Mrp4 KO mice but decreases at an adult age

Figure 5-6. Both mRNA and protein expression of Cyp2b10 are elevated in pre-pubertal Mrp4 KO mice but decrease in adulthood

Figure 5-7. Testosterone metabolism is increased in pre-pubertal Mrp4 KO animals 63

Figure 5-8. Liver testosterone concentration is decreased in pre-pubertal Mrp4 KO mice compared to WT

Figure 5-9. Androgen receptor target genes are downregulated in pre-pubertal Mrp4 KO mice

Figure 5-10. A general downregulation of Car target gene expression is not observed in pre-pubertal Mrp4 KO mice 


\section{LIST OF ABBREVIATIONS}

$\begin{array}{ll}\text { ABC } & \text { ATP binding cassette } \\ \text { AR } & \text { androgen receptor } \\ \text { ATP } & \text { adenosine triphophosphate } \\ \text { cAMP } & \text { cyclic adenosine 3,5-monophosphate } \\ \text { CAR } & \text { constitutive androstane receptor } \\ \text { CREB } & \text { cAMP response element binding protein } \\ \text { Cyp11 } \alpha 1 & \text { cholesterol side-chain cleavage enzyme } \\ \text { Cyp17 } \alpha 1 & \text { steroid 17-alpha-monooxygenase } \\ \text { Cyp450 } & \text { cytochrome p450 } \\ \text { DHT } & \text { dihydrotestosterone } \\ \text { hCG } & \text { human chorionic gonadotropin } \\ \text { IBMX } & \text { 3-isobutyl-1-methylxanthine } \\ \text { IHC } & \text { immunohistochemistry } \\ \text { iU } & \text { international unit } \\ \text { KO } & \text { knock out } \\ \text { LH } & \text { luteinizing hormone } \\ \text { Lhr } & \text { luteinizing hormone receptor } \\ \text { mRNA } & \text { messenger ribonucleic acid } \\ \text { Mrp4 } & \text { multi-drug resistance associated protein } 4 \\ \text { NBD } & \text { nucleotide binding domain } \\ \text { Pbr } & \text { peripheral benzodiazepine receptor } \\ \text { PBS } & \text { phosphate buffered saline } \\ \text { PCR } & \text { polymerase chain reaction } \\ \text { PDE } & \text { phosphodiesterase } \\ \text { PKA } & \text { protein kinase A } \\ \text { PROD } & \text { pentoxyresorufin O-dealkylase } \\ \text { RIA } & \text { radioimmunoassay } \\ \text { RNA } & \text { ribonucleic acid } \\ \text { StAR } & \text { steroidogenic acute regulatory binding protein } \\ \text { TMD } & \text { transmembrane binding domain } \\ \text { TUNEL } & \text { terminal deoxynucleotidyl transferase dUTP nick end labeling } \\ \text { WT } & \text { wild-type } \\ 17 \beta H S D 1 & \text { 3-beta-hydroxysteroid dehydrogenase 1 } \\ 3 \beta H S D 1 & \end{array}$




\section{CHAPTER 1. INTRODUCTION}

\section{ABC Trans porters}

By definition, ATP-binding cassette $(\mathrm{ABC})$ transporters are responsible for mediating the adenosine triphosphate (ATP) dependent unidirectional exclusion of both endogenous and exogenous compounds across membranes [1]. In 1976, the first member of the ABC transporter superfamily was identified. Ling and others described a $170 \mathrm{kD}$ membrane glycoprotein overexpressed in colchicine resistant cell lines and termed it P gp, a glycoprotein responsible for reducing drug permeability [2]. Over 15 years later, two additional $\mathrm{ABC}$ transporters were identified. The first was $\mathrm{ABCC} 1$, discovered by the laboratories of Cole and Deeley [3] while the second, ABCG2, was identified by three independent laboratories almost simultaneously [4-6]. Currently, these three transporters are considered to be the major drug transporters that contribute to the multidrug resistance phenotype observed in multiple tumors and cell lines [7], a phenomenon described as the simultaneous resistance to several structurally unrelated drugs that do not have a common mechanism of action [8].

While P-GP, ABCC1 and ABCG2 were the first transporters identified, there are currently 48 human $\mathrm{ABC}$ transporters described, each classified into seven separate subfamilies (ABCA-ABCG) based on the sequence and organization of their ATP binding domains [9]. As ABC transporters are either localized to the plasma membrane or to the membranes of intracellular organelles, they function to move compounds from the cytoplasm to outside the cell or into an intracellular compartment such as the endoplasmic reticulum, mitochondria or peroxisomes [9]. These transporters serve a wide variety of cellular roles such as regulating permeability by being expressed in the blood-brain barrier, blood cerebrospinal fluid, blood-testes barrier, and the placenta [10]. $\mathrm{ABC}$ transporters play a protective role by their ability to excrete toxins in such organs as the liver, kidney and gastrointestinal tract [11]. Additionally, they serve physiological roles in cellular lipid transport and maintenance of homeostasis [12]. With their broad expression pattern and functional capabilities, $\mathrm{ABC}$ transporters serve a wide variety of important physiological functions (Table 1-1).

Structurally, ABC transporters are comprised of two nucleotide binding domains (NBDs) and two transmembrane binding domains (TMDs), encoded by a single polypeptide [13]. The NBDs contains the ATP binding domains while the substrate binding domains are located within the TMDs. Within the NBDs are the characteristic Walker A and Walker B motifs, separated by approximately 90-120 amino acids. ABC proteins also contain an additional element, the signature $\mathrm{C}$ motif, located just upstream of the Walker B site [13]. The TMDs contain 6-11 membrane spanning $\alpha$-helices while the NBDs are located in the cytoplasm. ABC transporters are classified as full transporters if they contain two core units in tandem (TMD-NBD-TMD-NBD) that are active alone, or they are half transporters when only one core unit is present (TMDNBD). In the case of half transporters, they must form obligate homo- or hetero-dimers for activation [14]. 
Table 1-1. Localization and function of representative $\mathrm{ABC}$ transporters.

\begin{tabular}{lll}
\hline Transporte & Expression & Function \\
\hline ABCA1 & Ubiquitous & Cholesterol efflux to HDL [15] \\
ABCA6 & Ubiquitous & Macrophage lipid home os tasis [16] \\
ABCA12 & Lamellar granules/bodies & Lipid me tabolis m [17] \\
ABCB6 & Mitochondria & Heme trans port and bios ynthes is [18] \\
ABCB9 & Testes, brain, spinal cord & Peptide transport [19] \\
ABCB11 & Liver & Bile salt trans port [20] \\
ABCC1 & Lung, testes, peripheral blood & Organic anion trans porter [21] \\
ABCC4 & Multiple tissues & Drug res istance [22, 23] \\
ABCC7 & Exocrine tissues & Chloride ion channel [24] \\
ABCC9 & Skeletal muscle, heart & K(ATP) channel regulation [25] \\
ABCD3 & Peroxisomes & Peroxis ome biogenesis [26] \\
ABCG2 & Liver, intestine, breast & Vitamin B2 pump, he me efflux [27, 28] \\
ABCG5 & Liver, small intestine & Sterol transport [29] \\
\hline
\end{tabular}




\section{The Multi-drug Resistance Protein 4 (MRP4)}

MRP4 (ABCC4) is a member of the $\mathrm{C}$ subfamily of $\mathrm{ABC}$ transporters. The gene is located on chromosome 13q32.1, and at 1325 amino acids in length, is the shortest member of this family. It is a full transporter, comprised of two TMD and two NBD (Figure 1-1). The first functional properties of MRP4 were described in 1999 by Schuetz, et al using a human T-lymphoid cell line in which MRP4 overexpression was directly linked to impaired antiviral efficacy and increased efflux of antiviral nucleoside based drugs [30]. In vitro, MRP4 possesses the unique characteristic of being able to export a wide range of structurally diverse compounds. MRP4 has been shown to transport endogenous molecules that play key roles in cellular communication and signaling, including cyclic nucleotides, eicosanoids, adenosine diphosphate, and conjugated steroid hormones [31]. Other physiologically relevant substrates include folate, bile acids and glutathione, which are co-transported with bile acids [32-34]. In addition to endogenous substrates, MRP4 also transports a broad range of drug substrates including antivirals (adefovir [35] and tenofovir [36]), antibiotics (cefalosporins [37]) and cytotoxic agents (methotrexate [33], topotecan [38], 6-thioguanine and 6-mercaptopurine [39].

MRP4 is also unique from other C subfamily members by its ability to have dual membrane localization in polarized cell types. In renal proximal tubule cells, MRP4 is localized to the apical side of the membrane [23] whereas it is located in the basolateral membrane in prostate tubuloacinar cells [40] and choroid plexus epithelium [38]. Interestingly, in a colonic epithelial cell line, protein expression was seen in both the apical and basolateral membrane, with increased abundance on the apical side [41].

\section{Development of the Mrp4 KO mouse}

While in vitro studies have been crucial for understanding the transport function, substrates and membrane localization of MRP4, it was the development of the Mrp4 KO mouse model that derived both the physiological and pharmacological roles of this transporter. Engineered by Leggas, et al, the mouse was generated as follows. The Mrp4 gene contains 31 exons, with exon 27 targeted for disruption. This region lies between the Walker A and B motifs and is essential for their communication as well as the facilitation of ATP hydrolysis. Disruption of the Mrp4 gene in embryonic stem cells was achieved by replacing exon 27 with a neomycin resistance cassette by homologous recombination. Disruption of Mrp4 expression was ensured by the use of an oligonucleotide primer containing three in-frame stop codons engineered into exon 27. The result was a complete loss of Mrp4 expression and function. Examination of these animals showed breeding of Mrp4 heterozygous mice produced a normal Mendelian ratio, indicating Mrp4 was not required for normal development. Mrp4 KO mice bred normally with normal litter size and the expected male-female ratio. No abnormalities were observed in the brain, liver, lung or kidney when examined by microscopic histology. Liver and renal functions were also within the normal limits [38]. As the KO 


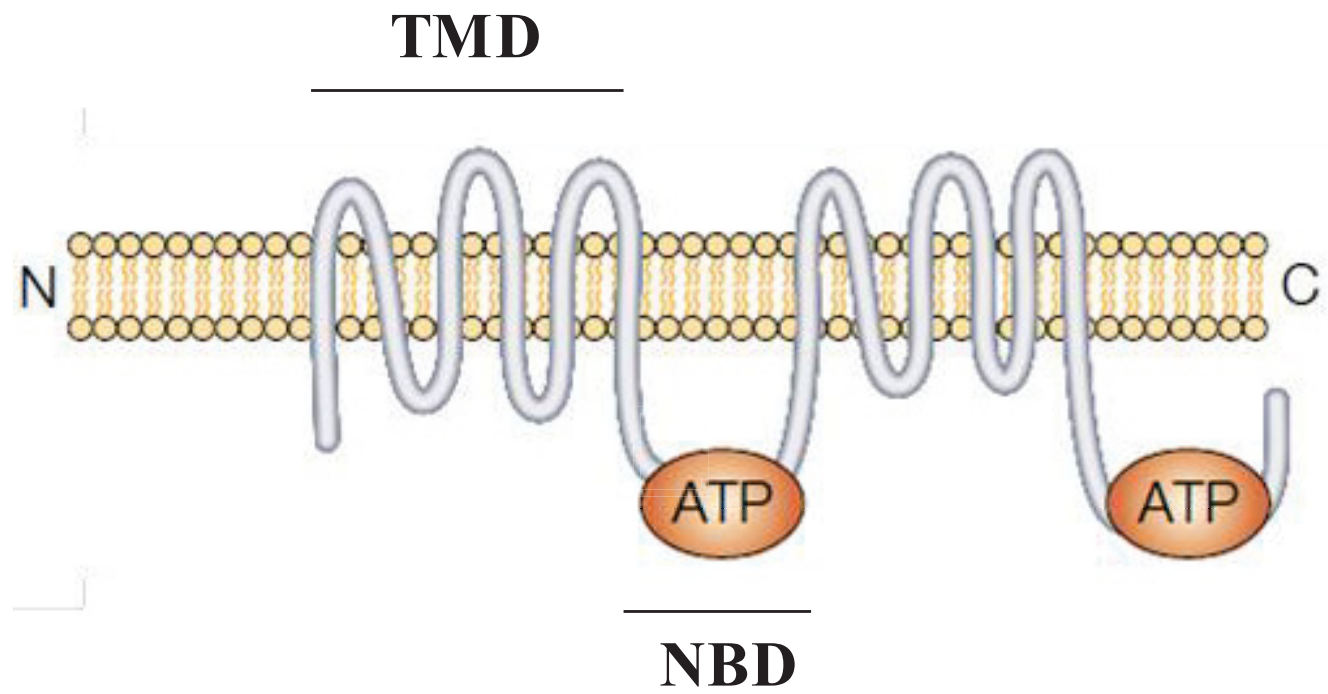

Figure 1-1. Structure of Mrp4. Mrp4 exhibits the classical ABC transporter core structure with two transmembrane domains (TMD), the site of substrate binding, and two nucleotide binding domains (NBD), the site for ATP binding. Each TMD contains six $\alpha-$ helices. Both the N-terminal and C-terminal regions of the transporter are located in the cytoplasm. Reprinted by permission from Macmillan Publishers Ltd: Gottesman MM, Fojo T and Bates SE. Nature Reviews Cancer. 2002 Jan;2(1): 48-58. 
mouse exhibited no overt detrimental effects from the absence of Mrp4, this indicated this mouse could be used as a crucial tool in deciphering the physiological role of Mrp4.

\section{Understanding the pharmacological role of Mrp4 through the KO mouse model}

Through this mouse model, Mrp4 was shown to play a critical protective role in organs including the brain, liver, kidney and bone marrow cells. While Mrp4 is mainly expressed in the luminal membrane of capillary endothelium, it has been detected in both the basolateral membrane of choroid plexus as well as in astrocytes [38, 42]. Studies on brain penetration revealed brain and cerebrospinal concentrations of topotecan were higher in the KO mouse compared to the WT [38]. These animals also exhibited increased adefovir concentrations in the brain, indicating Mrp4 is a component of the blood-brain barrier that exports nucleoside based analogues [43]. Localized to the apical membrane in kidney proximal tubules, Mrp4 is an important transporter for the elimination of many substrates. The KO mouse has shown Mrp4 to be involved in the tubular secretion of diuretics, antiviral drugs and cephalosporins [35, 37, 44]. Mrp4 protects the liver from toxic bile acid accumulation by facilitating their efflux into the blood for renal excretion as illustrated by the sensitization of $\mathrm{KO}$ mice to cholestaticinduced liver injury [22]. Expression of Mrp4 in bone marrow cell lineages (e.g. monocyte/macrophage and erythroid precursors) demonstrated its protective role against thiopurine-induced hematopoietic toxicity as $\mathrm{KO}$ mice were susceptible to dose dependent toxicity caused by the accumulation of 6-thioguanine nucleotides in these cells [45]. These and other studies illustrate the important role the Mrp4 KO mouse has played in understanding the critical physiological role of this transporter.

\section{The relations hip betwe en Mrp4 and cAMP}

One of the most physiologically important substrates transported by Mrp4 is cyclic adenosine 3,5-monophosphate (cAMP). First characterized in 1957 by Sutherland and Rall [46], this second messenger is a critical regulator of intracellular signal transduction. It was not until the mid-1990's, however, that the essential elements of cAMP mediated signaling had been detailed. Upon the formation of the hormonereceptor complex, there is a conformational change of the G-protein coupled receptor. This activates adenylyl cyclase which generates cAMP from ATP. In turn, cAMP activates PKA which elicits a host of metabolic or physiological responses through its downstream target phosphorylation [47].

Several transporters have been reported to efflux cAMP, but work performed in 2001 by Chen and colleges showed MRP4 transported cAMP at a higher affinity than other previously reported transporters [39]. Cyclic AMP was originally selected as a potential MRP4 substrate based on its structural similarity to the antiviral nucleotide substrates as well as the similar protein topology to MRP5 which had previously been shown to efflux cAMP [48]. Later studies highlighted the biological importance of MRP4-mediated cAMP export. Experiments performed in the gut epithelial cell line 
HT29-CL19A, which express both MRP4 and cystic fibrosis transmembrane receptor (CFTR) on the apical plasma membrane and can transport cAMP across this membrane. As CFTR is a channel activated by cAMP, inhibition of MRP4 by MK571 resulted in increased intracellular cAMP concentrations and activation of the CFTR channel [41]. Similarly, inhibition of MRP4 in mouse ventricular monocytes resulted in increased cAMP accumulation and stimulated contraction of the $\beta-1$ adrenocepter [49]. These studies, along with others, illustrated how impaired MRP4 function regulates cAMP concentration and therefore results in alterations of other cellular processes.

\section{The relations hip betwe en Mrp4 and ste roids}

In addition to the other critical endogenous substrates of MRP4 established by Chen, et al, this group was also the first to report MRP4's ability to efflux steroid conjugates. $\mathrm{ABCC} 1, \mathrm{ABCC} 2$ and $\mathrm{ABCC} 3$ had been previously established to transport $\mathrm{E}_{2} 17 \beta \mathrm{G}$, a steroid derivative [50-52]. Using inside-out membrane vesicles generated from MRP4 overexpressing insect cells, it was shown $\mathrm{E}_{2} 17 \beta \mathrm{G}$ was transported by MRP4 with affinity similar to ABCC3 [52]. Further evidence of MRP4's ability to transport steroids came in 2003 when it was shown dehydroepiandrosterone sulfate (DHEAS) could be effluxed by MRP4 in an inside-out membrane vesicle system [53]. As DHEAS is a major circulating steroid in humans, mainly produced in the adrenal glands, and was the highest affinity substrate for MRP4 at that time, these results suggested a major function of MRP4 may be the transport of DHEAS itself or of other structurally related steroids.

While initial data did suggest MRP4 may be responsible for effluxing steroid and steroid-like compounds, a later study revealed neither the primary male sex hormone testosterone nor dihydrotestosterone (DHT), the more potent reduced form of testosterone, were transported by MRP4 [54]. Interestingly, two separate reports showed MRP4 expression is androgen responsive as its expression is increased upon treatment with DHT [54, 55] but is decreased upon androgen withdrawal [54]. While not a direct transporter of testosterone or DHT, these data suggest that MRP4, as an androgen regulated gene, may be important in the progression of androgen dependent cancers, such as prostate cancer where MRP4 is highly expressed [54].

\section{Leydig Cells and Testosterone Regulation}

\section{Testes and its primary cell types}

The testes are the male sex organ responsible for two basic functions: sperm production and testosterone biosynthesis. The adult testes contain several major cell types. First, spermatogonial stem cells, residing at the luminal side of the basal membrane of the seminiferous tubules, undergo several successive mitotic divisions, developing into mature sperm cells. Sertoli cells, the second essential testicular cell type, 
act as a supporting structure for developing sperm as they are attached to the basal lamina of the seminiferous tubules. Their direct contact with proliferating and differentiating germ cells within the tubules are essential for providing both physical and nutritional support for spermatogenesis [56]. Finally, Leydig cells lie in the interstitial space between the seminiferous tubules and function to both synthesize and secrete testosterone [57] (Figure 1-2). Comprising only 5\% of mature testes volume, there are approximately 500 million Leydig cells present in the adult human male [58]. As adult Leydig cells are post-mitotic, this population arises during puberty and persists for the whole adult life [59]. A normal adult human male produces approximately $7 \mathrm{mg}$ testosterone daily but also produces other androgens such as androstenedione and dehydroepiandrosterone (DHEA) [60]. However, due to strain differences in mice, absolute testosterone concentrations cannot be established for this species.

\section{Testosterone biosynthesis in the Leydig cells}

Testosterone biosynthesis is stimulated when luteinizing hormone (LH) is released form the anterior pituitary gland and acts on its receptor located on the plasma membrane of Leydig cells. This initiates a cascade of events including the activation of adenylyl cyclase, increased intracellular cAMP formation which then activates protein kinase A (PKA). PKA phosphorylates the steroidogenic acute regulatory protein (StAR), a mitochondrial associated protein, which translocates cytoplasmic cholesterol from the outer mitochondrial membrane to the inner mitochondrial membrane. This is considered to be the rate-limiting step in testosterone biosynthesis. In addition to StAR, cholesterol is also brought into the mitochondria by a second importer, peripheral benzodiazepine receptor $(\mathrm{PBR})$. Once inside the mitochondria, cholesterol is converted to pregnenolone by the enzyme cholesterol side chain cleavage $(\mathrm{Cyp} 11 \alpha 1)$ where it is then translocated into the smooth endoplasmic reticulum. It is then converted to testosterone via a series of reactions involving 3-beta-hydroxysteroid dehydrogenase (3ßHSD), steroid 17-alphamonooxygenase (Cyp17 $\alpha$ ) and 17-beta-hydroxysteroid dehydrogenase (17ßHSD) [6163] (Figure 1-3). After synthesis is complete, testosterone exits the Leydig cells be a process generally accepted as passive diffusion [64] where upon release, it enters the circulation where it inhibits the release of LH from the anterior pituitary [65], ultimately creating a pulsatile cycle of testosterone formation and secretion. After the onset of puberty, over $95 \%$ of circulating testosterone is derived from the testes with the remainder arising from testosterone precursors DHEA and androstenedione, both originating from the adrenal gland [66].

\section{Testosterone maintains testicular homeos tasis}

In the male, testosterone plays the lead role in both morphological development as well as reproductive function. The absolute requirement for testosterone is supported by experiments such as testosterone suppression, hormone withdrawal, and animal KO models. Utilizing a testosterone deficiency model in rats, administration of a chronic, 


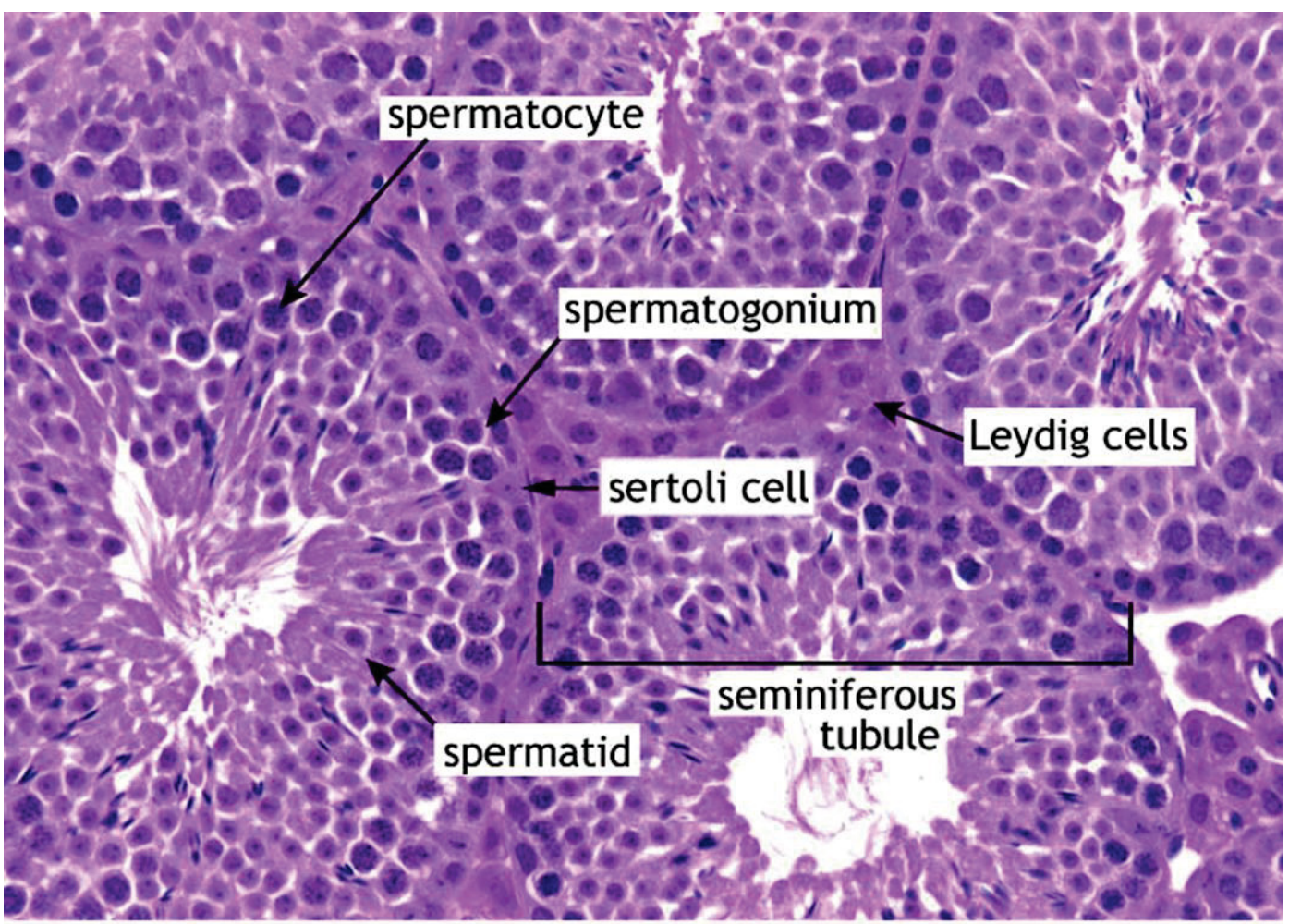

(1) Deltagen Inc.

Figure 1-2. Histology of the tes tes. Testes histology as visualized by H\&E staining at 40X magnification. Labeled are the Leydig cells which lie in the interstitium between the seminiferous tubules. Inside the seminiferous tubules, both the Sertoli cells as well as developing sperm cells (spermatogonium, spermatocytes and spermatids) are visible. Reprinted with permission from DeltaBase histology atlas. http:/www.deltagen.com/target/histologyatlas/atlas files/male rep/testis 40X.jpg. Accessed October 16, 2012. 


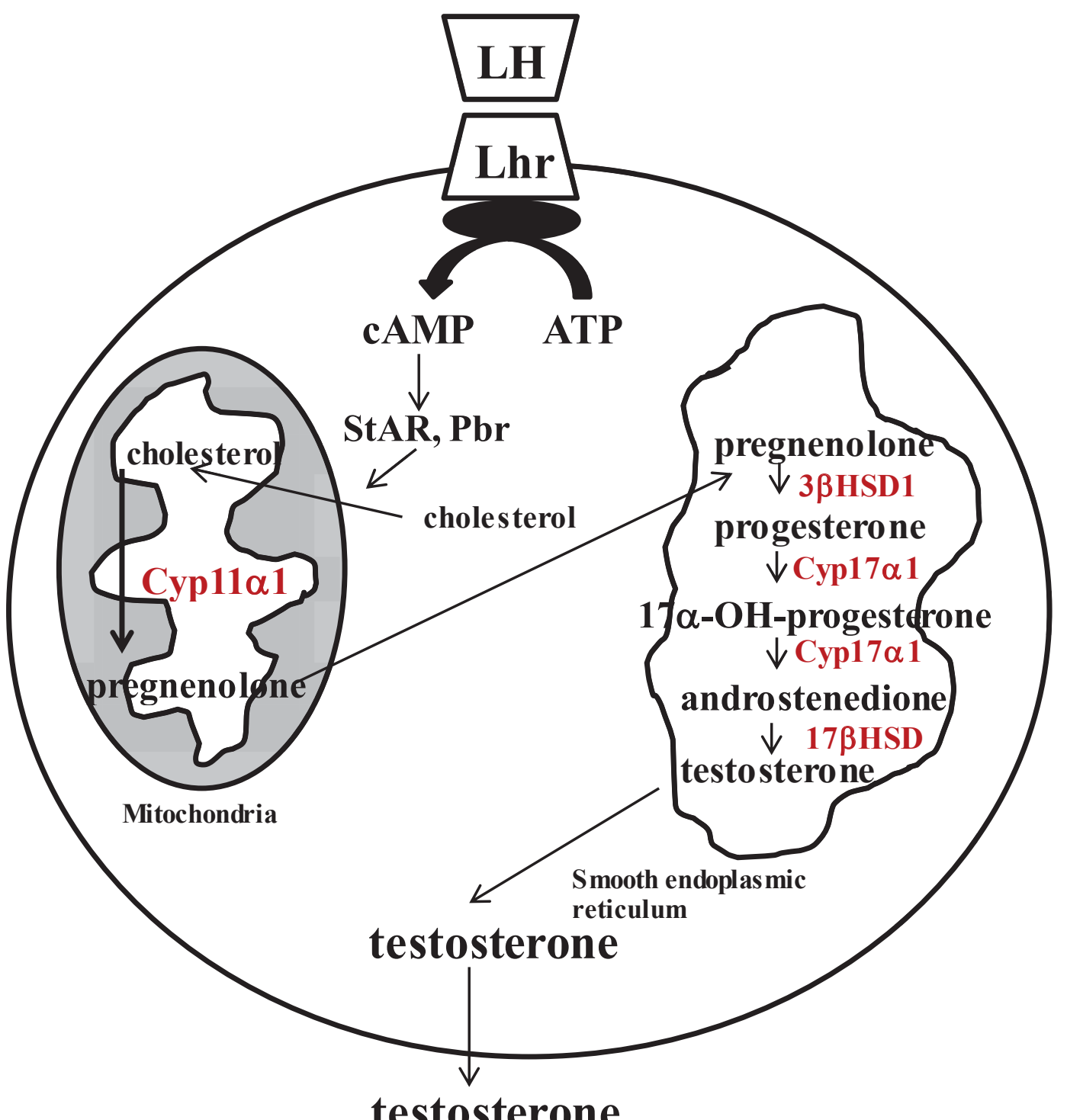

Figure 1-3. Testosterone biosynthesis pathway. Illustration of the molecular events involved in testosterone production by Leydig cells. Luteinizing hormone binds to receptors on the Leydig cell plasma membrane, thereby initiating a cascade of events that includes increased intracellular cAMP formation, translocation of cholesterol into the mitochondria (with the involvement of steroidogenic acute regulatory protein and peripheral benzodiazepine receptor), association of cholesterol with Cyp11 $\alpha 1$, production of pregnenolone from cholesterol in the mitochondria, translocation of pregnenolone from the mitochondria to the smooth endoplasmic reticulum, and conversion of pregnenolone to testosterone via a series of reactions in the smooth endoplasmic reticulum. All biosynthesis enzymes are colored red. 
low dose testosterone/estradiol implant resulted in the suppression of LH to undetectable levels with testicular testosterone concentration reported as less than $3 \%$ of controls. As a result, production of elongated spermatids, a late stage germ cell, ceased. Administration of high dose testosterone produced an increase in testosterone concentration as well as normalized spermatid maturation [67]. Suppression of gonadotropin-releasing hormone, the upstream hormone responsible for the release of $\mathrm{LH}$ from the anterior pituitary, resulted in an LH deficiency and decreased intratesticular testosterone levels, thereby creating a severe spermatogenic impairment [68]. Reduction in testicular and prostatic weights was also observed, highlighting the importance of testosterone in the maintenance of androgen dependent organs.

Hormone withdrawal experiments also emphasize the critical role of testosterone in supporting spermatogenesis. Removal of androgens from adult rats by hypophysectomy resulted in an acute, stage specific regression of the seminiferous tubule epithelium, leading to a reduced number of early stage spermatocytes attached to the basal lamina. Additionally, elongated spermatids exhibited an abnormal morphology with atypical head shapes and abnormalities in the flagellum [69]. Following hypophysectomy and elimination of all residual testosterone by flutamide, spermatogenesis was observed to rarely proceed beyond meiosis. A minimal amount of round spermatids could be observed and elongated spermatids were virtually non-existent [70].

The utilization of animal $\mathrm{KO}$ models also enforced testosterone as an important regulator of spermatogenesis and reproductive function. Similar to observations made with gonadotropin suppression, the loss of the gonadotropin-releasing hormone gene in a mouse model produced a congenital functional gonadotropin deficiency, resulting in deficient $\mathrm{LH}$ and testosterone concentrations secondary to the absence of gonadotropinreleasing hormone [71]. Studies in hypogonadal mice lacking gonadotropin releasing hormone show a decrease in testosterone synthesis genes Cyp $11 \alpha 1$ and Cyp17 1 early as postnatal day 5 [72], contributing to decreased testosterone and spermatogenic arrest. Subdermal implants of either testosterone or DHT into gonadotropin-releasing hormone deficient mice induced complete spermatogenesis and a dose-dependent increase in all germ cell types induced by both testosterone and DHT [73]. Targeted disruption of the Lhr gene in mice produced infertile males with reduced testicular weight, disorganized seminiferous tubule structure and arrested spermatogenesis. Few Leydig cells were detected, consistent with decreased testosterone concentration. Testosterone replacement therapy in Lhr KO mice improved spermatogenic capacity and although sperm counts remained low, sperm motility was achieved [74].

\section{Testosterone is a critical regulator of multiple physiological processes}

In addition to sustaining testicular homeostasis, testosterone is vital to multiple physiological processes. Testosterone and DHT both act on the androgen receptor (AR) which, when bound to an androgen, interacts with androgen response elements in the DNA and induces subsequent effects on transcriptional activity. As multiple cell types 
express AR, testosterone can influence a vast array of actions. One major target of testosterone is the skeletal system, with much focus on bone growth and health.

Androgen receptors are present in all layers of the human growth plate, and multiple studies have suggested testosterone, via the AR, influences longitudinal bone growth in early puberty [75]. In a rodent model, testosterone injected directly into the growth plate increased its width by approximately $15 \%$ over controls [76]. Testosterone, both directly and through aromatization to estrogen, influence bone marrow stromal cells, preadipocytes, endothelial cells within bone marrow and osteoblastic progenitors which expresses AR and estrogen receptors [77]. In particular, DHT directly stimulates the proliferation of osteoblast precursors and the differentiation of osteoblasts via Wnt signaling [78].

The utilization of testosterone therapies draws attention to its ability to promote retention and gain of muscle mass, particularly in symptomatic hypogonadal men or in the elderly male population. Short term testosterone therapy administered to elderly men possessing serum testosterone concentration at the lower limit of the normal range provided benefits such as increases in serum testosterone and lean body mass as well as decreased urinary hydroxyproline excretion, an indication of declining bone resorption [79]. Studies examining elderly, hypogonadal men undergoing testosterone therapy have reported increased muscle volume as well as increased leg and arm muscle strength [80], decreased body fat coupled with increased lean body mass [81] and elevated muscle protein synthesis [82].

Multiple epidemiological studies have stressed the importance of testosterone in the metabolic syndrome, a term encompassing such physiological features as abdominal obesity, insulin resistance, hypertension and dyslipidemia [83]. Testosterone administration in non-obese men showed correlation between increased serum testosterone and decreased visceral fat accumulation [84] while androgen therapy in older men also resulted in reduced abdominal and peripheral adipose tissue [85]. The Telecom Study, a large epidemiological study of healthy males, observed a potential association of testosterone and cardiovascular risk factors. Serum triglycerides, total cholesterol, lowdensity lipoprotein cholesterol, and plasma insulin were higher while values of serum high-density lipoprotein cholesterol were lower in men with lower serum testosterone levels [86]. An inverse association between low endogenous testosterone levels and increased systolic blood pressure was reported in a study analyzing normal males [87] while middle-aged men with abdominal obesity, upon administration of a regimen of testosterone therapy, exhibited decreased diastolic blood pressure as well as depressed plasma triglycerides, cholesterol and fasting blood glucose concentrations [88].

While these types of studies do not mechanistically determine how testosterone affects these processes, they do provide solid evidence of its role in the regulation of certain human physiological conditions. As maintaining proper testosterone concentration is a crucial, it also becomes necessary to understand the factors which contribute to and affect normal testosterone biosynthesis itself. 


\section{Regulation of Testosterone Biosynthes is}

\section{Functional StAR and Pbr are necessary for testosterone synthesis}

The entry of cholesterol, the precursor of testosterone, into the mitochondria is widely considered to be the rate-limiting step of testosterone biosynthesis. As a result, proper functioning of StAR and Pbr, the two cholesterol import genes, becomes a critical regulatory point in testosterone biosynthesis. Regulation of StAR has been demonstrated to involve multiple transcription factors and signaling pathways. StAR was originally identified as a phosphoprotein with phosphorylation sites for both PKA and protein kinase C. Comparison of StAR protein sequences from multiple species indicated two consensus PKA motifs at serine 57 and serine 195 [89] while studies performed in glomerula cells demonstrated protein kinase C can also phosphorylate StAR [90]. Phosphorylation of StAR is crucial for proper steroidogenesis. The functional significance of this was exhibited in a series of experiments in which serine to alanine mutants of the StAR protein were examined in Cos-1 cells engineered to produce steroids. Mutation at the conserved PKA target site at serine 57 had no effect on synthesis; however, a mutation at serine 195 resulted in an approximate 50\% reduction in steroid concentration. Furthermore, mutation of this residue to an aspartic acid slightly increased StAR activity, as measured by pregnenolone synthesis. These results suggested that phosphorylation of StAR at serine 195 increases its biological activity which partially accounts for the immediate effects of cAMP on steroid production [89]. Several theories exist as to how phosphorylation by PKA affects the mechanistic function of StAR. A report by Baker, et al showed cholesterol binding to StAR was not affected by a mutation at serine 195 but concluded the action of PKA enhanced the capacity of StAR to function at the mitochondria [91]. These same studies showed a reduced ability to induce steroidogenesis when recombinant human StAR bearing the same mutation was introduced in vitro into isolated mitochondria. Another hypothesis contends PKA phosphorylation of StAR increases the time it spends at the outer mitochondrial membrane, suggesting that its activity is proportional to the amount of time it resides at the membrane [92]. The absence of StAR as examined by a $\mathrm{KO}$ mouse model revealed animals that possessed a residual capacity for steroidogenesis with severely depressed serum testosterone levels. Additionally, an accumulation of lipid droplets was observed in both the gonads and adrenal glands of StAR KO animals [44]. As the mutation at serine 195 is one of the many point mutations in human StAR that reportedly gives rise to congenital lipoid adrenal hyperplasia [93], proper function of StAR is required for normal steroidogenesis and maintenance of steroid-related functions.

As exhibited with StAR, it is crucial for Pbr, the second cholesterol importer, to be fully functional. Whereas StAR acts to bring cholesterol into the outer mitochondrial membrane, $\mathrm{Pbr}$ has been shown to translocate cholesterol from the outer mitochondrial membrane to the inner mitochondrial membrane [94]. The critical role of Pbr was demonstrated in studies where knocking down Pbr expression led to an attenuation of human chorionic gonadotropin (hCG)-induced cholesterol into the mitochondria as well as impaired steroid synthesis. This occurred even in the presence of hormone induced 
StAR activity [95]. The disruption of $\mathrm{Pbr}$ in a steroid producing $\mathrm{R} 2 \mathrm{C}$ rat Leydig cell line resulted in a 10\% production of steroids when compared to the normal cells. Addition of a CYP11 $\alpha 1$ substrate, 22R-hydroxycholesterol, to the Pbr negative cells restored steroid production, indicating the cholesterol transport mechanism was impaired due to the absence of $\mathrm{Pbr}$ [96]. The efforts to generate a $\mathrm{Pbr} \mathrm{KO}$ mouse resulted in embryonic lethality, suggesting $\mathrm{Pbr}$ is involved in the basic functions necessary for embryonic development [97]. A conditional $\mathrm{Pbr} \mathrm{KO}$ animal has not been reported so in the in vivo contribution of $\mathrm{Pbr}$ has yet to be fully elucidated.

A 2001 report by West and colleagues proposed a physical interaction occurred between StAR and Pbr as measured by fluorescence energy transfer [98]. Two subsequent experiments suggested Pbr may actually regulate the function of StAR by controlling its import into the mitochondria. First, in Leydig cells where Pbr levels were knocked down, low levels of mature StAR protein formed in response to hormone induction. This correlated with the absence of steroid formation [95]. In the same report, it was demonstrated that a $\mathrm{Pbr}$ antagonist given in the presence of hCG produced an inhibition of steroid synthesis in Leydig cells, corresponding with a decrease in mature StAR protein formation. These results raised the hypothesis that the import and processing of StAR into the mitochondria may be dependent on Pbr. This was tested by the addition of in vitro transcribed/translated mature StAR into mitochondria of MA-10 Leydig cells increased steroid formation, but cells with knocked down Pbr failed to form steroids even in the presence of StAR. Reincorporation of Pbr rescued the ability of the mitochondria to respond to StAR, suggesting a functional interaction between StAR and $\mathrm{Pbr}$ at the outer mitochondrial membrane where Pbr controls StAR import and processing into mitochondria as well as StAR mediated cholesterol transport [95]. These data demonstrate the importance of both StAR and $\mathrm{Pbr}$ as critical regulators of steroidogenesis and also highlight their dependence on each of for maximal functional capacity.

\section{Cyclic AMP regulates multiple processes in the testosterone synthesis pathway}

The second messenger, cAMP, is responsible for the regulation of a host of biological processes, often through the activation of PKA. Careful scrutiny of the testosterone biosynthesis pathway reveals multiple steps are under cAMP regulation. The initial step, activation of $\mathrm{Lhr}$, is regulated by cAMP concentration. Experiments performed by Kishi, et al in LH/hCG receptor (alternate name for Lhr) expressing rat granulosa cells indicated basal cAMP activity is required for $\mathrm{LH} / \mathrm{hCG}$ receptor expression. However, when cells were incubated for longer periods of time with hCG, the $\mathrm{LH} / \mathrm{hCG}$ receptor exhibited decreased mRNA expression. The authors concluded that a labile destabilizing factor induced by cAMP may be responsible for the degradation of the $\mathrm{LH} / \mathrm{hCG}$ receptor mRNA [99]. Studies performed several years earlier in MA-10 cells showed that when treated with hCG or a cAMP derivative, 8-bromo-cAMP, there was a reduction in LH/hCG receptor mRNA expression and, additionally, a decrease in receptor number on the membranes as a result of receptor mediated endocytosis [100]. The reduction in $\mathrm{LH} / \mathrm{hCG}$ receptor mRNA expression was shown to be a result of a decreased rate of transcription when these cells were treated with 8-bromo-cAMP [101]. 
The decrease in receptor expression as a result of increased cAMP is a regulatory checkpoint to prevent continuous receptor activation and therefore constant stimulation of steroid synthesis.

Cholesterol import genes are also subject to cAMP regulation. Cyclic AMP activates transcription of cAMP-responsive genes through the interaction of the cAMP response element (CRE) binding protein (CREB) with a conserved CRE sequence in the promoter regions of these genes [102]. Instead of the typical CRE binding motif, StAR contains a cAMP responsive region which is mediated by protein kinases [103]. The classical cAMP-PKA signaling cascade has been shown to upregulate the transcription of the StAR gene [104, 105]. Studies performed by Stocco and colleagues reported transfection of MA-10 and Cos-1 cells with a vector containing wild-type CREB resulted in increased steroidogenesis, StAR promoter activity and StAR mRNA expression. The increase in activity was not observed when a dominant negative or non-phosphorylatable CREB was transfected into cells [106]. It was concluded that while the StAR promoter did not contain a consensus CRE site, CREB could play a role in StAR promoter transactivation, potentially by binding to an alternate non-consensus site or by binding to the promoter in an indirect manner. Cyclic AMP has been shown to regulate StAR protein expression through PKA activity. Mouse adrenocortical Y1 cells and derived PKA mutant adrenal tumor Kin-8 cells were treated with 8-bromo-cAMP, with StAR mRNA detectable in both cell lines, but Kin-8 cells had only a 50\% expression level compared to that of the Y1 cells. Increased StAR protein was observed in the normal Y1 cells while it was undetectable in the mutant PKA Kin-8 line [107]. Analysis of the second cholesterol importer, $\mathrm{Pbr}$, has not revealed it to be a target of CREB activation but a study has suggested there is a cAMP-inducible element regulating its structure and function. Using MA-10 cells as a model system, Boujrad and others showed treatment with hCG resulted in increased cAMP concentration as well as elevated steroid formation as a result of hCG binding to benzodiazepine. This was completely reversed upon the addition of a selective PKA inhibitor, indicating $\mathrm{Pbr}$ is potentially regulated by cAMP [108].

Phosphorylation of CREB by PKA is also a critical cAMP-regulated component of the testosterone biosynthesis pathway. Three genes directly involved in the synthesis of testosterone, Cyp17 $\alpha$, Cyp $11 \alpha$ and $3 \beta \mathrm{HSD}$, all contain CREB binding sites within their promoters [109]. This effect can be observed by studies which demonstrated that, in the absence of cAMP, de novo synthesis of Cyp17 $\alpha$ was halted in cultured Leydig cells, and the major steroid product produced was progesterone. Upon chronic cAMP treatment, the major product was shifted back to testosterone, indicating the requirement of cAMP for Cyp17 $\alpha$ function and, thereby, its importance in sustaining testosterone synthesis [110]. The duration of phosphorylation at serine 133, the CREB phosphorylation site, can determine the efficacy of downstream target gene expression. Experimental analysis has shown sustained phosphorylation promotes increased CREB target gene induction while a rapid phosphorylation/dephosphorylation cyclic did not promote gene induction [111]. 


\section{Testosterone metabolism}

Steroid hormones are maintained by a dynamic balance between steroidogenesis and steroid inactivation (Figure 1-4). This ensures correct physiological function is continuously occurring. While the liver is the most important organ involved in steroid hormone metabolism, other organs including the skin [112], lung, spleen and intestine [113] have been implicated in the breakdown of steroids. Steroid metabolism does not always reduce the biological activities of hormones but instead can render them inactive through metabolic conversion. Elimination of these lipophilic molecules from the cell occurs through an array of enzymatic reactions followed by their transport across the cell membrane. In general, the major metabolic pathways of steroids in humans are the following: oxidation, primarily through hydroxylation, by cytochrome P450 (CYP 450) enzymes [114], conjugation with glucuronide [115] or sulfate [116] and O-methylation by catechol O-methyltransferase [117]. Steroid hydroxylation produces products with higher polarity so the metabolites are more easily conjugated and excreted [118]. As with most steroid metabolism, the liver is responsible for the majority of steroid metabolism resulting from CYP450 hydroxylation [114]. In humans, there are 18 families and 43 subfamilies of CYP450 genes [119]. Steroids are metabolized by several members of the CYP450 families including CYP1A, CYP1B, CYP2B, CYP2C, CYP3A,CYP7A and CYP7B [113] however CYP2B and CYP3A are largely responsible for testosterone metabolism. Hydroxylation of testosterone can occur at, but is not limited to, the following positions: $2 \alpha, 6 \alpha, 6 \beta, 7 \alpha, 16 \alpha, 16 \beta$, and $17 \beta$ [120]. The CYP3A family isoforms account for up to $60 \%$ of the total CYPs present in the human liver with CYP3A4 considered to be the most versatile enzyme involved in the metabolism of endogenous steroid hormones [121]. Studies have demonstrated CYP3A4

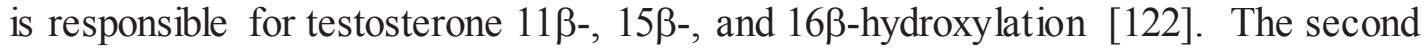
important CYP family involved in testosterone metabolism, CYP2, accounts for approximately $30 \%$ of human hepatic CYPs [123]. It has been shown that human CYP2B6 is the only CYP involved in 16 $\alpha$ - [124] and 16 $\beta$-hydroxylation [125]. CYP2C19 is also capable of metabolizing testosterone, forming androstenedione as a major metabolite [126]. CYP19A1, also known as aromatase, can transform testosterone into estradiol in regions such as the ovary, placenta and brain [127].

As it has been shown CYPs metabolize steroids, there are also reports that steroids are able to regulate CYP expression, namely mouse Cyp2b10 (CYP2B6 in humans) and testosterone. Work performed in mice by Honkakoski, et al demonstrated that castrated males presented with elevated Cyp2b10 mRNA and protein expression in comparison to intact animals. This was accompanied by an increase in Cyp2b10 catalytic activity. This was alleviated upon testosterone administration to the castrated males [128]. These data were one of the first to suggest a negative correlation between Cyp2b10 expression and testosterone concentration. Later evidence further confirmed this result. As hepatic Cyp2b10 had been identified as a direct target of the nuclear orphan receptor CAR [129], experiments were performed in which HepG2 cells were 


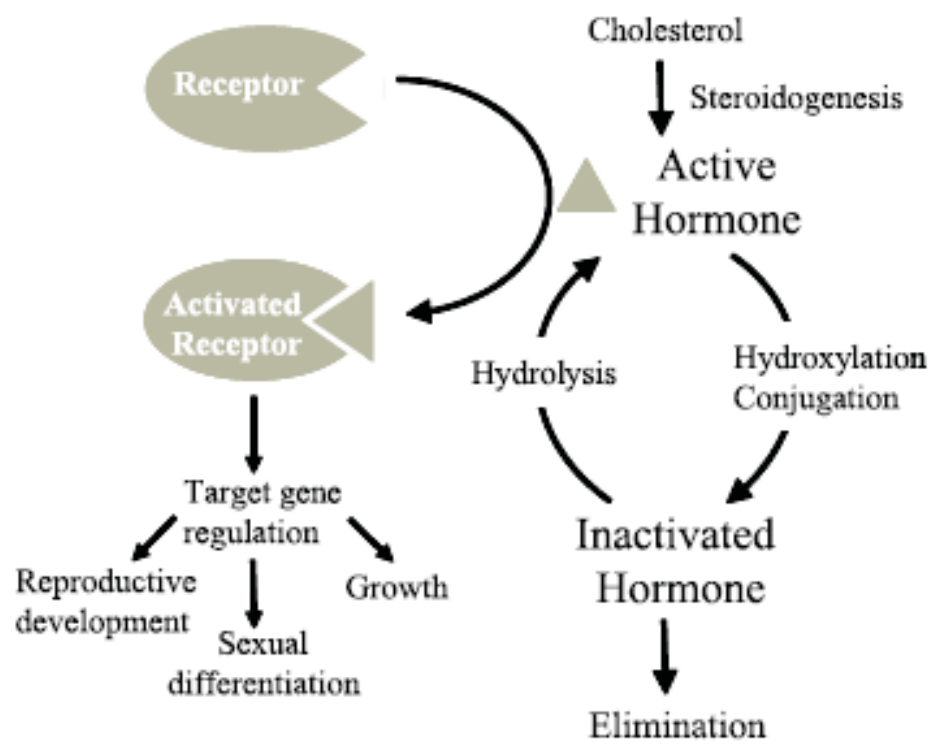

Figure 1-4. The balance betwe en steroid bios ynthesis and inactivation. Steroid hormones are maintained through a dynamic balance between steroidogenesis and steroid inactivation to ensure their proper physiological functions, which are largely mediated through the activation of ligand-specific steroid hormone receptors.

Reprinted from Chemico-Biological Interactions, 147(3), You L, Steroid hormone biotransformation and xenobiotic induction of hepatic steroid metabolizing enzymes, 233-246, copyright 2004, with permission from Elsevier. 
transfected with NR1, a CAR-responsive enhancer found in both mouse and human Cyp2b genes. Treatment with either testosterone, androstenedione, progesterone or androstenediol all resulted in a dose-dependent decrease in NR1 activity, indicating repression occurred through CAR activation. This was reversed by the addition of estrogens [130]. These collective results indicate Cyp2b10 and testosterone exist in a crucially balanced relationship, as the expression of one component tightly regulates the expression of the other. 


\section{CHAPTER 2. THE ABSENCE OF MRP4 IN LEYDIG CELLS RESULTS IN REDUCED INTRATESTICULAR TESTOSTERONE CONCENTRATION*}

\section{Introduction}

Expression of multiple $\mathrm{ABC}$ transporters present in the testes has been well established in the literature. Pgp, Abcg2, Abcc1, Abcb9, Abcb6, Abcb8 and Abca5 have all been identified in various testicular cells types. Abca5 localization is reported in Leydig cells [131]; however, its exact role has yet to be elucidated. Similarly, the precise contribution of Abca9, Abcb6 and Abcb8 has not been determined with respect to testicular function. Interestingly, the transcripts of each of these transporters have been identified in distinct cell types. Abcb9 was identified in Sertoli cells while Abcb6 was expressed in the germline, with positive expression observed in spermatocytes and early spermatids. Abcb8 transcript was detected in Sertoli cells and peritubular cells as well as spermatogonia and spermatocytes [132]. Even without full functional characterization, it is immediately detectable that $\mathrm{ABC}$ transporters have no discernible distribution pattern in the testes.

Other $\mathrm{ABC}$ transporters have been more extensively characterized with respect to functional contribution as well as cellular localization. Immunohistochemical staining has revealed that Pgp, Abcg2 and Abcc1, like the aforementioned transporters, have no distinct expression pattern in the testes. Pgp is found in myoid cells, Leydig cells and endothelial cells; Abcg2 has been identified in myoid and endothelial cells while Abcc1 is localized to both Sertoli cells, and to a lesser extent, Leydig cells [133]. Additionally, Abcg2 was recently discovered to be localized to spermatogonial stem cells, providing the first evidence of this transporter in this compartment [134]. As these transporters are located in different cell layers of the normal testes, it was suggested they provided optimal protection of spermatogenesis by exporting potentially harmful substrates. While there are multiple studies confirming the protective role of these transporters in the testes, that data will not be discussed as our main focus concerns the relatively undefined role of transporters in regulating testicular steroid biosynthesis.

A 2010 report by Sivils, et al was the first to describe how the absence of an Mrp transporter, namely Abcc1, resulted in reduced serum and testicular testosterone levels in the absence of drug challenge [135]. This work provided the first evidence that a transporter may influence the steroid biosynthetic process although the mechanism was not elucidated.

Prior to the work presented here, it was well established that Mrp4 is expressed in both human and murine testes [136, 137], although its cellular localization and precise contribution had yet to be established. As it might be hypothesized that Mrp4 plays a

\footnotetext{
* Modified with permission. Morgan JA., et al. Deregulated hepatic metabolism exacerbates impaired testosterone production in Mrp4-deficient mice. J Biol Chem, 2012. 287(18): p. 14456-66 [138].
} 
protective role in the testes, as seen with Pgp, Abcg2, and Abcc1, no data existed to support this. There was also no evidence linking Mrp4 as a regulator of testosterone biosynthesis although it was reported that neither testosterone nor DHT were substrates for Mrp4 [54]. Through the use of the Mrp4 KO mouse, my contribution was to provide a more in-depth understanding of the importance Mrp4 provides in testes, beginning with its cellular localization and examination of testicular function.

\title{
Experimental Procedure
}

\begin{abstract}
Animals
The generation of the Mrp4 KO mouse had been described previously [38]. All mice used during the duration of these studies were maintained on a mixed C57BL6/129 background and generated by intercrossing littermates. Mice were housed and fed under identical conditions until experiments were performed.
\end{abstract}

\section{Immunohistoche mistry (IHC)}

Whole testes were harvested from Mrp4 WT and KO mice and immediately formalin fixed. Samples were submitted to the St. Jude Veterinary Pathology Core where they were paraffin embedded and sectioned into 4 micron sections. Following standard slide mounting procedure, the testes sections were stained with $\mathrm{M}_{4} \mathrm{I}-10$, a monoclonal Mrp4 antibody (a gift from Dr. George Scheffer). Testes were stained with hematoxylin \& eosin (H\&E) for analysis of overall testicular morphology. Additionally, they were stained with an antibody for the cell proliferation marker, Ki67, and for terminal deoxynucleotidyl tranferase dUTP nick end labeling (TUNEL), an antibody detecting cell apoptosis. All staining was performed using the LabVision 720 autostainer (Thermo Shandon).

\section{Immunoblotting}

Testes from pre-pubertal and adult WT and KO mice were ultrasonically disrupted in a mixture of M-Per reagent (Thermo Scientific) plus a protease inhibitor cocktail (Roche Diagnostics). Protein concentration was determined by the Bradford assay method [139]. Proteins were suspended in a mixture of 2X Laemmeli sample buffer containing 5\% $\beta$-mercaptoethanol but were not denatured by boiling. Proteins were then size fractionated by sodium dodecyl sulfate polyacrylamide gel electrophoresis. All gels were hand cast. The running gel was composed of $29.2 \%$ acrylamide- $0.8 \%$ Bis (National Diagnostics, Inc.), $1.5 \mathrm{M}$ Tris-0.4\% SDS (Sigma Aldrich), double deionized water, 10\% ammonium persulfate (Biorad) and Temed (Biorad). The stacking gel consisted of 29.2\% acrylamide- $0.8 \%$ Bis (National 
Diagnostics, Inc.), $0.5 \mathrm{M}$ Tris-0.4\% SDS (Sigma Aldrich), double deionized water, 10\% ammonium sulfate (Biorad) and Temed (Biorad).

Following size fractionation, the proteins were transferred onto a nitrocellulose membrane (Midwest Scientific) overnight in a solution of $10 \% 1 \mathrm{X}$ Tris-glycine (Amresco), 20\% methanol, and 70\% double deionized water. Following transfer, blots were blocked in a 10\% milk/phos phate buffered saline (PBS)-Tween solution for 60 minutes then washed $3 \mathrm{X}$ for 5 minutes with $1 \mathrm{X}$ PBS-Tween. Primary antibodies were made in a $10 \%$ milk/PBS-Tween solution, and blots were rocked at room temperature for 150 minutes then washed $5 \mathrm{X}$ for 5 minutes each in $1 \mathrm{X}$ PBS-Tween. Secondary antibody were made in the same solution and incubated for 60 minutes at room temperature, followed by the same washing step as just described. Blots were then exposed to enhanced chemiluminescence reagent (GE Healthcare) for one minute and protein was visually detected by exposure to film (Denville Scientific).

\section{Testicular te stosterone measurement}

Testicular testosterone concentration was measured from WT and KO mice by harvesting testes, homogenizing in $1 \mathrm{X}$ PBS with a glass Dounce homogenizer, and centrifuging at $5900 \mathrm{xg}$ for 5 minutes at $4^{\circ} \mathrm{C}$. The supernatant was then combined with 1 $\mathrm{ml}$ diethyl ether, vortexed, and the organic phase was collected and dried down under a stream of $\mathrm{N}_{2}$ at room temperature. The dried fraction was reconstituted in $0.2 \mathrm{ml} 1 \mathrm{X}$ PBS. Testosterone concentration was then measured by a ${ }^{125}$ I-labeled radioimmunoassay (RIA) (MP Biomedicals) according to the manufacturer's instructions. Concentration of testicular testosterone was expressed as $\mathrm{ng} / \mathrm{mg}$ of testes weight.

\section{Immunohis toche mical counting}

All IHC quantitation was performed on a minimum of three mice per age and genotype group. Counts were taken on five random fields per slide at $40 \mathrm{X}$ magnification on a Nikon Eclipse $T_{i}$ microscope. For TUNEL and Ki67 staining, the cell was considered positive if greater than $50 \%$ of the individual cell was stained.

\section{Results}

\section{Mrp4 is localized to Leydig cells}

As expected, immunoblot analysis revealed Mrp4 protein expression in whole testes extract from Mrp4 WT testes. Mrp4 was also detected in the isolated Leydig cell fraction from WT testes. No protein expression was observed in Leydig cells or whole testes from $\mathrm{KO}$ animals. Analysis of Abcc 1 (Mrpl) showed decreased expression in Leydig cells as compared to whole testes, where Abcc1 (Mrp1) is highly expressed in the 
Sertoli cells that reside in the seminiferous tubules [140] (Figure 2-1A). In accordance with the immunoblot analysis, IHC confirmed Mrp4 localization in the Leydig cells of both mouse (Figure 2-1B) and human (Figure 2-1C). Mrp4 was undetectable inside the seminiferous tubules, indicating it is not expressed in Sertoli or germ cells. These results provide the first evidence of Leydig cell localization of Mrp4.

\section{The abse nce of Mrp4 in Leydig cells does not affect ge ne ral reproductive parameters}

Phenotypically, Mrp4 WT and KO animals are indistinguishable from one another. Both genotypes of mice are reproductively normal, producing comparable litter sizes (Figure 2-2A) and ratios of offspring that conform to classical Mendelian inheritance (not shown). In addition, testes weight was comparable between the genotypes, although KO mice did exhibit a slight increase (Figure 2-2B). As general reproductive parameters were not altered between WT and KO mice, the loss of Mrp4 was then examined with respect to total Leydig cell number. Immunohistochemical analysis of testes of mice ranging in age from 3 weeks to 6 weeks revealed similar number of absolute Leydig cells, with the exception of 3 week old $\mathrm{KO}$ mice. These mice exhibited an approximate 30\% reduction in Leydig cell number (Figure 2-2C). Leydig cell proliferation analysis of the same samples demonstrated WT and $\mathrm{KO}$ mice had proportional numbers of proliferating cells (Figure 2-2D). However, 6 week old Mrp4 KO mice did possess fewer proliferating cells than did their WT counterparts. Overall, our results revealed the absence of Mrp4 in Leydig cells does not generally affect their total cell number or proliferation status.

\section{Pre-pubertal Mrp4 KO mice are deficient in testicular te stosterone}

It had been previously observed that the loss of an Mrp transporter expressed in the Leydig cells resulted in testosterone deficiency [135]. In addition to Leydig cells, this transporter was simultaneously expressed in Sertoli cells, so the transporter's exact role in testosterone reduction could not be discerned with respect to its Leydig cell expression. For these studies, our initial analysis revealed Mrp4 expression to be solely localized to the Leydig cells, making it possible to reveal the role Mrp4 plays in these cells and how its loss affects the testes as a whole.

Initial experiments focused on pre-pubertal mice. Prior work in our lab revealed Mrp4 protein expression increases in the testes as mice mature from pre-pubertal animals to adulthood (Figure 2-3), so it was of interest to examine our animals at two different stages of sexual maturity. Pre-pubertal mice were designated as exactly 21 days of age as genes responsible for steroid biosynthesis can show upregulation as early as 25 days after birth $[141,142]$, indicating the onset of puberty. Examination of testicular testosterone concentration revealed a drastic decrease in levels of the Mrp4 KO mouse, only $20 \%$ of the concentration observed in WT animals (Figure 2-4). 


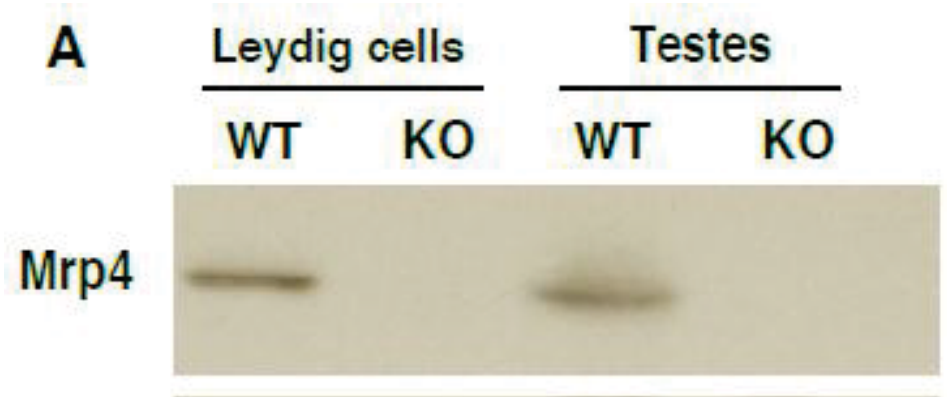

Mrp1

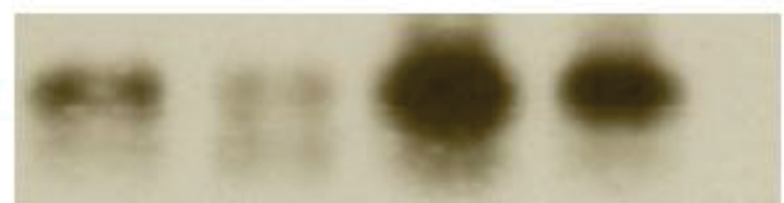

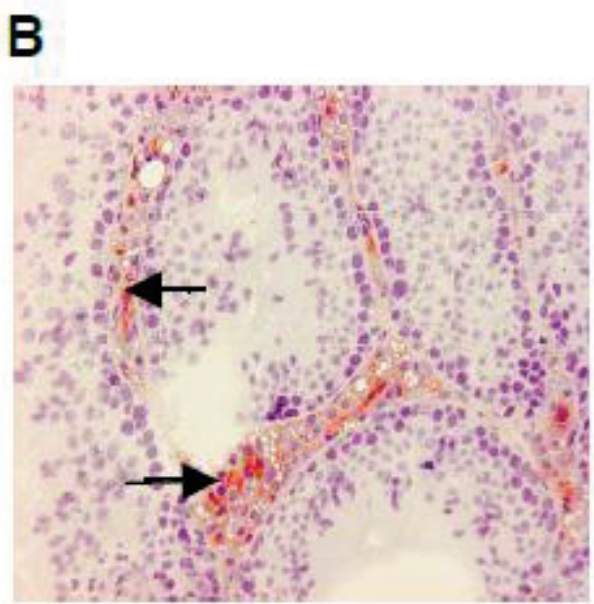

Mouse
C

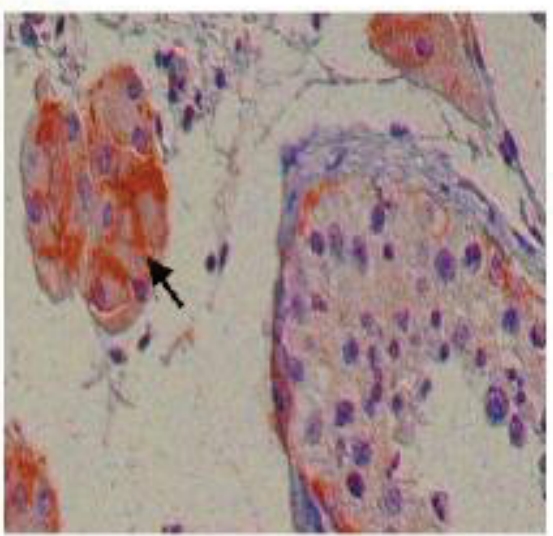

Human

Figure 2-1. Mrp4 is expressed in Leydig cells. (A) Immunoblot analysis of Mrp4 and Mrp1 protein in Leydig cell and testes. Immunohistochemical analysis (400x magnification) shows Mrp4 is visible in both (B) mouse and (C) human Leydig cells as indicated by the red staining (see arrows). 

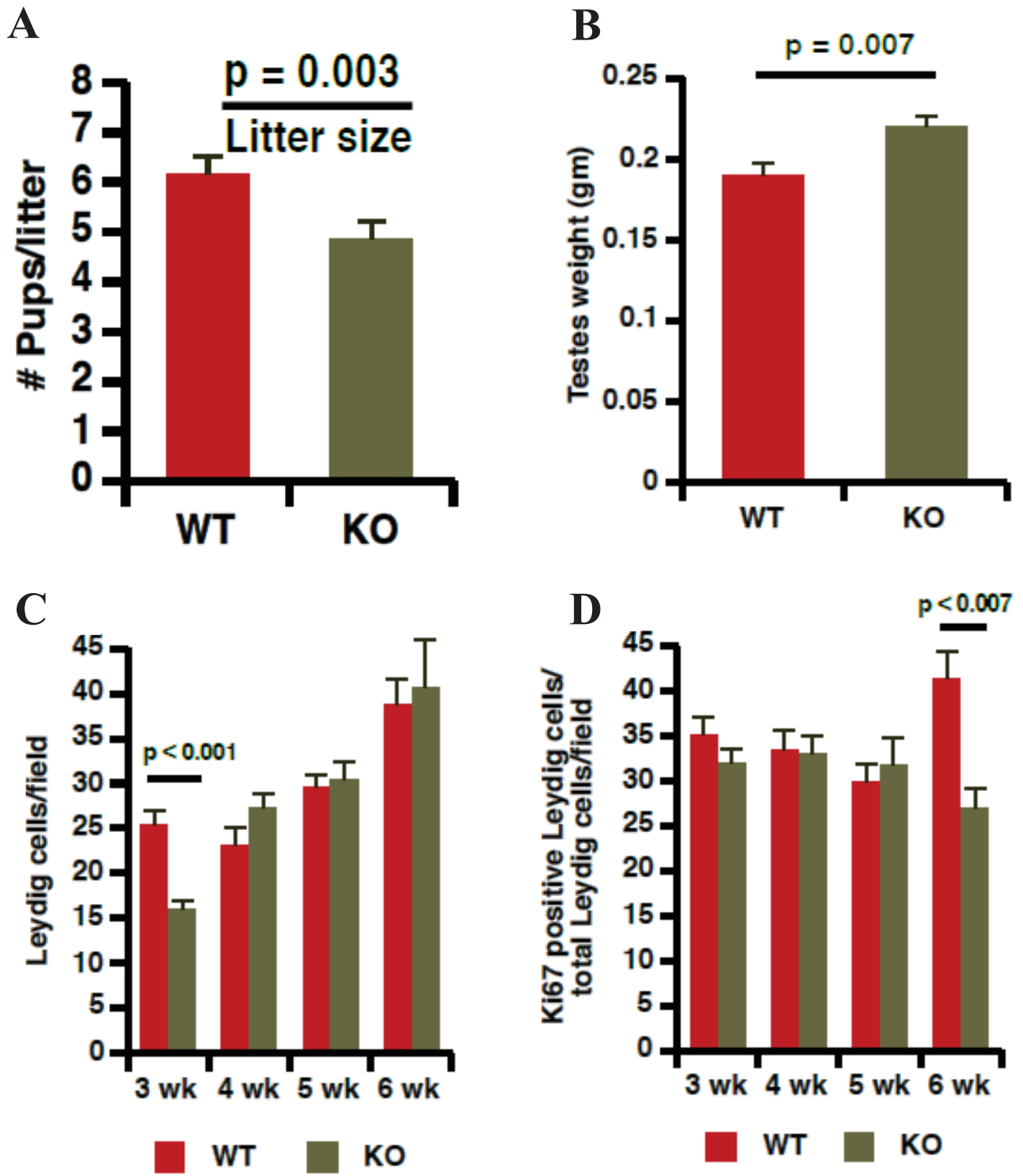

Figure 2-2. Mrp4 KO mice dis play normal reproductive parameters. (A) Average number of pups per litter in WT $(\mathrm{n}=51$ litters $)$ and $\mathrm{KO}(\mathrm{n}=53$ litters $)$ matings.

(B) Mean testes weight of Mrp4 WT $(n=37)$ and KO $(n=37)$ mice. (C) Mean testicular Leydig cell counts $(\mathrm{n}=3$ mice per age and genotype). (D) Mean testicular Leydig cell proliferation (Ki67+ cells per total Leydig cell number) $(n=3$ mice per age and genotype). All error bars $=\mathrm{SE}$. 

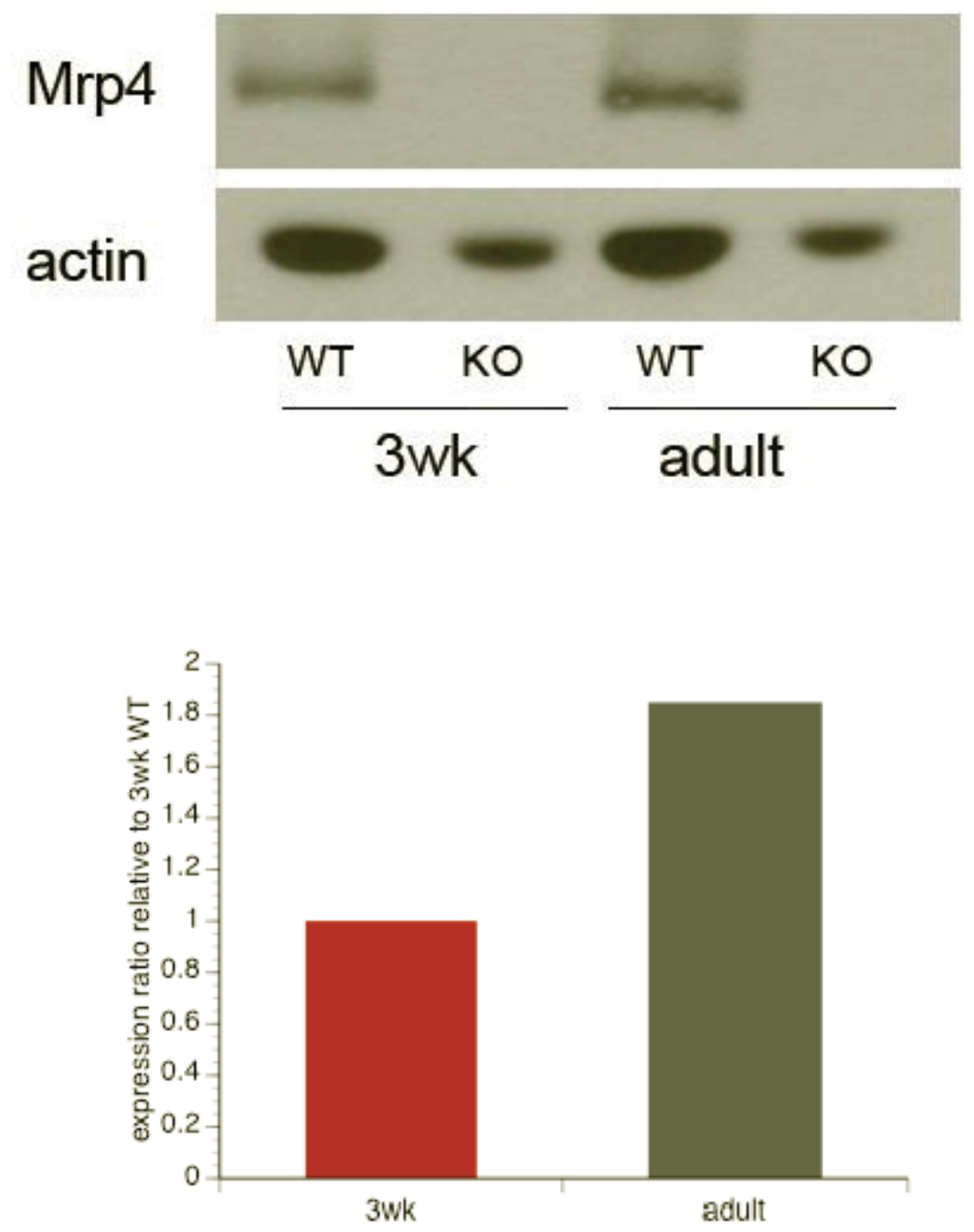

Figure 2-3. Mrp4 protein expression incre as es with age. Immunoblot analysis of Mrp4 expression in testes of WT and KO mice (left). Actin was used as a loading control (top). Expression ratios plotted from absolute band intensity (bottom) using Image J software. 


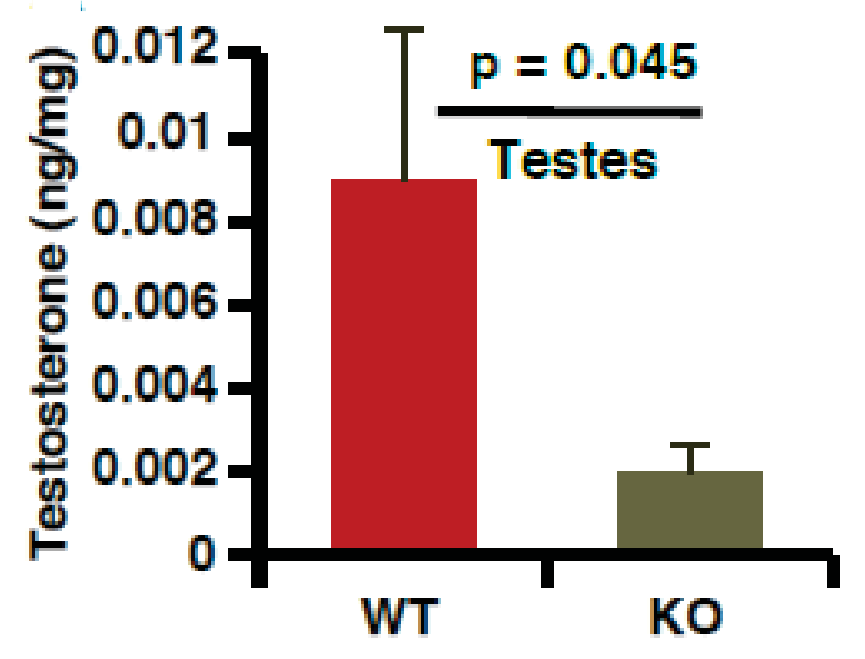

Figure 2-4. Pre-pubertal Mrp4 KO mice are de ficient in tes ticular testosterone. Testosterone concentration in Mrp4 WT $(n=9)$ and KO $(n=4)$ testes as measured by ${ }^{125}$ I-labeled radioimmunoassay. 
To assess how the absence of Mrp4 affected the testes, several parameters were analyzed. As testosterone is required for gamete maturation [143], analysis was conducted on whole testes in order to determine germ cell maturation status. Primary spermatids were detected in $50 \%$ of the seminiferous tubules of WT mice compared to only $25 \%$ in KO mice (Figure 2-5A), indicating WT testes possess a more mature germ cell population. In conjunction, germ cell proliferation was investigated in the same sample set. Using Ki67, a marker for cell proliferation, a 33\% reduction in proliferating germ cells was observed in the KO seminiferous tubules (Figure 2-5B). This result suggested defective germ cell mitosis occurred in the absence of Mrp4. To further confirm this result, expression analysis of testicular RNA showed genes important in germ cell mitosis, including Ccnb1, Cdc25c, and E2f, were slightly reduced in KO testes. $\mathrm{pRm1}$, a gene important in gamete chromatin assembly, was drastically reduced in these animals (data not shown) confirming germ cell maturation is defective in KO mice. In addition, as germ cell maturation is controlled by both proliferation and apoptosis [144], the number of apoptotic cells was assessed by TUNEL staining of the whole testes. Results showed a greater than $30 \%$ increase in TUNEL positive cells in tubules of KO mice as compared to their WT counterparts (Figure 2-5C).

\section{Conclusions}

We show that Mrp4 is localized specifically to the Leydig cells of the testes, but its absence does not affect general reproductive parameters including litter size or Mendelian inheritance ratio. Testes weight is unaltered between the genotypes, and total Leydig cell number is comparable between WT and $\mathrm{KO}$ as mice approach adulthood with the exception of the 3 week age. Similarly, Leydig cell proliferation was comparable as mice aged.

Examination of pre-pubertal Mrp4 KO mouse testes revealed decreased intratesticular testosterone concentration in comparison to WT animals. This was accompanied by impaired spermatogenesis and reduced germ cell proliferation. Additionally, increased germ cell apoptosis was observed in these same KO animals. 

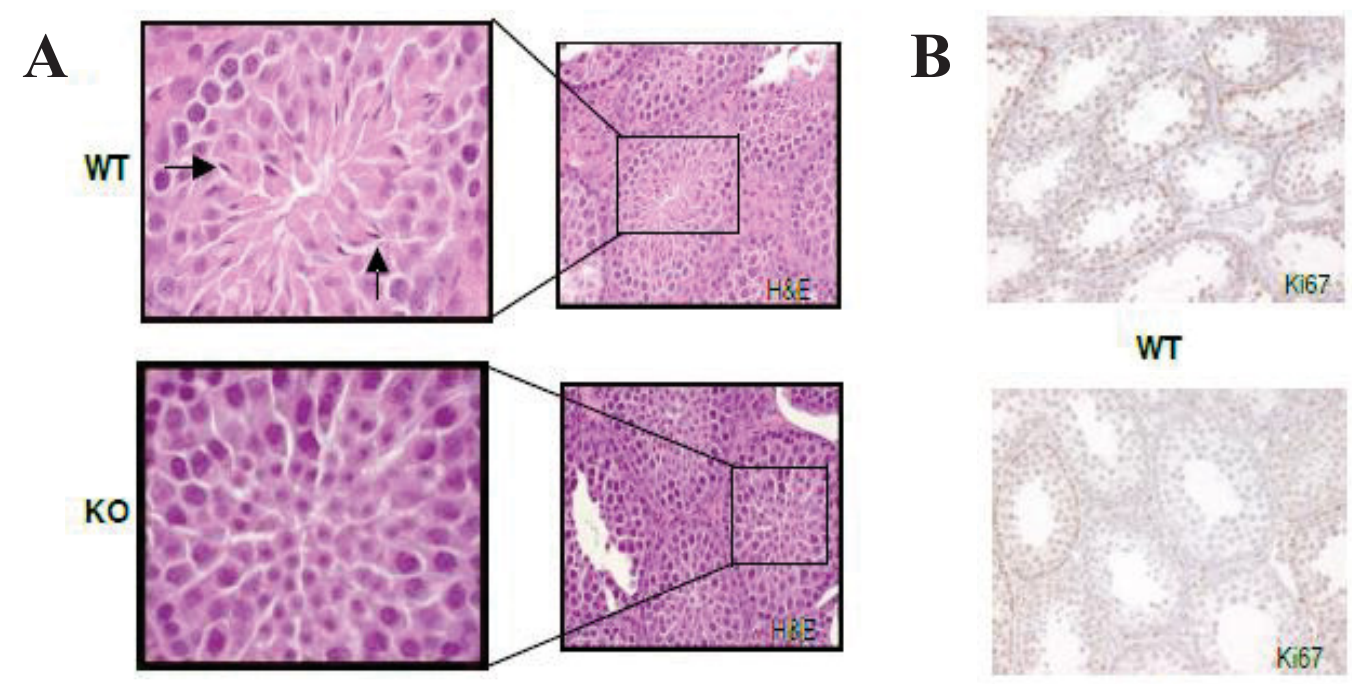

WT
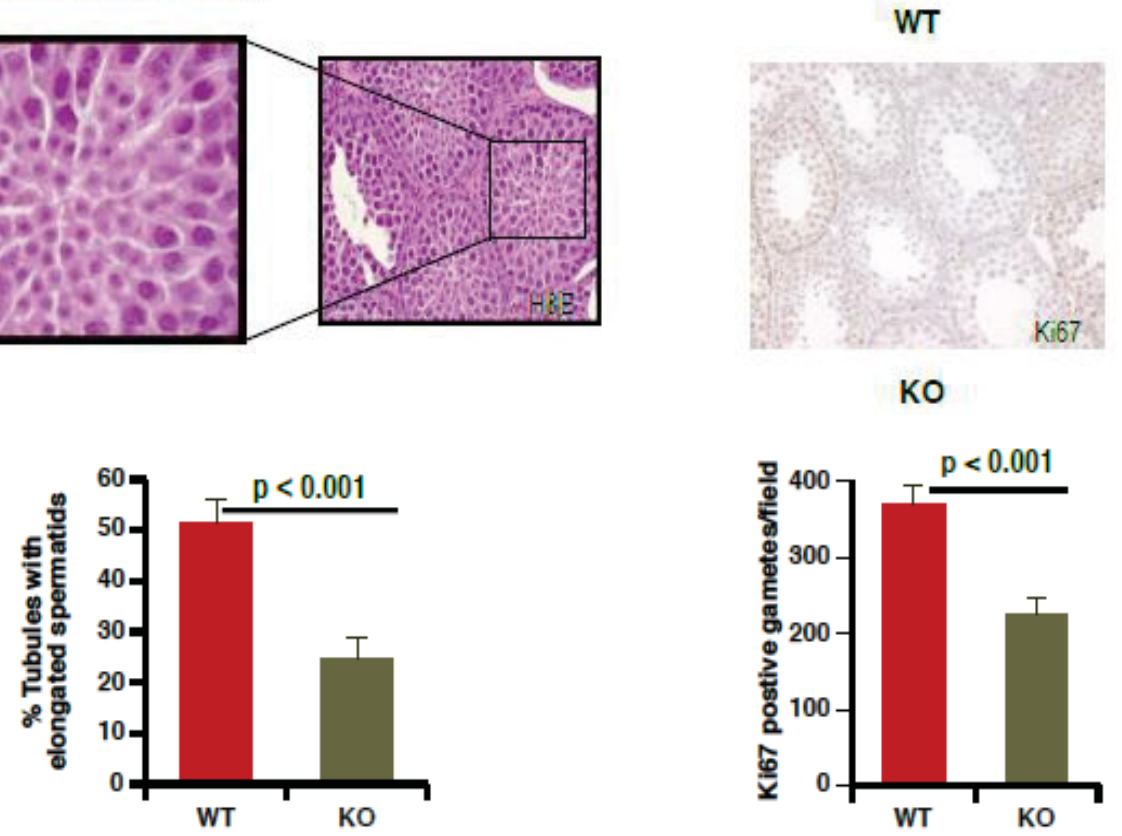

KO
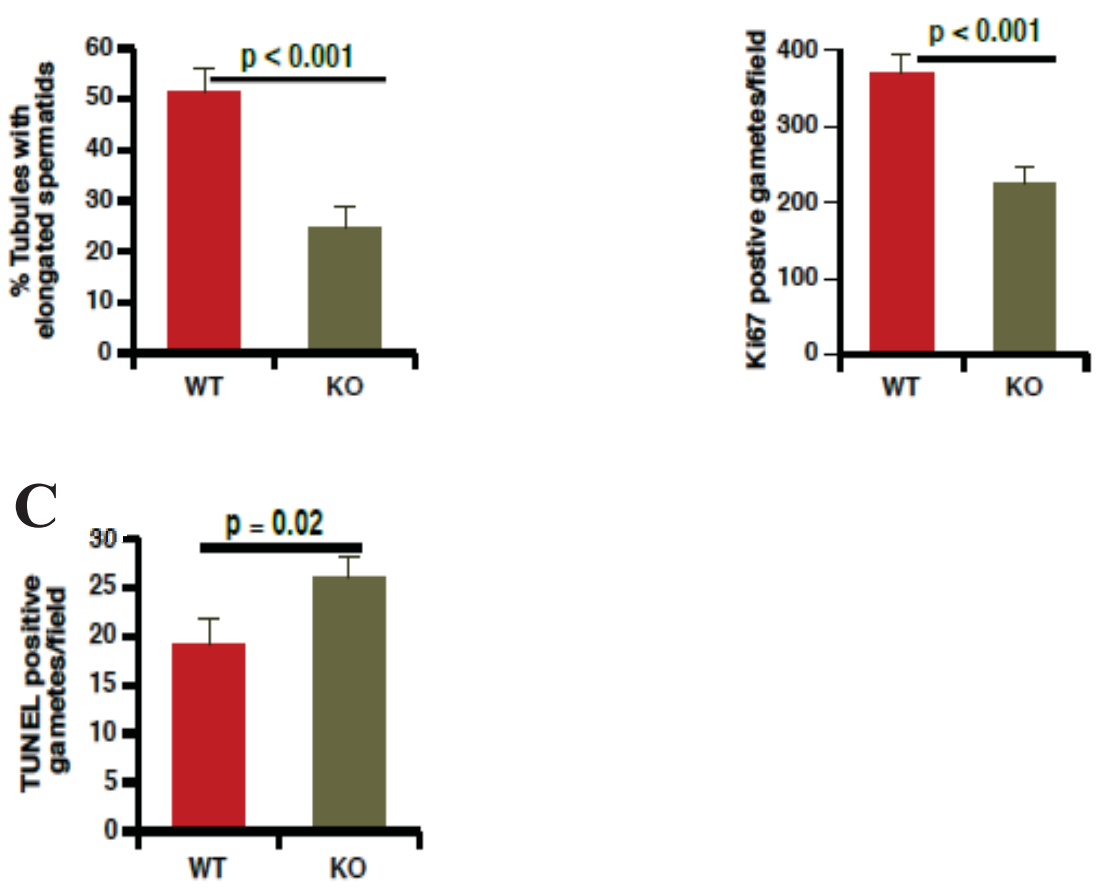

Figure 2-5. Pre-pubertal Mrp4 KO mice exhibit impaire d testicular morphology. (A) Testicular morphology of WT and KO mice (H\&E stain, 40x magnification). Arrows indicate elongated spermatids in WT mice but immature spermatogonia are only detected in $\mathrm{KO}$ mice. Enlarged insets show these cells in the seminiferous tubules lumen. Graph below quantitates percentage of seminiferous tubules containing elongated spermatids as examined in a high power field. (B) Cell proliferation in testes utilizing Ki67 staining. Graph below is a quantification of Ki67+ cells expressed as mean number per high power field (40x magnification). (C) Mean number of apoptotic germ cells per high power field (40x magnification) by TUNEL assay. All error bars $=\mathrm{SE}$. 


\section{CHAPTER 3. TESTICULAR TESOSTERONE BIOSYNTHESIS IS IMPAIRED IN MRP4 KO MICE*}

\section{Introduction}

Testosterone biosynthesis is dependent on both acute and chronic stimulation of Leydig cells by the pituitary hormone LH which binds to specific high affinity receptors on the cell surface. This results in the activation of adenylate cyclase followed by increased cAMP, mediating both acute and chronic effects of LH. The rapid, acute response involves the transport of cholesterol, the precursor of testosterone, to the inner mitochondrial membrane by way of cholesterol transport proteins StAR and Pbr. Chronic stimulation of Leydig cells by LH is required for optimal expression of enzymes and proteins necessary for testosterone biosynthesis. The beginning steps of the conversion of cholesterol to the ultimate product of testosterone begin with cholesterol metabolized to pregnenolone through the actions of the enzyme Cyp $11 \alpha 1$. Pregnenolone then exits the mitochondria and is transferred to the smooth endoplasmic reticulum where addition reactions involving $3 \beta \mathrm{HSD} 1$, Cyp17 $\alpha 1$, and $17 \beta \mathrm{HSD} 1$ result in the final product of testosterone [61-63]

Interference with many of the steps involved in testosterone biosynthesis can result in decreased, or in some instances, complete ablation of testosterone production. Studies utilizing Lhr KO mice demonstrated that adult testes were devoid of mature Leydig cells and exhibited thin seminiferous tubules with arrested spermatogenesis. Full steroidogenesis was not achievable without gonadotropin stimulation [145, 146]. Impeded StAR function and expression also negatively impacts steroid biosynthesis. Mutation of the conserved PKA target site serine 195 resulted in an approximate $50 \%$ reduction in steroid production in Cos-1 cells engineered to generate steroids [89]. Decrease in StAR mRNA and protein expression by environmental factors such as exposure to phthalate esters and heavy metals also result in decreased steroidogenesis [147]. Similarly, loss of the second cholesterol transport protein, Pbr, produces impaired steroid biosynthesis. Targeted disruption of $\mathrm{Pbr}$ in a R2C Leydig cell line resulted in steroid production in only $10 \%$ of the cells when compared to WT [97]. These collective results demonstrate the importance of an unimpaired biosynthesis pathway is necessary for maximal steroid production.

In addition to the above mentioned mechanisms, these and other genes directly involved in steroid biosynthesis are regulated by cAMP. Anakwe and Payne exhibited that, in the absence of cAMP. de novo synthesis of Cyp17 $\alpha$ ceases in cultured Leydig cells, with the major steroid product becoming progesterone. Chronic cAMP treatment then shifted the major product back to testosterone, indicating the requirement of cAMP

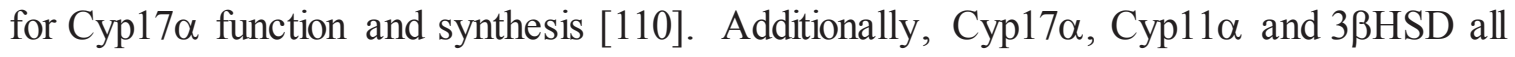

*Modified with permission. Morgan JA., et al. Deregulated hepatic metabolism exacerbates impaired testosterone production in Mrp4-deficient mice. J Biol Chem, 2012. 287(18): p. 14456-66 [138]. 
contain promoters with CREB binding sites [109], a transcription factor whose activation results in increased transcription of these downstream target genes. As CREB activation is a cAMP dependent process, it is required for maximal expression of these biosynthesis genes.

Inhibition of cAMP by a phosphodiesterases (PDE) expressed in Leydig cells also highlighted the importance of cAMP as a modulator of testosterone biosynthesis.

Through the use of isolated Leydig cells in a PDE8A KO mouse model, an increase was observed in LH stimulated testosterone production, likely due to increased cAMP concentration. PDE8A KO Leydig cells treated with 3-isobutyl-1-methylxanthine (IBMX), a pan PDE inhibitor, exhibited an even more robust increase in testosterone concentration when stimulated with LH [148]. These results indicate inhibition of cAMP dependent PDEs is a potent way to modulate LH signaling and steroid biosynthesis while also emphasizing cAMP concentration is critical for testosterone production.

Based on the results obtained in Chapter 2, we sought to determine the mechanism by which testicular testosterone concentration was reduced in Mrp4 KO mice. As the testosterone biosynthesis pathway can be regulated at multiple levels, it was imperative to examine each individual component to determine the exact defect that resulted in decreased testosterone.

\section{Experimental Procedure}

\section{LH meas ure ment}

Whole blood was collected by retro-orbital eye bleed from WT and $\mathrm{KO}$ mice, incubated at $4^{\circ} \mathrm{C}$ for 2 hours, then centrifuged at $5900 \mathrm{x} \mathrm{g}$ for 5 minutes in order to separate the serum from the remaining clotted blood. LH concentrations were assayed from the serum by the Center for Research in Reproduction Ligand Assay and Analysis Core at the University of Virginia School of Medicine (Charlottesville, VA). LH was measured by an immunoradiometric sandwich assay and the final concentration was expressed in $\mathrm{ng} / \mathrm{ml}$.

\section{Immunoblot analys is}

Immunoblot analysis was performed in whole testes samples as described in Chapter 2 with the exception that all protein samples examined were denatured by boiling for 5 minutes at $95^{\circ} \mathrm{C}$ in a $2 \mathrm{X}$ Laemmeli sample buffer containing $5 \% \beta$-mercaptoethanol. The assayed proteins were Lhr (AbD Serotec), StAR (Santa Cruz Biotechnology, Inc.),

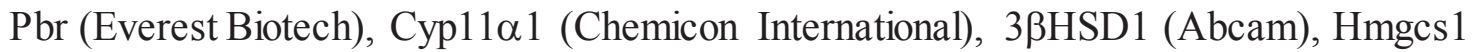
(Abcam), Dhcr7 (Santa Cruz Biotechnology, Inc.), VDAC (Mitosciences), CREB and phospho-CREB Ser133 (Cell Signaling Technology). Relative protein quantities were determined by densitometry using ImageJ software. 


\section{Leydig cell tes tosterone measure ment}

Leydig cells were isolated as previously described from three mice of each genotype. Samples were pooled for analysis, and testosterone was measured directly using the RIA as described previously. Testosterone concentration is expressed as ng/ug protein.

\section{cAMP determination}

Basal cAMP measurements were taken from freshly isolated Leydig cells which were immediately lysed in $0.1 \mathrm{M}$ hydrochloric acid. Intracellular cAMP content was assayed using the acetylated version of a cAMP complete enzyme-linked immunosorbent assay (Enzo Life Sciences ) according to the manufacturer's instructions. Results are expressed as pmol per $10^{6}$ cells.

Under stimulated conditions, isolated Leydig cells were plated at a density of $10^{6}$ cells per well in a six well plate using DMEM/F12 media (Invitrogen). Cells were treated with a $10 \mathrm{mIU} / \mathrm{ml} \mathrm{LH}$ (Sigma), a physiological concentration, and $0.1 \mathrm{mM}$ IBMX (Sigma), a PDE inhibitor. Following a three hour incubation at $37^{\circ} \mathrm{C}$, cells were collected using a cell lifter, centrifuged at $5900 \mathrm{x}$ g for 5 minutes at $4^{\circ} \mathrm{C}$, and cAMP concentration was assayed as described above.

\section{CREB phosphorylation}

Leydig cells were isolated from WT and KO mice, plated at a density of $10^{6}$ cells in a six well plate in DMEM/F12 media (Invitrogen). Cells were then stimulated with 10 $\mathrm{mIU} / \mathrm{ml} \mathrm{LH}$ for the indicated time points. Cells were harvested, protein was measured by Bradford assay, and the samples were subjected to immunoblot analysis probing for phospho-CREB133 and total CREB (Cell Signaling Technology). The loading control was an unknown protein that cross-reacted with the antibody but remained constant among the samples. Densitometry was assessed using ImageJ software.

\section{RNA isolation}

Leydig cells were isolated from three mice of both WT and KO testes and homogenized in $1 \mathrm{ml}$ Trizol Reagent (Invitrogen) using a hand held homogenizer. Samples were incubated at room temperature for 5 minutes to allow for complete dissociation of nucleoprotein complexes. Following incubation, $0.2 \mathrm{ml}$ chloroform was added, samples were vigorously shaken for 15 seconds and incubated at room temperature for 3 minutes. Samples were then centrifuged at $12000 \mathrm{x}$ g for 15 minutes at $4^{\circ} \mathrm{C}$. After centrifugation, the aqueous phase was collected, mixed with $0.5 \mathrm{ml}$ isopropyl alcohol and incubated at room temperature for 10 minutes. Samples were centrifuged at $12000 \mathrm{x}$ g for 10 minutes at $4^{\circ} \mathrm{C}$. The supernatant was removed, the pellet was washed 
with $1 \mathrm{ml} \mathrm{75 \%}$ ethanol, vortexed, then centrifuged at $7500 \mathrm{xg}$ for 5 minutes at $4^{\circ} \mathrm{C}$. The ethanol wash was removed, the pellet was air dried then dissolved using RNAse free water by incubating for 10 minutes for at $60^{\circ} \mathrm{C}$.

\section{Real-time PCR}

Real-time polymerase chain reaction (PCR) was performed on isolated Leydig cells using $20 \mathrm{ng}$ of diluted cDNA with SYBR Green (Invitrogen) and $300 \mathrm{nM}$ gene specific primers using the ABI 7900HT sequence detection system (ABI). Primer sequences were designed using Primer Express (ABI). The PCR protocol was as follows: 10 minute denaturation step, 40 cycles of two-step PCR $\left(15\right.$ seconds at $95^{\circ} \mathrm{C}$ and 60 seconds at $\left.60^{\circ} \mathrm{C}\right)$ followed by a dissociation step $\left(15\right.$ seconds at $95^{\circ} \mathrm{C}, 15$ seconds at $60^{\circ} \mathrm{C}$ and 15 seconds at $95^{\circ} \mathrm{C}$ ). The fold difference in expression was normalized to the housekeeping gene Gapdh and was calculated using the $\Delta \Delta \mathrm{C}_{\mathrm{t}}$ method. The following primer sequences were utilized: Lhr (sense, 5'-GCGCGCCGGATGGT-3'; antisense, 5' AAAGCTTGTGATGGGATTACTTTGA-3'), StAR (sense, 5' CGGGTGGATGGGTCAAGTT-3'; antisense, 5'GGACAGCTCCTGGTCACTATAGAGT-3'), Pbr (sense, 5' CTGGACACTGGCTCCCATCT-3'; antisense, 5'CCAGCTCTTTCCAGACTATGTAGGA), Cyp11 $\alpha 1$ (sense, 5'-GGCCGGCGGATTGC3'; antisense, 5'-CATCACGGAGATTTTGAACTTCAA-3'), 3ßHSD1 (sense, 5'CCCAGGCAGACCATCCTAGA-3'; antisense, 5' GAACACAGGCCTCCAATAGGTT-3'), and Cyp17 $\alpha 1$ (sense, 5'CCAGAGAAGTGCTCGTGAAGAA-3'; antisense, 5'-CCTTTTCCTTGGTCCGACAA3').

\section{Microarray expression analys is}

RNA was purified from Leydig cells of pre-pubertal and adult WT and KO mice. Analysis used nine pre-pubertal and five adult mice per genotype. RNA from each age and genotype group was combined prior to analysis. After RNA quality was confirmed (Agilent Bioanalyzer 2100), RNA was processed using the Affymetrix one-cycle target labeling protocol and hybridized overnight to the Affymetrix Mouse 430 vs 2 array. Array signals were summarized using the MAS 5 algorithm and $\log _{2}$ transformed prior to analysis.

Microarray analysis was performed by using the Spotfire Decision Site version 9.1 (TIBCO). For genes interrogated by multiple probe sets, a single expression value was calculated using the maximum signal reported across redundant probe sets. Genes associated with steroid metabolism were identified by annotations curated from Entrez Gene, Gene Ontology and GeneGo Metacore terms [149]. For cAMP target genes, the PKA, CREB and cAMP pathways were curated from known direct and indirect target genes. 


\section{Results}

\section{Expression of Lhr, but not $\mathrm{LH}$ concentration, is decreased in Mrp4 KO mice}

Both LH concentration and the upregulation of Lhr in response to stimulation are critical initial steps in the regulation of testosterone synthesis. Because of this, our examination began with these critical factors. In adult mice, serum LH concentration was not significantly different between the genotypes (Figure 3-1A). However, immunoblot analysis of total Lhr protein revealed an approximate reduction of $70 \%$ in $\mathrm{KO}$ mice (Figure 3-1B). While the comparable circulating LH levels were an unexpected result as we would have predicted elevated concentrations in the $\mathrm{KO}$ due to decreased testosterone, decreased Lhr protein expression was the first indication that a defect existed in the biosynthesis pathway itself.

Lhr signaling is essential for steroidogenesis as well as cholesterol homeostasis [150]. Two genes important in de novo cholesterol biosynthesis were examined in isolated Leydig cells by real-time PCR. Both Hmgcs1 and Dhcr7 mRNA levels were decreased in KO mice as compared to WT animals (Figure 3-2A). Measurement of total serum cholesterol showed no difference in levels between the genotypes (Figure 3-2B), indicating the defect in LH-regulated cholesterol biosynthesis appears to be Leydig cell specific.

\section{Cyclic AMP concentration is drastically diminished in Mrp4 KO Leydig cells}

The concentration of cAMP within the Leydig cell is crucial for the regulation of testosterone biosynthesis. As our results showed upstream components of the testosterone biosynthesis pathway were downregulated, it was essential to measure cAMP in our mice to determine how its potential alteration may contribute to decreased testicular testosterone in Mrp4 KO mice. Prior to analysis of cAMP levels, measurement of testosterone concentration in isolated Leydig cells revealed decreased levels in Mrp4 KO cells (Figure 3-3A), analogous to the reduction observed in whole testes sample. These results aid in confirming the deficiency in testosterone originates in Leydig cells and is not dependent on other factors acting on these cells.

Analysis of basal cAMP concentration in Leydig cells showed an inherent defect in cAMP concentration (Figure 3-3B). In Leydig cells stimulated with a physiological concentration of LH, cAMP concentration remained lower in Mrp4 KO than in WT cells (Figure 3-3C). Although cAMP levels were elevated in both genotypes in response to LH stimulation, KO Leydig cells exhibited a modest two fold increase in cAMP concentration while WT cells produced a five-fold elevation over basal levels. 

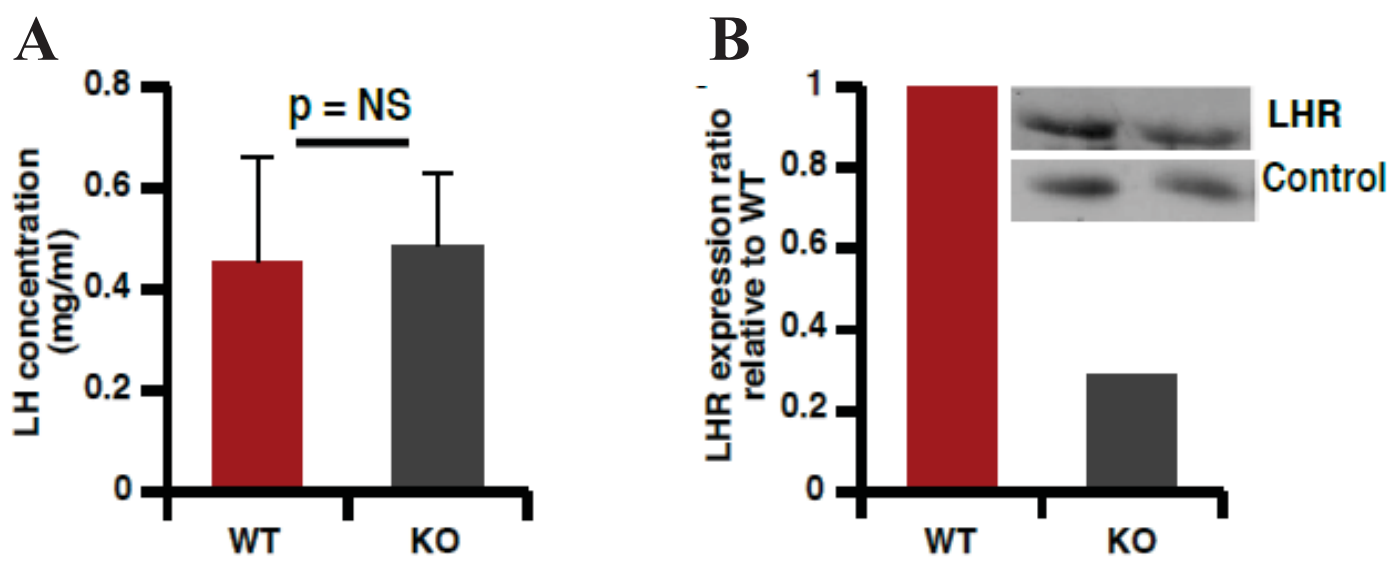

Figure 3-1. Luteinizing hormone receptor expression, but not LH concentration, is alte red in Mrp4 KO mice. (A) Serum LH concentration measured by radioimmunoassay ( $\mathrm{n}=3$ mice/genotype). (B) Lhr protein in Leydig cells as assessed by immunoblot analysis. A nonspecific band was used as a loading control. Graph below expresses ratios of band intensity. All error bars $=\mathrm{SE}$. 

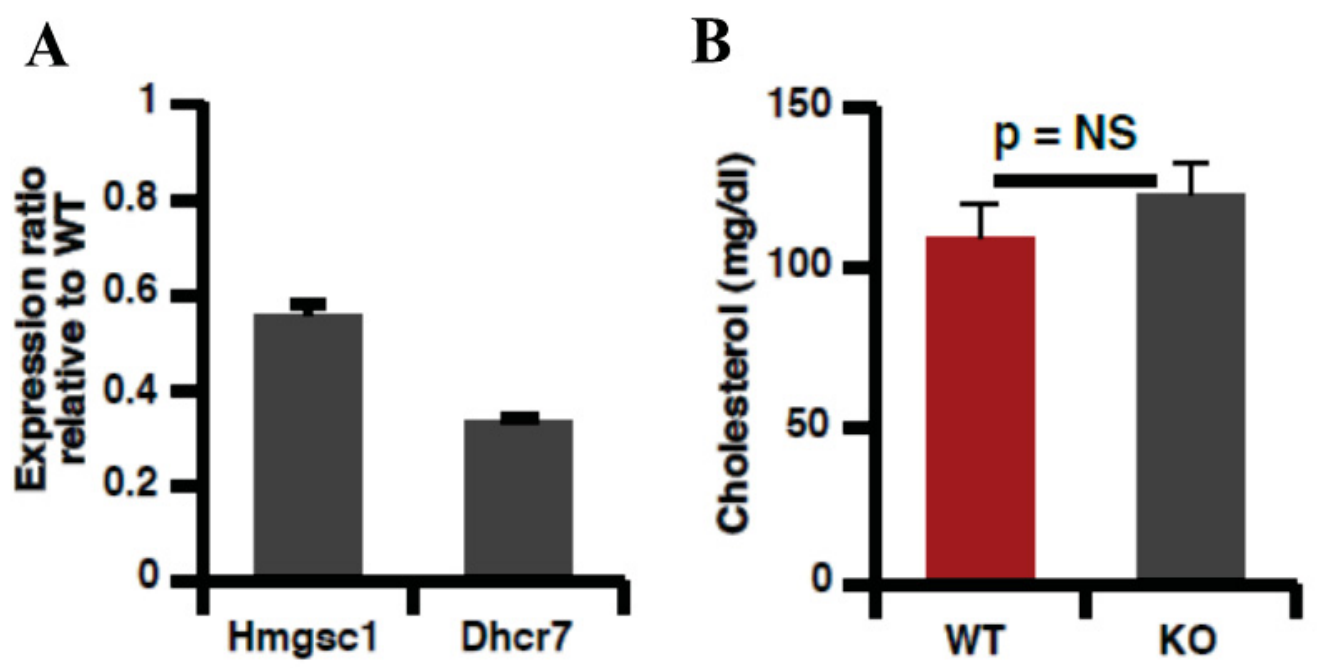

Figure 3-2. Cholesterol bios ynthesis genes are reduced in Mrp4 KO mice but serum cholesterol concentrations are unchanged between genotypes.

(A) Cholesterol gene expression in KO Leydig cells by real-time PCR, presented as the mean ratio of expression in WT cells. (B) Serum cholesterol concentration measured by enzymatic assay $(\mathrm{WT}, \mathrm{n}=10, \mathrm{KO}, \mathrm{n}=8)$. All error bars $=\mathrm{SE}$. 

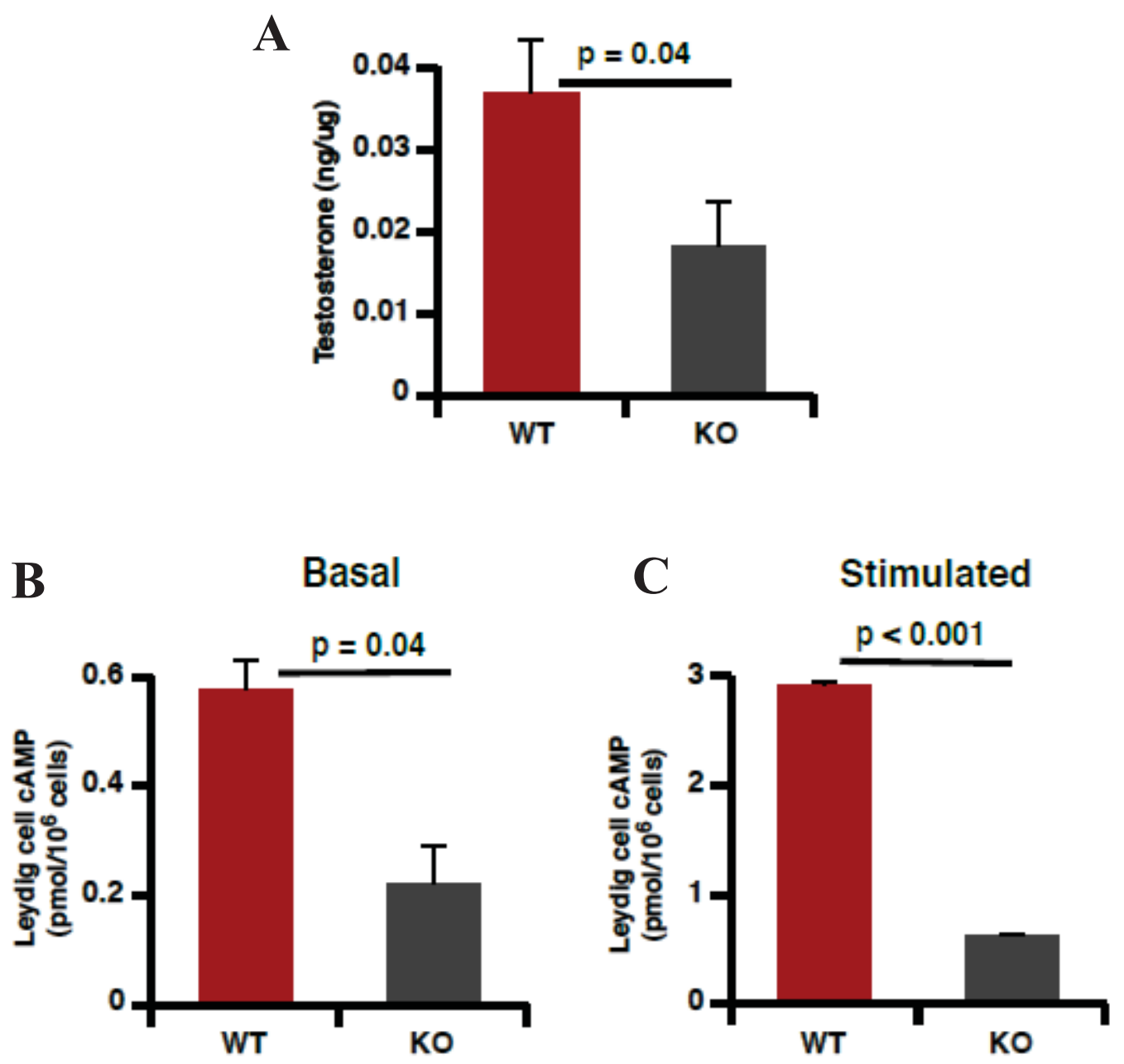

Figure 3-3. Cyclic AMP concentration is decre ased in Mrp4 KO Leydig cells. (A) Testosterone concentration in adult Leydig cells as measured by radioimmunoassay ( $\mathrm{n}=3$ mice/genotype). (B) cAMP concentration in Leydig cells under basal conditions as evaluated by enzyme immunoassay ( $\mathrm{n}=3$ mice/genotype). (C) cAMP concentration in Leydig cells stimulated with $10 \mathrm{mIU}$ LH $(\mathrm{n}=3$ mice/genotype). All error bars $=\mathrm{SE}$. 


\section{CREB activation, a cAMP dependent phe nomenon, and downstre am target ge ne expression are reduced in Mrp4 KO Leydig cells}

To further validate the decrease seen in cAMP concentration in Mrp4 KO Leydig cells, both CREB phosphorylation status and its downstream target gene expression were examined. CREB mediated transcription requires phosphorylation at a particular residue, Ser133. Activated by a variety of protein kinases, this site is phosphorylated by cAMP dependent PKA [151] thereby promoting gene transcription of a wide array of targets. Initial experiments focused on the phosphorylation status of CREB in WT and KO Leydig cells. Stimulation with a physiological concentration of LH showed a rapid increase in the amount of phospho-CREB while decreasing total CREB protein in WT samples. In stark contrast, KO Leydig cells exhibited slow CREB phosphorylation under LH stimulation and show minimal change in the phospho-CREB/CREB ratio versus the unstimulated state (Figure 3-4A). In the absence of stimulation, CREB protein expression was similar in WT and $\mathrm{KO}$ cells.

Microarray expression analysis was then utilized to curate target genes common to PKA, CREB and cAMP activation pathways to determine if gene expression downstream of CREB was altered in KO Leydig cells. A total of 38 genes were identified (Table 3-1) and all showed strongly reduced expression in pre-pubertal and adult KO Leydig cells (Figure 3-4B). These findings corroborated the results, implicating the lack of Mrp4 in Leydig cells impairs LH mediated cAMP formation, thereby disrupting CREB mediated transcription.

\section{Ge nes directly involved in te stosterone biosynthesis are downre gulated in Mrp4 KO Leydig cells}

Initial analysis of a broad spectrum of genes related to steroid biosynthesis showed striking similarities in the expression of affected genes in pre-pubertal and adult KO Leydig cells (Figure 3-5). As our data revealed both cAMP concentration and CREB phosphorylation to be impaired in KO Leydig cells, coupled with the fact that genes involved directly in testosterone biosynthesis contain promoters with CREB binding sites, expression of these specific genes were investigated. Real-time PCR analysis of Leydig cell mRNA indicated a reduction in all testosterone biosynthesis genes evaluated (Figure 3-6A). The most substantial decrease occurred with StAR expression where a reduction of over $60 \%$ was observed. In contrast, minimal reduction of $\mathrm{Pbr}$, the second cholesterol importer, was seen in KO Leydig cells. Decreased mRNA expression

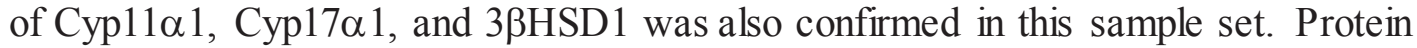
expression of these genes revealed a similar pattern of reduced expression in the $\mathrm{KO}$ (Figure 3-6B) with the exception of $\mathrm{Pbr}$. Of the mitochondrial proteins examined, StAR, $\mathrm{Pbr}$, and VDAC, only StAR was reduced. The decreased proteins levels of Cyp $11 \alpha 1$ and $3 \beta H S D 1$ were also consistent with the mRNA data, and these overall results reinforce the findings of reduced testicular testosterone in Mrp4 $\mathrm{KO}$ mice. 
A
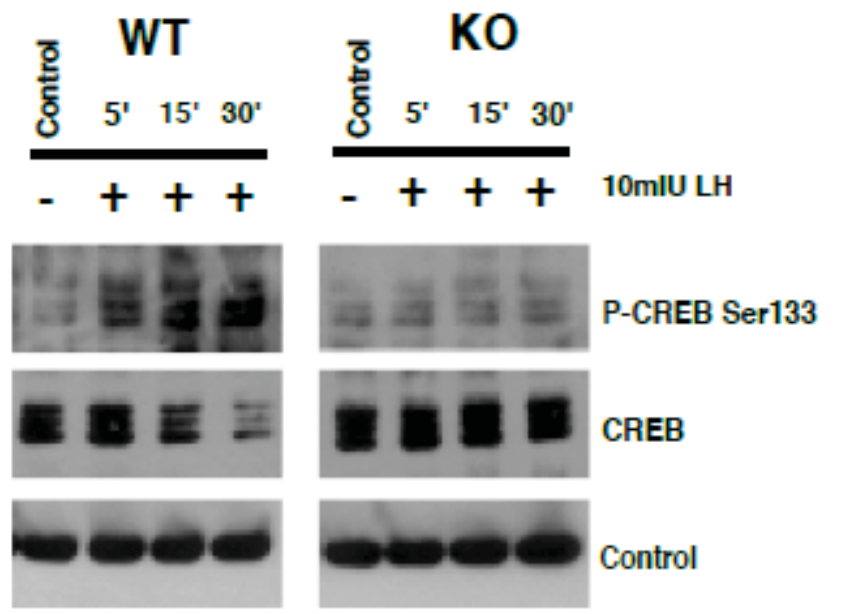

CREB

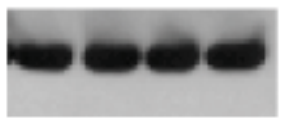

Control

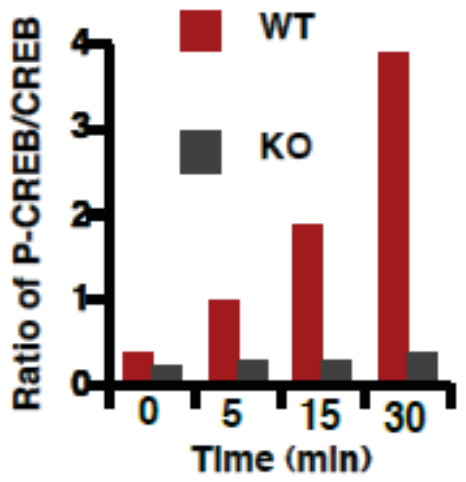

B

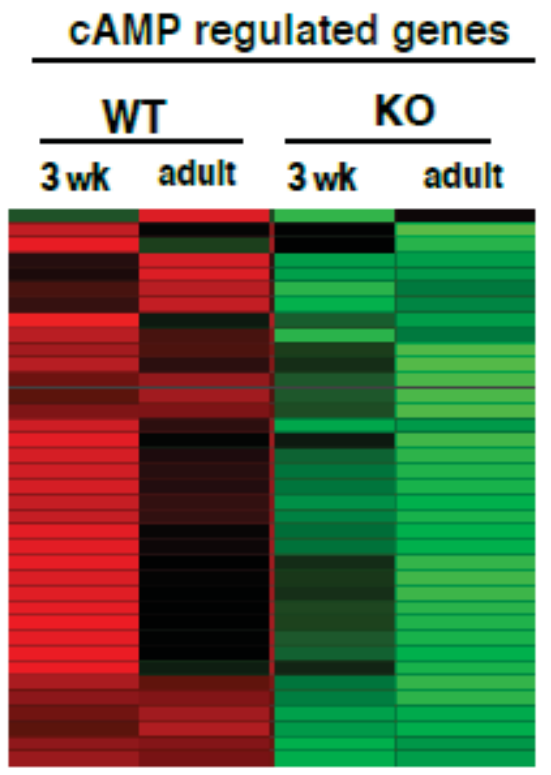

Figure 3-4. CREB phos phorylation and CAMP regulated genes are downre gulated in Mrp4 KO Leydig cells. (A) Immunoblot analysis of CREB and phosphor-CREB (Ser133) at the indicated time points and treatment conditions. The loading control was an unknown protein cross-reactive with the antibody that remained constant among the samples. The graph at right shows ratio of phosphor-CREB to CREB. (B) Selection of cAMP-regulated genes for query. The heat map represents the gene expression in WT and KO Leydig cells. 
Table 3-1. cAMP-, PKA-, and CREB-regulated genes in Leydig cells.

\begin{tabular}{|c|c|}
\hline Gene Symbol & Gene Name \\
\hline GLG1 & golgi apparatus protein 1 \\
\hline BMP6 & bone morphogenetic protein 6 \\
\hline CLCN3 & chloride channel 3 \\
\hline NRP1 & neuropilin 1 \\
\hline PPP3CB & protein phosphatase 3 , catalytic subunit, beta isoform \\
\hline CTNNB1 & catenin (cadherin associated protein), beta 1 \\
\hline YWHAB & $\begin{array}{l}\text { tyrosine } 3 \text {-monooxygenase/tryptophan } 5 \text {-monooxygenase } \\
\text { activation protein, beta polypeptide }\end{array}$ \\
\hline GNA13 & guanine nucleotide binding protein, alpha 13 \\
\hline HDGF & hepatoma-derived growth factor \\
\hline ADCY9 & adenylate cyclase 9 \\
\hline MYLK & myosin, light polypeptide kinase \\
\hline PPP1R8 & protein phosphatase 1 , regulatory (inhibitory) subunit 8 \\
\hline KCTD12 & potassium channel tetramerisation domain containing 12 \\
\hline MAP2K5 & mitogen-activated protein kinase 5 \\
\hline AKAP11 & A kinase anchor protein 11 \\
\hline AKAP9 & A kinase anchor protein 9 \\
\hline CREBBP & CREB binding protein \\
\hline YWHAZ & $\begin{array}{l}\text { tyrosine } 3 \text {-monooxygenase/tryptophan } 5 \text {-monooxygenase } \\
\text { activation protein, zeta polypeptide }\end{array}$ \\
\hline CLCN6 & chloride channel 6 \\
\hline ITPR1 & inositol 1,4,5-triphosphate receptor 1 \\
\hline PYGB & brain glycogen phosphorylase \\
\hline SMAD4 & MAD homolog 4 (Drosophila) \\
\hline CHUK & conserved helix-loop-helix ubiquitous kinase \\
\hline YWHAG & $\begin{array}{l}\text { tyrosine } 3 \text {-monooxygenase/tryptophan } 5 \text {-monooxygenase } \\
\text { activation protein, gamma polypeptide }\end{array}$ \\
\hline H1F0 & H1 histone family, member 0 \\
\hline CLCN1 & chloride channel 2 \\
\hline CREB1 & cAMP response element binding protein 1 \\
\hline KCTD3 & potassium channel tetramerization domain-containing protein 3 \\
\hline PIK3R4 & $\begin{array}{l}\text { phosphatidylinositol } 3 \text { kinase, regulatory subunit, polypeptide } 4 \text {, } \\
\text { p150 }\end{array}$ \\
\hline PPP1R12A & protein phosphatase 1 , regulatory subunit $12 \mathrm{~A}$ \\
\hline GRB2 & growth factor receptor bound protein 2 \\
\hline ATF1 & activating transcription factor 1 \\
\hline PPKAR1A & protein kinase, cAMP dependent regulatory, type I, alpha \\
\hline PLCG1 & phospholipase $\mathrm{C}$, gamma-1 \\
\hline PPKD3 & protein kinase D3 \\
\hline
\end{tabular}


Table 3-1. cont.

\begin{tabular}{ll}
\hline Gene Symbol & Gene Name \\
\hline ADD3 & adducin 3 (gamma) \\
POLR2B & polymerase (RNA) II (DNA directed) polypeptide B \\
PDE3B & phosphodiesterase 3B, cGMP inhibited \\
\hline
\end{tabular}




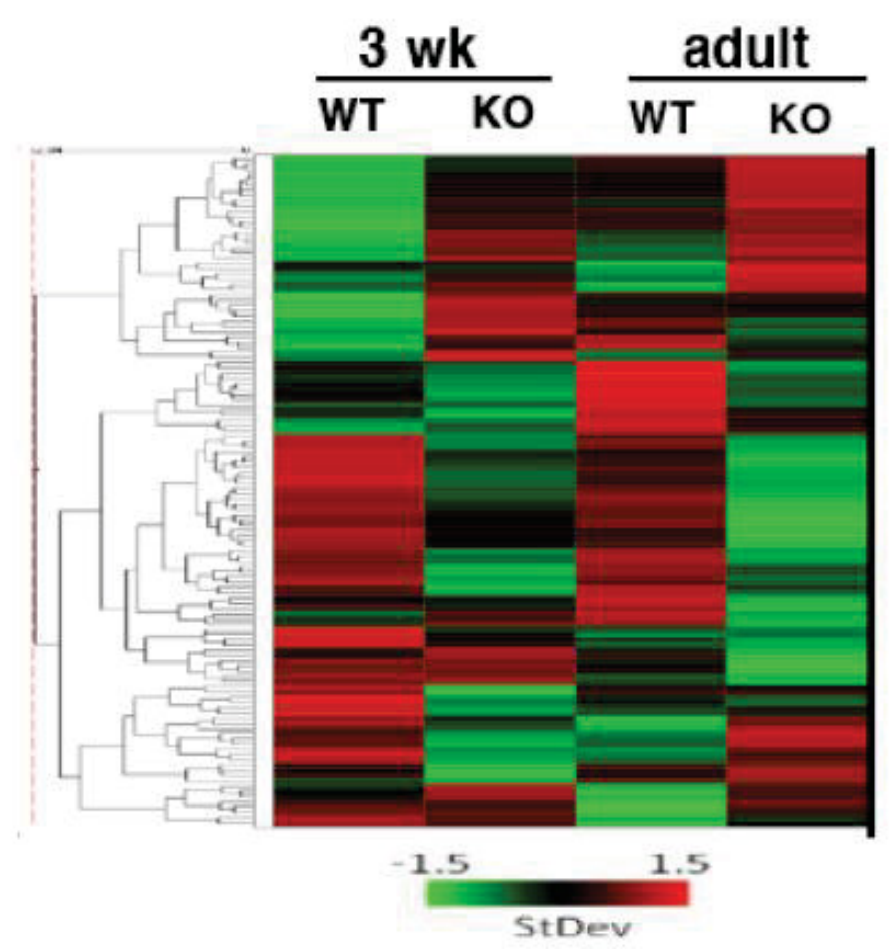

Figure 3-5. Steroid bios ynthe sis and related ge nes have a distinct expression pattern in Mrp4 WT and KO mice. The expression of steroid biosynthetic genes in pre-pubertal and adult Mrp4 WT and KO mice as examined by microarray analysis. Hierarchical cluster was performed on 'steroid' genes curated from EntrezGene, Gene Ontology and Metacore. 


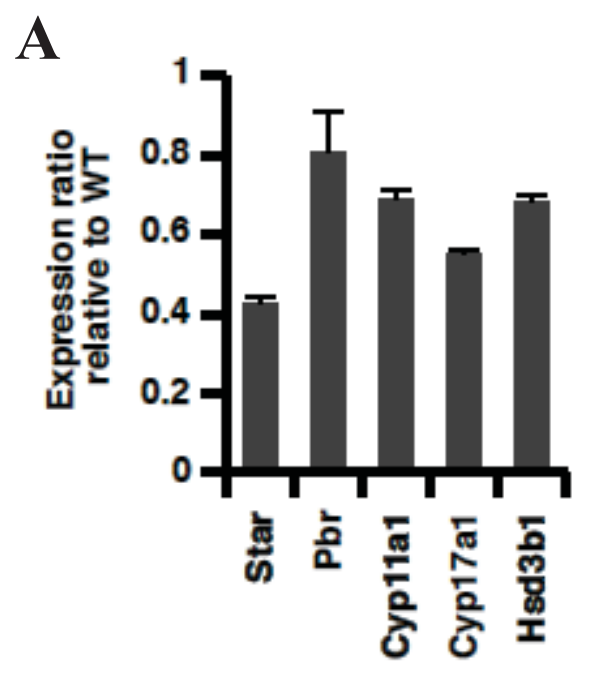

B
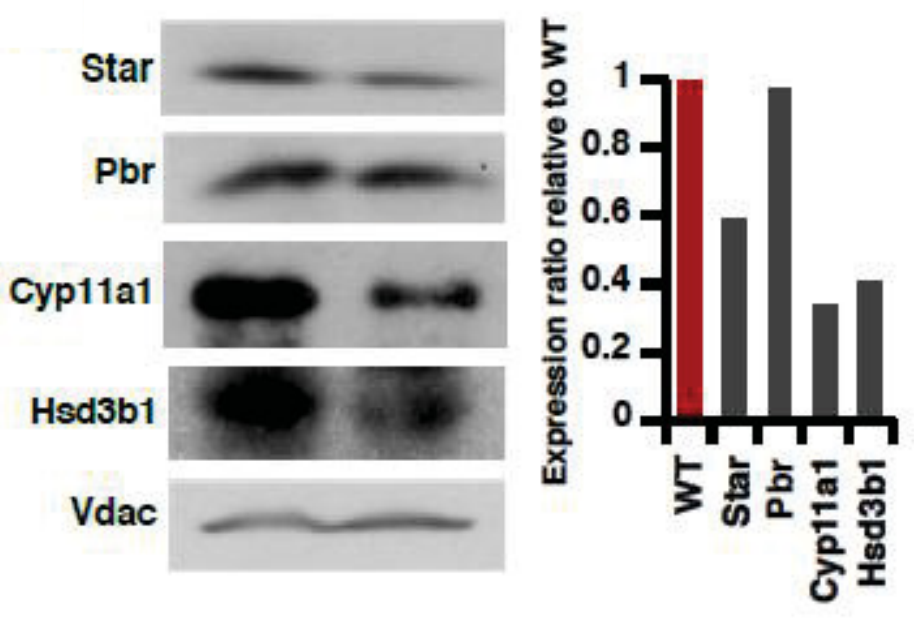

Figure 3-6. Genes involved directly in te stosterone biosynthesis are downre gulate d in Mrp4 KO Leydig cells. (A) Real-time PCR analysis of testosterone biosynthesis gene expression in Mrp4 KO Leydig cells (normalized to GAPDH expression). (B) Immunoblot analysis of testosterone biosynthesis gene expression. Vdac was used as a loading control. All error bars $=\mathrm{SE}$. 


\section{Acute Mrp4 inhibition results in elevated intrace llular cAMP concentrations}

The aforementioned results exhibited the importance of Mrp4 in regulating normal testosterone biosynthesis; however, the reduced intracellular cAMP concentration observed in the KO mice was still perplexing as cAMP is a substrate for Mrp4 [39]. As Leydig cells in culture produce testosterone in a dose dependent manner upon LH stimulation (Figure 3-7A) and also express testosterone biosynthesis proteins including StAR and Cyp $11 \alpha 1$ (Figure 3-7B), we utilized this system to examine the factors resulting in decreased Mrp4 KO cAMP concentration.

Treatment of WT Leydig cells with $10 \mathrm{mIU}$ LH resulted in increased testosterone in the media in contrast to the unstimulated group. Inhibition of Mrp4 with 10uM MK571 produced a sizeable decrease in testosterone concentration, similar to the unstimulated cells (Figure 3-8A). Simultaneous measurement of intracellular cAMP revealed concentrations were elevated greater than five-fold when Mrp4 was inhibited (Figure 3-8B). Protein expression levels examined under these same conditions showed both Lhr and StAR were downregulated when Mrp4 was inhibited while Cyp11 $\alpha 1$ expression was not affected (Figure 3-8C). Analysis of other ABC transporters present in the testes (Abcc1 and $\mathrm{Abcg} 2$ ) exhibited no change in expression levels when Mrp4 $\mathrm{KO}$ Leydig cells are stimulated with LH (Figure 3-9).

\section{Conclusions}

Neither circulating LH nor cholesterol levels were altered between the Mrp4 WT and $\mathrm{KO}$ mice; however, Leydig cell Lhr protein expression was downregulated in the $\mathrm{KO}$ animal while key cholesterol biosynthesis genes were also decreased. Cyclic AMP concentration was also decreased in KO Leydig cells in both the basal state as well as in LH stimulated cells. CREB phosphorylation, a cAMP dependent event, was attenuated in KO Leydig cells stimulated with LH and accordingly, downstream target gene expression was decreased. In conjunction, mRNA and protein expression were decreased for several key testosterone biosynthesis genes including Cyp $11 \alpha 1$, Cyp $17 \alpha 1$ and most crucial, cholesterol importer, StAR.

In contrast with cAMP concentrations observed in the KO animal, acute inhibition of WT Leydig cells in culture showed increased intracellular concentrations when stimulated with LH. Both Lhr and StAR protein expression was decreased upon Mrp4 inhibition while Cyp1 $1 \alpha 1$ protein was unchanged. No change in expression was observed in other testes transporters when WT Leydig cells were LH stimulated. 
A

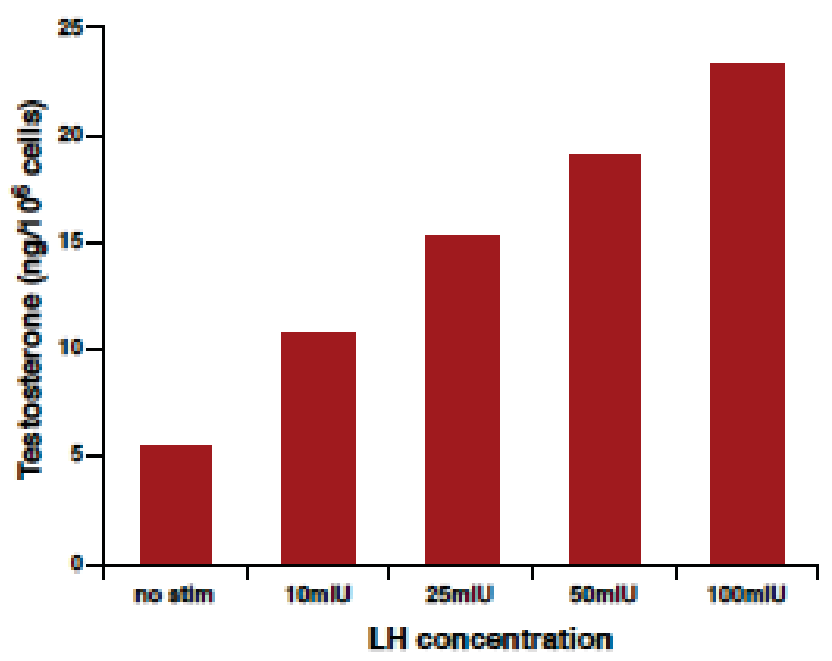

B

$(+)$ ctrl

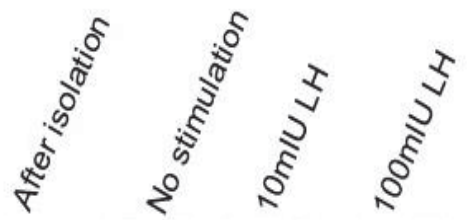

StAR

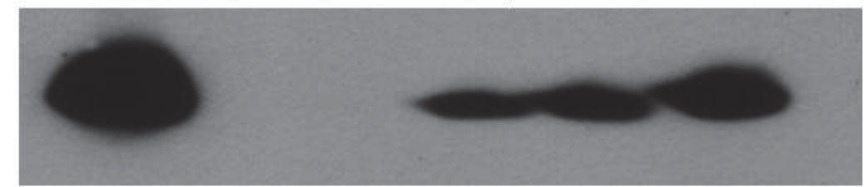

Cyp11a1

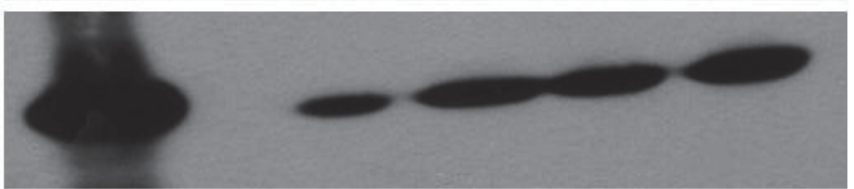

Figure 3-7. Cultured Leydig cells exhibit properties observed in vivo.

(A) Testosterone concentration in WT Leydig cells upon stimulation with various concentrations of LH as measured by radioimmunoassay. (B) Immunoblot analysis of testosterone biosynthesis genes in culture under indicated treatment conditions. 
A
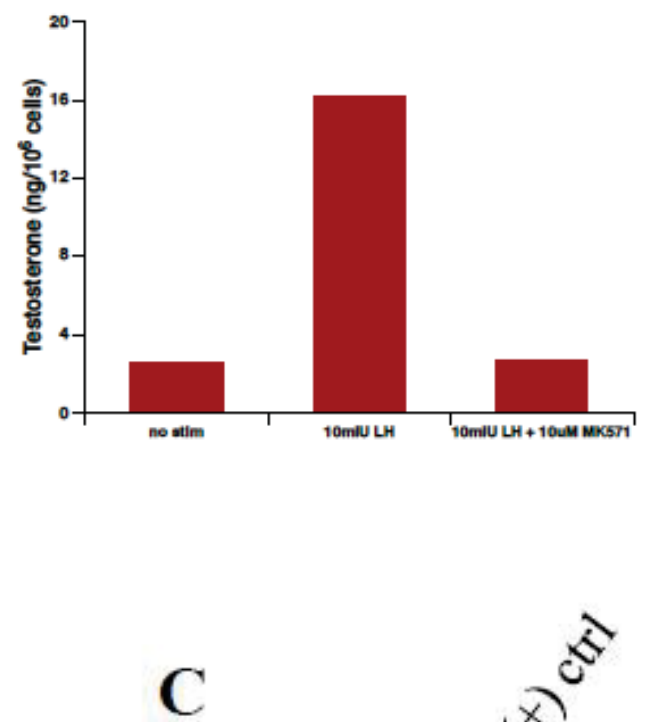

B
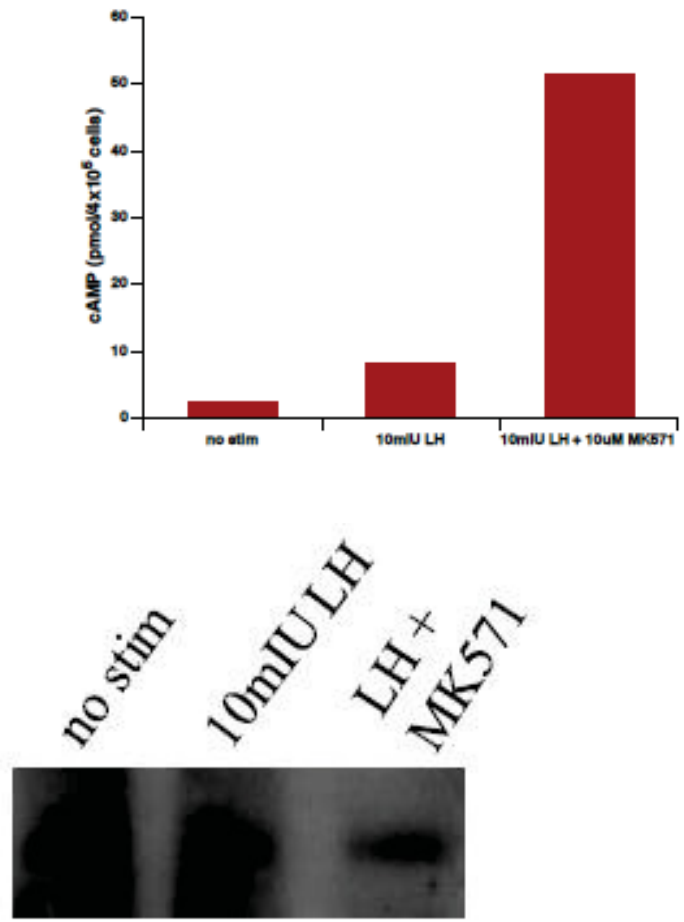

StAR
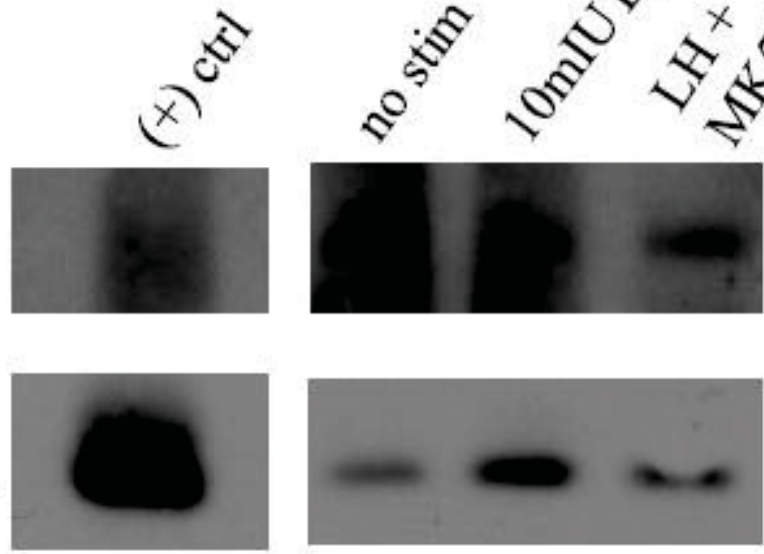

Lhr

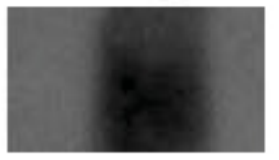

Cyp $11 \alpha 1$
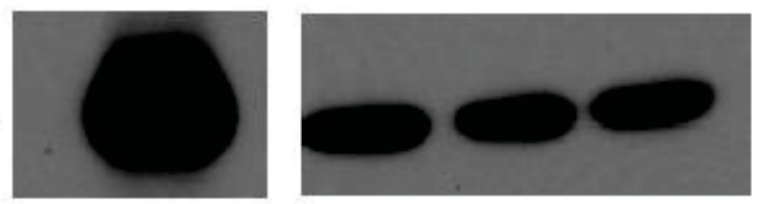

ctrl

band

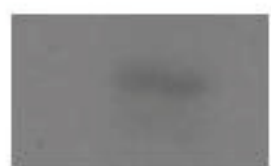

Figure 3-8. Acute inhibition of Mrp4 results in increased intracellular cAMP concentration but downregulated Lhr and StAR protein expression.

(A) Testosterone concentration in Mrp4 WT Leydig cells under the indicated treatment conditions as measured by radioimmunoassay. (B) cAMP concentration in Mrp4 WT

Leydig cells as assessed by enzyme immunoassay. (C) Protein expression as determined by immunoblot analysis in WT Leydig cells. 

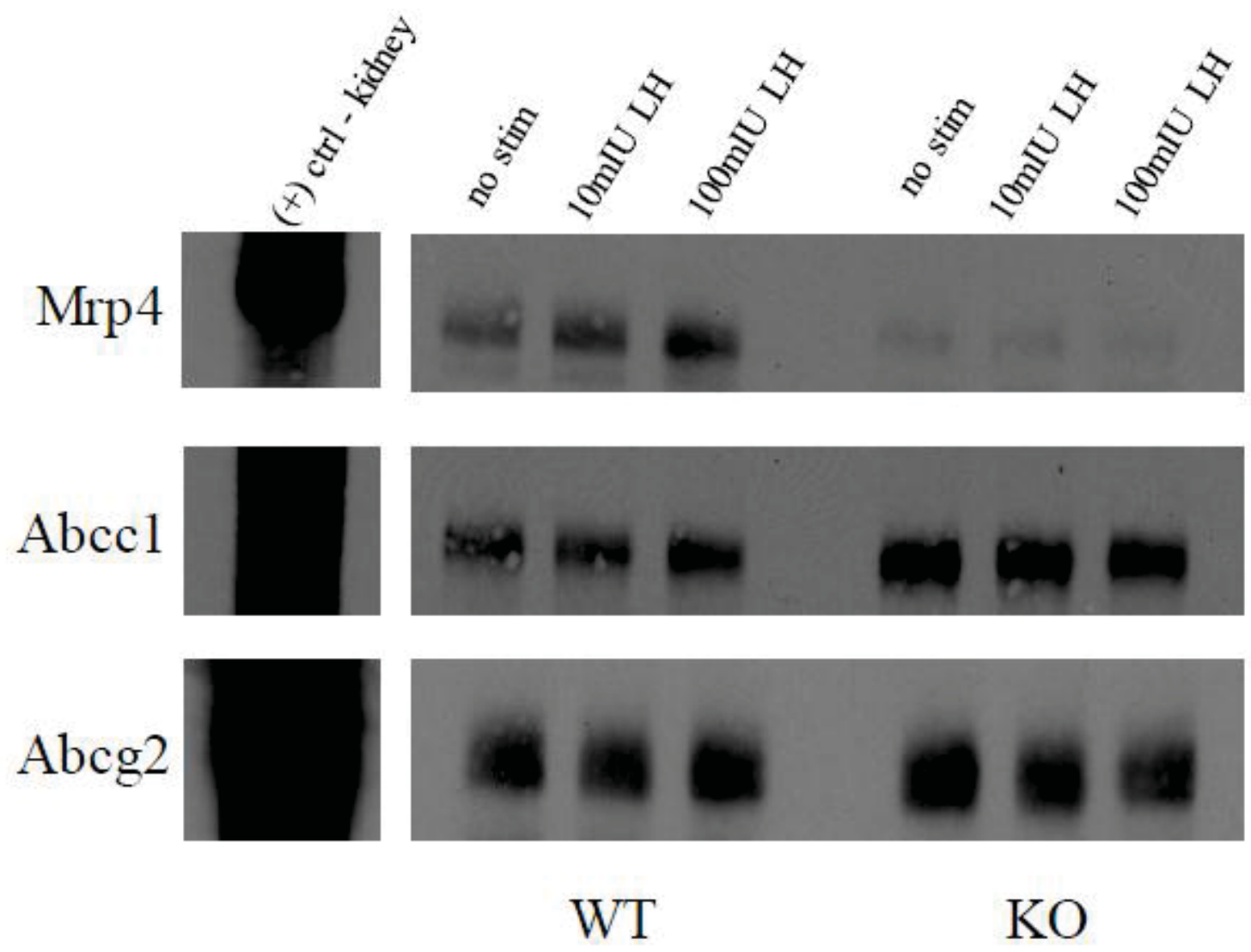

Figure 3-9. Alternate $A B C$ trans porters are not upregulated upon $\mathrm{LH}$ stimulation. Protein expression of Abcc1 and Abcg2 in Mrp4 WT and KO cultured Leydig cells under the indicated conditions. 


\section{CHAPTER 4. ADULT MRP4 KO MICE MAINTAIN A TESTICULAR TESTOSTERONE DEFICIENCY WHILE POSSESSING NORMAL TESTES MORPHOLOGY*}

\section{Introduction}

Adequate testosterone concentration is required for the maintenance of normal spermatogenesis although the absolute amount required is still unknown. Studies have exhibited experimental testosterone reduction can lead to an abolition of sperm production when testicular testosterone concentration is less than $20 \%$ of the controls [152]. Hormonal removal has been shown to induce germ cell apoptosis [153] while the presence of testosterone maintains spermatogenic homeostasis by inhibiting death signals for germ cells [154]. Additionally, gonadotropin withdrawal in rodents has shown to reduce the number of germ cells progressing through the multiple stages of spermatogenesis [155].

Our data regarding pre-pubertal Mrp4 $\mathrm{KO}$ animals revealed reduced intratesticular testosterone accompanied by impaired spermatogenesis, germ cell proliferation and increased apoptosis. As $\mathrm{KO}$ mice are reproductively normal (discussed in chapter 2), my goal was to characterize the adult mice testes in the same manner as with the pre-pubertal animals in order to determine if all observed deficiencies were still present.

\section{Experimental Procedure}

\section{Immunohis toche mis try}

Whole testes and prostate were harvested from Mrp4 WT and KO mice and immediately formalin fixed. Samples were submitted to the St. Jude Veterinary Pathology Core where they were paraffin embedded and sectioned into 4 micron sections. Following standard slide mounting procedure, the testes sections were stained with H\&E for analysis of overall testicular morphology. Additionally, testes were stained with an antibody for the cell proliferation marker, Ki67, and for TUNEL, an antibody detecting cell apoptosis. All staining was performed using the LabVision 720 autostainer (Thermo Shandon).

\footnotetext{
* Modified with permission. Morgan JA., et al. Deregulated hepatic metabolism exacerbates impaired testosterone production in Mrp4-deficient mice. J Biol Chem, 2012. 287(18): p. 14456-66 [138].
} 


\section{Testicular te stosterone measurement}

Testicular testosterone concentration was measured from WT and KO mice by harvesting testes, homogenizing in $1 \mathrm{X}$ PBS with a glass Dounce homogenizer, and centrifuging at $5900 \mathrm{x}$ g for 5 minutes at $4^{\circ} \mathrm{C}$. The supernatant was then combined with $1 \mathrm{ml}$ diethyl ether, vortexed, and the organic phase was collected and dried down under a stream of $\mathrm{N}_{2}$ at room temperature. The dried fraction was reconstituted in $0.2 \mathrm{ml} 1 \mathrm{X} \mathrm{PBS}$. Testosterone concentration was then measured by an ${ }^{125}$ I-labeled RIA (MP Biomedicals) according to the manufacturer's instructions. Concentration of testicular testosterone was expressed as ng/mg of testes weight.

\section{Immunohis toche mical counting}

All IHC quantitation was performed on a minimum of three mice per age and genotype group. Counts were taken on five random fields per slide at 40X magnification on a Nikon Eclipse $\mathrm{T}_{\mathrm{i}}$ microscope. For TUNEL and Ki67 staining, the cell was considered positive if greater than $50 \%$ of the individual cell was stained.

\section{Results}

As a result of the findings from our pre-pubertal animals, it was imperative that the same set of experiments were performed on the adult mice to determine if the testicular testosterone deficiency persevered into adulthood. Most laboratory mouse strains have a reported pubertal onset of 34-38 days after birth (online ref). To ensure that sexually mature animals were being examined, mice greater than 8 weeks of age were selected for analysis.

Adult Mrp4 KO mice had a six-fold reduction in testicular testosterone concentration in comparison to WT mice (Figure 4-1). Despite reduced testosterone, histological examination revealed readily detectable mature sperm cells in the seminiferous tubule lumen (Figure 4-2A). In conjunction, germ cell proliferation was equivalent among the genotypes as determined by Ki67 positive staining (Figure 4-2B). Germ cell apoptosis was similar between the WT and KO animals (Figure 4-2C). These data indicate that, despite decreased intratesticular testosterone levels, Mrp4 $\mathrm{KO}$ mice have morphologically normal testes. 


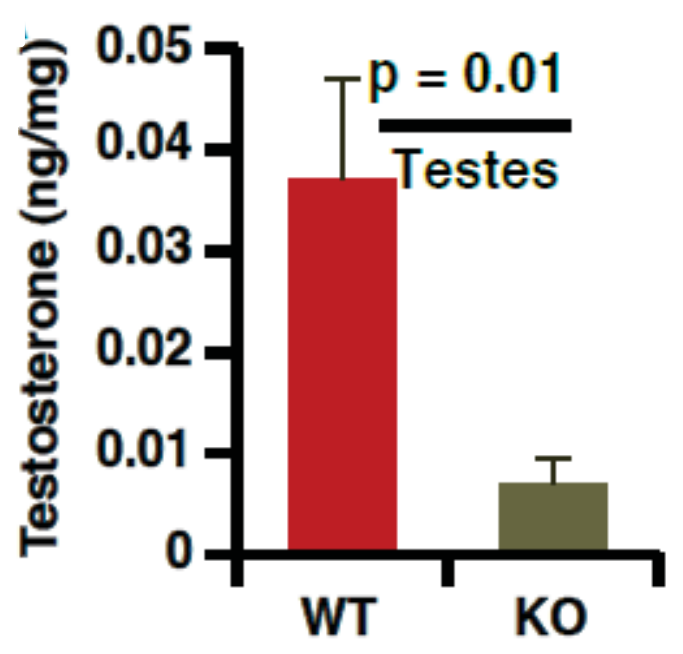

Figure 4-1. Testicular testosterone is decreased in adult Mrp4 KO mice.

Testosterone concentration in adult Mrp4 WT $(n=7)$ and KO $(n=4)$ mice as measured by radioimmunoassay. Error bars $=\mathrm{SE}$. 
A

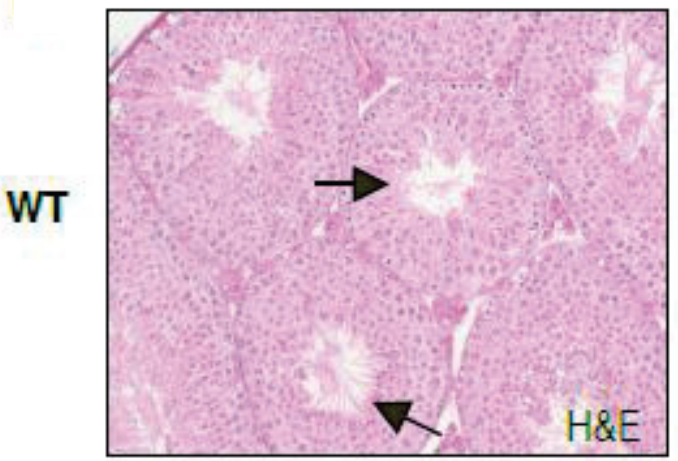

B

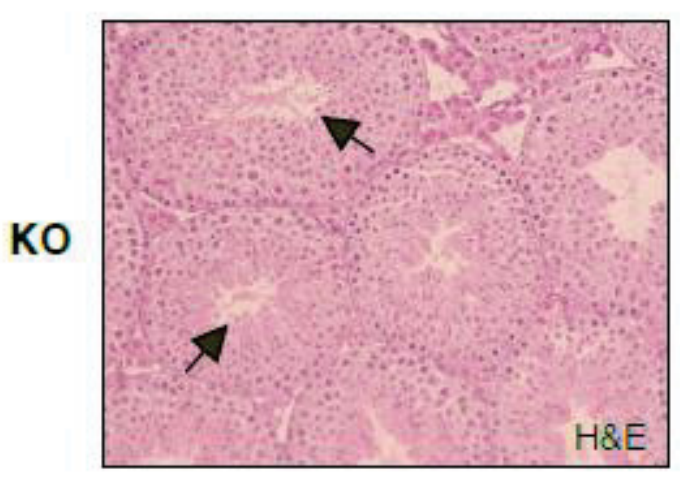

C

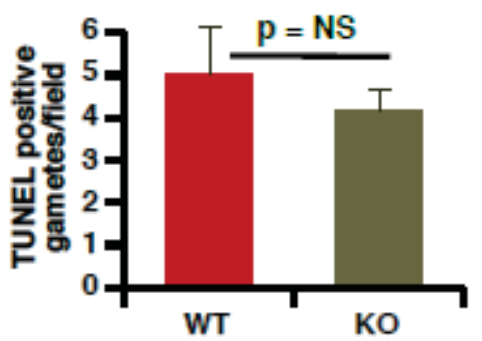

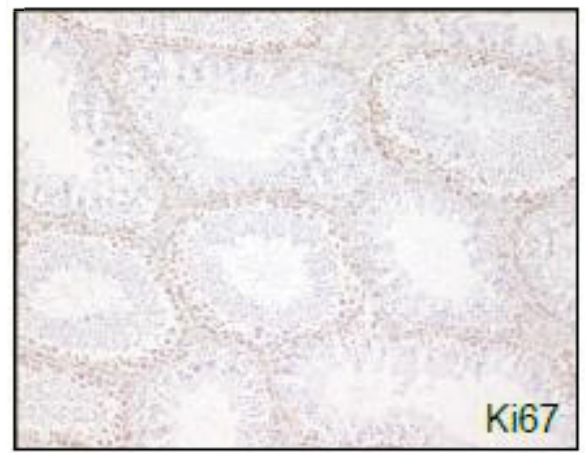
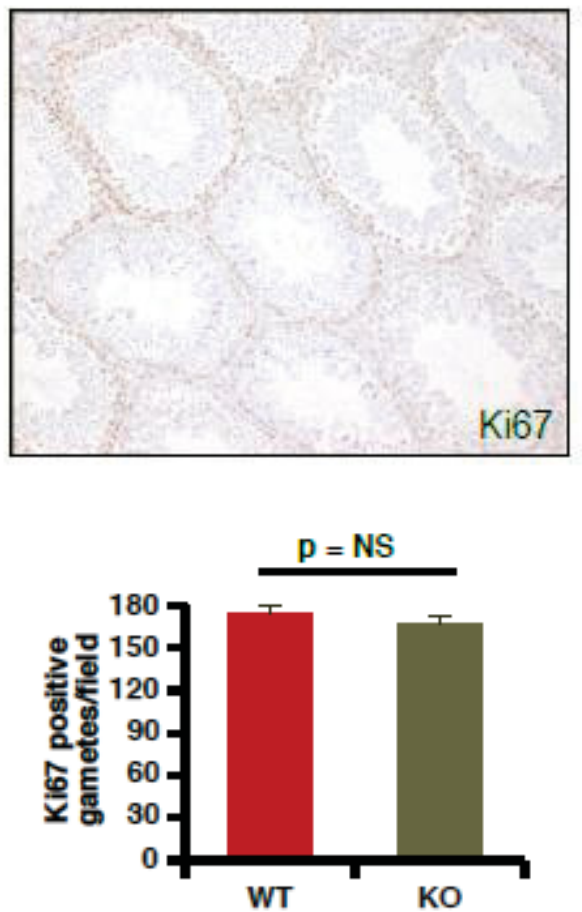

Figure 4-2. Testicular de ficiencies are absent in the adult Mrp4 KO mouse. (A) Testicular morphology as examined by H\&E staining (20X magnification). Arrows indicate mature sperm tail in the seminiferous tubule lumen. (B) Immunohistochemical analysis of cell proliferation with Ki67 antibody. Graph below quantitates Ki67+ cells. (C) Quantification of apoptotic cells by TUNEL positive staining. All error bars $=$ SE. 


\section{Conclusions}

Adult Mrp4 KO mice showed greatly reduced testicular testosterone when compared to WT animals but possessed a mature sperm cell population with normal germ cell proliferation and minimal apoptosis. 


\section{CHAPTER 5. DECREASED SERUM TESTOSTERONE IN PRE-PUBERTAL MRP4 KO MICE RESULTS FROM INCREASED METABOLISM *}

\section{Introduction}

The liver is the most important organ of steroid hormone metabolism. Biological activities of hormones are not always reduced by steroid metabolism but can be rendered inactive by metabolic conversion. Steroid molecules are eliminated from cells through an array of enzymatic reactions followed by transport across the cell membrane. In the liver, several categories of reactions occur that alter steroid hormone activity: hydroxylation, conjugation, and oxido-reduction. The major metabolic pathway of steroids is through hydroxylation by cytochrome p450 enzymes [114] which are expressed in almost every tissue with the exception of skeletal muscle and red blood cells [156]. Several constitutively expressed Cyp enzymes are involved in testosterone inactivation in a regioselective and stereospecific manner [157] as they catalyze nicotinamide adenine dinucleotide phosphate (NADPH) dependent monooxygenation of their hydrophobic substrates [158]. The enzymatic reactions of testosterone hydroxylation include, but are not limited to, hydroxylation at the following positions: $2 \alpha, 6 \alpha, 6 \beta, 7 \alpha, 16 \alpha, 16 \beta$, and $17 \beta$ [120]. 6 $\beta$-hydroxylation is the major route of NADPH dependent oxidative metabolism, accounting for over $75 \%$ of the total hydroxylated metabolites generated by human liver microsomes when testosterone, androstenedione or progesterone are used as substrates [159].

Testosterone is primarily metabolized by members of the Cyp2 and Cyp3 families. Although human CYP3A4 (Cyp3a11 in mice) is generally regarded as the most versatile enzyme involved in endogenous steroid metabolism [121], mouse Cyp2b10 (CYP2B6 in humans) plays an important role in testosterone metabolism. In vitro and in vivo studies have shown Cyp2b10 and testosterone exist in a negative relationship [128, $130]$ as testosterone can suppress Cyp2b10 expression and vice versa.

Our preliminary data reveals serum testosterone concentration is decreased in prepubertal Mrp4 KO mice, but levels are restored to a more normal concentration once these mice reach adulthood. My goal was to examine the potential mechanisms by which testosterone concentration was reduced in these animals, mainly focusing on Cyp2b10 expression and activity.

\footnotetext{
* Modified with permission. Morgan JA., et al. Deregulated hepatic metabolism exacerbates impaired testosterone production in Mrp4-deficient mice. J Biol Chem, 2012. 287(18): p. 14456-66 [138].
} 


\section{Expe rimental Procedure}

\section{Serum testosterone measure ment}

Serum testosterone was measured by collecting whole blood from Mrp4 WT and $\mathrm{KO}$ mice and incubating at $4^{\circ} \mathrm{C}$ for 90 minutes in a microtainer collection tube (Becton Dickinson). Samples were spun at $1200 \mathrm{x}$ g for 90 seconds, serum was collected, and testosterone was measured by ${ }^{125}$ I-labeled RIA (MP Biomedicals) per the manufacturer's instructions. Serum testosterone concentration is expressed as $\mathrm{ng} / \mathrm{ml}$.

\section{Androstenedione measure ment}

Whole blood was collected by retro-orbital eye bleed from WT and $\mathrm{KO}$ mice, incubated at $4^{\circ} \mathrm{C}$ for 2 hours, then centrifuged at $5900 \mathrm{x}$ g for 5 minutes in order to separate the serum from the remaining clotted blood. Androstenedione concentrations were assayed from the serum by the Center for Research in Reproduction Ligand Assay and Analysis Core at the University of Virginia School of Medicine (Charlottesville, VA). Androstenedione concentration was measured by RIA, and the final concentration was expressed in $\mathrm{ng} / \mathrm{ml}$.

\section{Immunoblot analysis}

Immunoblot analysis was performed in whole testes samples as described in Chapter 2. Testes were probed for the following ABC transporters: Abcc1 (Abcam), Abcb1 (Thermo Scientific), Abcg2 (Axxora), Abcc4 (M $\mathrm{M}_{4} \mathrm{I}-10$, a gift from Dr. George Scheffer), and Abcc5 ( $\mathrm{M}_{5} \mathrm{I}-10$, a gift from Dr. George Scheffer). Actin (Sigma Aldrich) was used as a loading control.

Liver microsomes were examined for protein expression of the following Cyps: Cyp2b10, Cyp3a11 and Cyp1a2 (a gift from Dr. Erin Schuetz).

\section{Immunohis tochemistry}

Whole prostate was harvested from Mrp4 WT and KO mice and immediately formalin fixed. Samples were submitted to the St. Jude Veterinary Pathology Core where they were paraffin embedded and sectioned into 4 micron sections. Following standard slide mounting procedure, samples were stained with H\&E for analysis of overall prostate morphology. All staining was performed using the LabVision 720 autostainer (Thermo Shandon). 


\section{Real-time PCR}

Real-time PCR was performed on whole liver samples from WT and $\mathrm{KO}$ mice using 20ng of diluted cDNA with SYBR Green (Invitrogen) and $300 \mathrm{nM}$ gene specific primers using the $\mathrm{ABI} 7900 \mathrm{HT}$ sequence detection system (ABI). Primer sequences were designed using Primer Express (ABI). The PCR protocol was as follows: 10 minutes denaturation step, 40 cycles of two-step PCR $\left(15\right.$ seconds at $95^{\circ} \mathrm{C}$ and 60 seconds at $\left.60^{\circ} \mathrm{C}\right)$ followed by a dissociation step $\left(15\right.$ seconds at $95^{\circ} \mathrm{C}, 15$ seconds at $60^{\circ} \mathrm{C}$ and 15 seconds at $95^{\circ} \mathrm{C}$ ). The fold difference in expression was normalized to the housekeeping gene Gapdh and was calculated using the $\Delta \Delta \mathrm{C}_{\mathrm{t}}$ method. The primer sequences utilized were as follows: Cyp2b9 (sense, 5' - TGCTCAAGTACCCCCATGTCA-3'; antisense, 5' - AGAGAAAGTCCAAAAGGAGA-3'), Cyp2b10 (sense, 5'-

TCTTCCAACGTTCCCCATTG-3'; antisense, 5' - TCTTCCAACGTTCCCCATTG-3'), Cyp7a1 (sense, 5' - AATGCACTTGGATCCTGAAATCTAC-3'; antisense, 5' TTCATCAAGGTACCGGTCGTATT-3'), Cyp7b1 (sense, 5' CGGCCCTGTTCCTCCTTAC-3'; antisense, 5' GATAAGGAAGCCAACCTTTTATCAAG-3'), Cyp3a11 (sense, 5' CCAAACCTCTGCCATTTTTAGG-3'; antisense, 5'GCACTCCATGTCGAATTTCCA-3'), Cyp3a13 (sense, 5' GCTGATGATAAACTCCCAGAATTACAA-3'; antisense, 5'CCAAAGAATCTCATAAAGC-3') and Cypla2 (sense, 5'ATCCTTTGTCCCCTTCACCAT-3'; antisense, 5' - GGGAATGTGGAAGCCATTCA3').

\section{Microarray analysis}

Analysis of liver gene expression used three mice per genotype and age group. Samples were quality assessed as described in chapter 3 then processed using the Affymetrix 3' IVT express protocol. Labeled targets were hybridized on the HT_MG430_PM plate array and processed using the Gene-Titan system. Array signals were summarized using the RMA algorithm with Affymetrix Expression Console software. Cytochrome p450 targets were identified using Affymetrix Gene annotations while transcriptional targets of AR and CAR were identified using curated terms from GeneGo and Metacore pathways.

\section{Liver micros ome is olation}

Approximately 50-100 mg liver samples from pre-pubertal and adult mice were homogenized in homogenization buffer (100 mM Tris base, $100 \mathrm{mM} \mathrm{KCl,} 1 \mathrm{mM}$ ethylenediaminetetraacetic acid and $20 \mathrm{uM}$ butylated hydroxytoluene) using a Potter pestle attached to an electric drill motor. Samples were centrifuged at $18,500 \mathrm{x} g$ for 15 minutes at $4^{\circ} \mathrm{C}$, supernatant collected then spun at $106,000 \mathrm{x} \mathrm{g}$ for 60 minutes at $4^{\circ} \mathrm{C}$. The pelleted microsomal fraction was resuspended in microsomal storage buffer (100 $\mathrm{mM}$ potassium phosphate, $1 \mathrm{mM}$ ethylenediaminetetraacetic acid, $1 \mathrm{mM}$ dithiothreitol, 20 
uM butylated hydroxytoluene and 20\% glycerol). Microsome protein concentration was determined using by the Bradford assay method.

\section{Testosterone metabolite analys is}

Mouse liver microsomes were suspended in $10 \mathrm{mM}$ phosphate buffer $(\mathrm{pH} 7.4)$ containing $10 \mathrm{mM} \mathrm{MgCl}_{2}$ and $2.4 \mathrm{mM}$ NADPH. Testosterone was added (200uM final concentration) followed by a 60 minute incubation at $37^{\circ} \mathrm{C}$. The reaction was terminated by the addition of an equal volume of cold methanol and precipitated proteins were separated by centrifugation at $13000 \mathrm{x}$ g for 5 minutes at room temperature. One hundred microliters of sample were injected into the HPLC system for metabolite analysis. HPLC was performed using the Waters 500-717-2487 systems (Waters) and chromatographic separation was achieved using a reverse phase Hibar RT 250-4 pre-packed column (Merck). The mobile phase was 50\% methanol, 50\% water $(\mathrm{v} / \mathrm{v})$ with a run time of 50 minutes. Data acquisition and analysis was performed using Empower 2 software. The rate of formation of each metabolite is expressed at picomole $/ \mathrm{mg} / \mathrm{min}$. The following standards were used: $6 \alpha$-hydroxytestosterone, $6 \beta$-hydroxytestosterone, $16 \alpha$ hydroxytestosterone, 16 $\beta$-hydroxytestosterone, and $7 \alpha$-hydroxytestosterone (Steraloids, Inc.)

\section{Liver tes tosterone me as urement}

Liver samples were harvested from pre-pubertal and adult WT and KO mice, and testosterone was extracted and measured as described in chapter 2.

\section{PROD ass ay}

Approximately $20 \mathrm{ug}$ of liver protein extract was combined with $0.2 \mathrm{ml}$ Buffer A (1.25 mM ethylenediaminetetraacetic acid, $1 \mathrm{mg} / \mathrm{ml}$ bovine serum albumin, $10 \mathrm{uM}$ dicumerol, $4 \mathrm{uM}$ 7-pentoxyresorufin, and $40 \mathrm{mM}$ Tris $\mathrm{pH} 8.3$ ). Samples were incubated for 1 minute at $37^{\circ} \mathrm{C}$, and the reaction was started by the addition of $25 \mathrm{ul}$ of $10 \mathrm{mM}$ NADPH. The mixture was incubated for 5 minutes at $37^{\circ} \mathrm{C}$, and the reaction was stopped by adding $.25 \mathrm{ml}$ ice cold methanol. Samples were then spun at $5900 \mathrm{x} \mathrm{g}$ at $4^{\circ} \mathrm{C}$.

Florescence was read at an excitation/emission spectra of 558/590. 


\section{Results}

\section{Se rum testosterone concentration is dras tically reduced in pre-pubertal Mpr4 KO mice but is restore d with age}

Measurement of serum testosterone concentration in pre-pubertal Mrp4 KO mice revealed an approximate $90 \%$ reduction when compared to Mrp4 WT animals (Figure 5-1A). Interestingly, upon reaching adulthood, serum testosterone levels were relatively normal between the genotypes (Figure 5-1B). Circulating androstenedione concentrations were similar between the genotypes at both ages (Figure 5-1C), indicating the adrenal gland was not affecting the observed serum testosterone concentration. Additionally, immunoblot analysis of adult adrenal glands revealed no major alterations in StAR or Pbr protein expression, suggesting the increased serum testosterone in $\mathrm{KO}$ a mouse is not a result of increased testosterone biosynthesis in the adrenal glands (Figure 5-2). To confirm that circulating testosterone was significantly altered in prepubertal $\mathrm{KO}$ animals, prostate morphology was examined as the prostate requires exogenous testosterone for maturation [160]. Immunohistochemical analysis showed impaired prostate maturation in the pre-pubertal KO mouse, exhibiting disorganized tubular structure and enlarged interstitial space (Figure 5-3A) as compared to its WT counterpart. By adulthood, when serum testosterone levels were similar between the genotypes, prostate morphology was indistinguishable (Figure 5-3B), representative of a normal circulating testosterone concentration.

\section{Additional ABC transporters expressed in the testes are not unre gulated in the Mrp4 KO mouse}

As other $\mathrm{ABC}$ transporters are expressed in the testes and interact with steroids which are structurally similar to testosterone [161], we examined their expression in adult testes to determine if that may account for the rise in serum testosterone in $\mathrm{KO}$ mice. All inspected transporters (Abcc1, Abcb1, Abcg2 and Abcc5) showed no increase in protein expression in these animals (Figure 5-4A). Abcc2 expression was undetectable. Likewise, real-time PCT analysis of Slco6b1 and Slco6c1, reported androgen efflux transporters [162] showed no upregulation in Leydig cells (Figure 5-4B). These findings suggested the rise in circulating testosterone concentration in the adult $\mathrm{KO}$ mouse was not a product of increased expression of steroid efflux transporters.

\section{Decreased serum testosterone in pre-pube rtal Mrp4 KO mice is a res ult of incre as ed testosterone me tabolism by Cyp2b10}

Microarray analysis of pre-pubertal liver samples of Mrp4 WT and KO mice showed increased Cyp2b10 expression in KO mice as compared to WT. Expression levels returned to those seen in WT mice once the KO mice reached adulthood. Other 

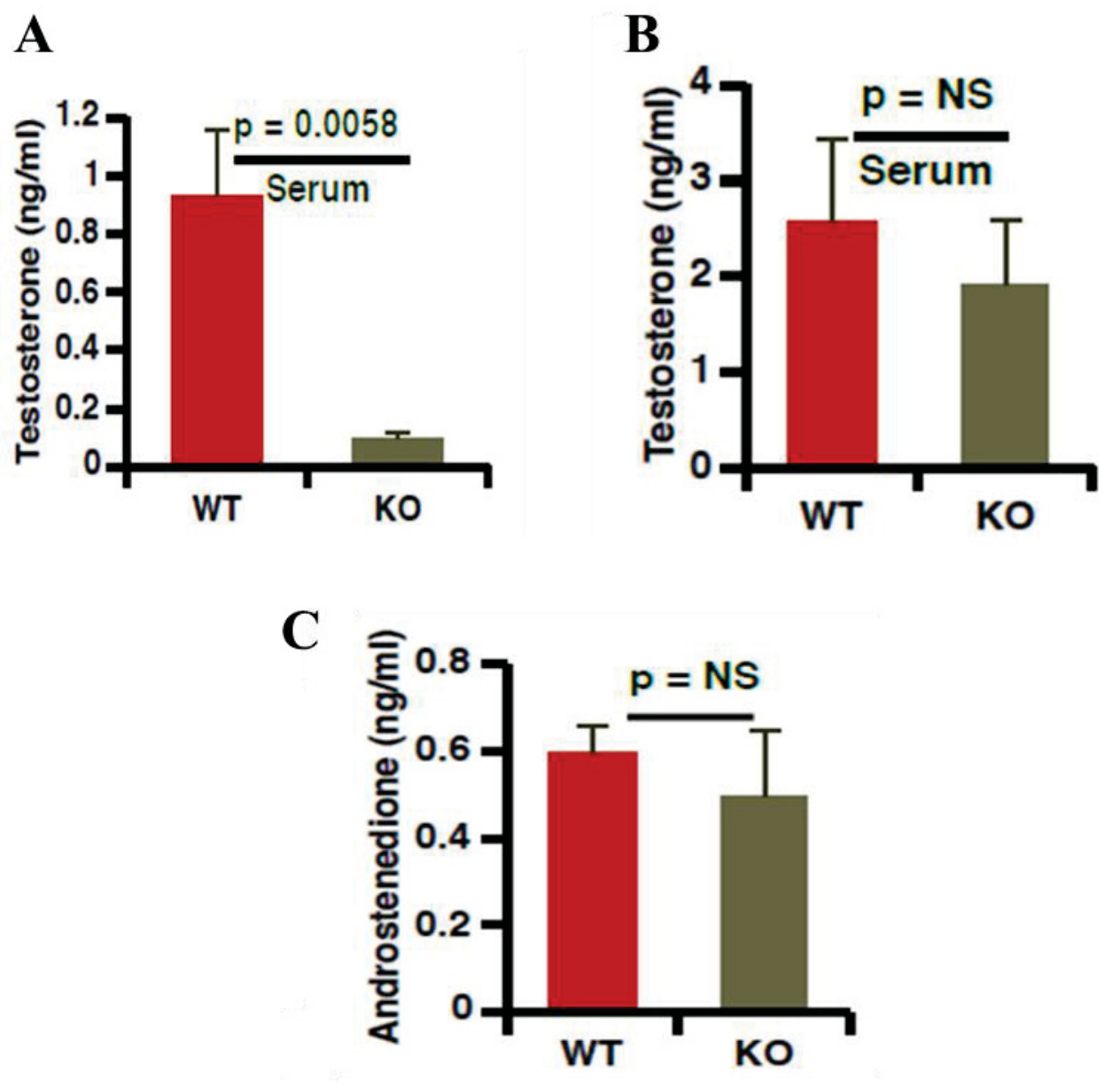

Figure 5-1. Serum testosterone concentration is decreased in the pre-pubertal Mrp4 KO mouse but normalizes with age. (A) Serum testosterone concentration in pre-pubertal Mrp4 mice as measured by radioimmunoassay (WT, $\mathrm{n}=7 ; \mathrm{KO}, \mathrm{n}=10$ ). (B) Serum testosterone concentration in adult Mrp4 mice as measured by radioimmunoassay (WT, $\mathrm{n}=10 ; \mathrm{KO}, \mathrm{n}=15$ ). (C) Serum androstenedione concentration in adult mice assessed by radioimmunoassay ( $\mathrm{n}=2$ mice/genotype). All error bars $=\mathrm{SE}$. 


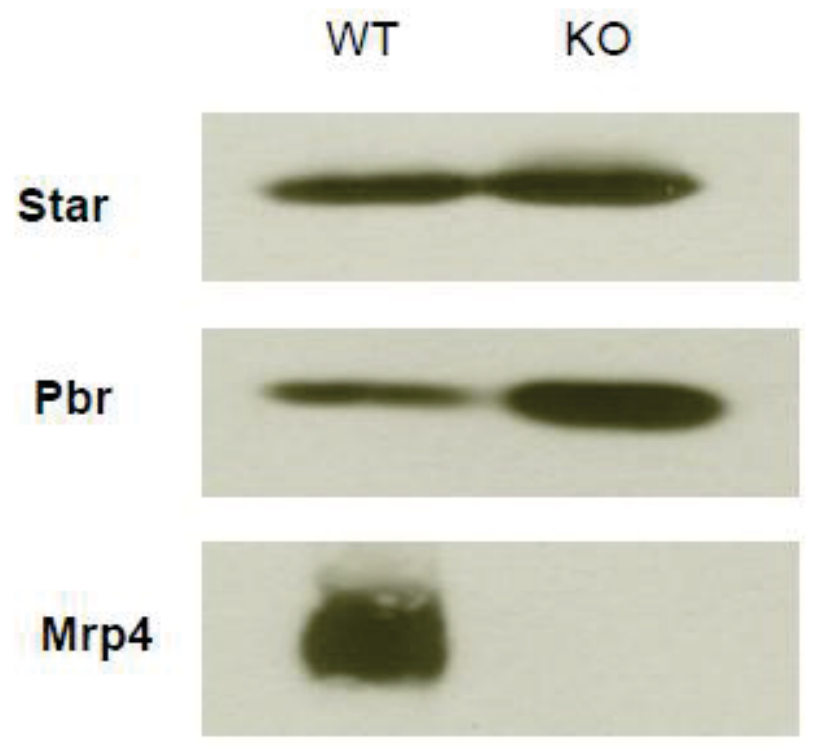

Figure 5-2. Protein expression of cholesterol importers are not decreased in Mrp4 KO adre nal glands. Expression of StAR and Pbr in Mrp4 WT and KO mouse adrenal glands as determined by immunoblot assay. 

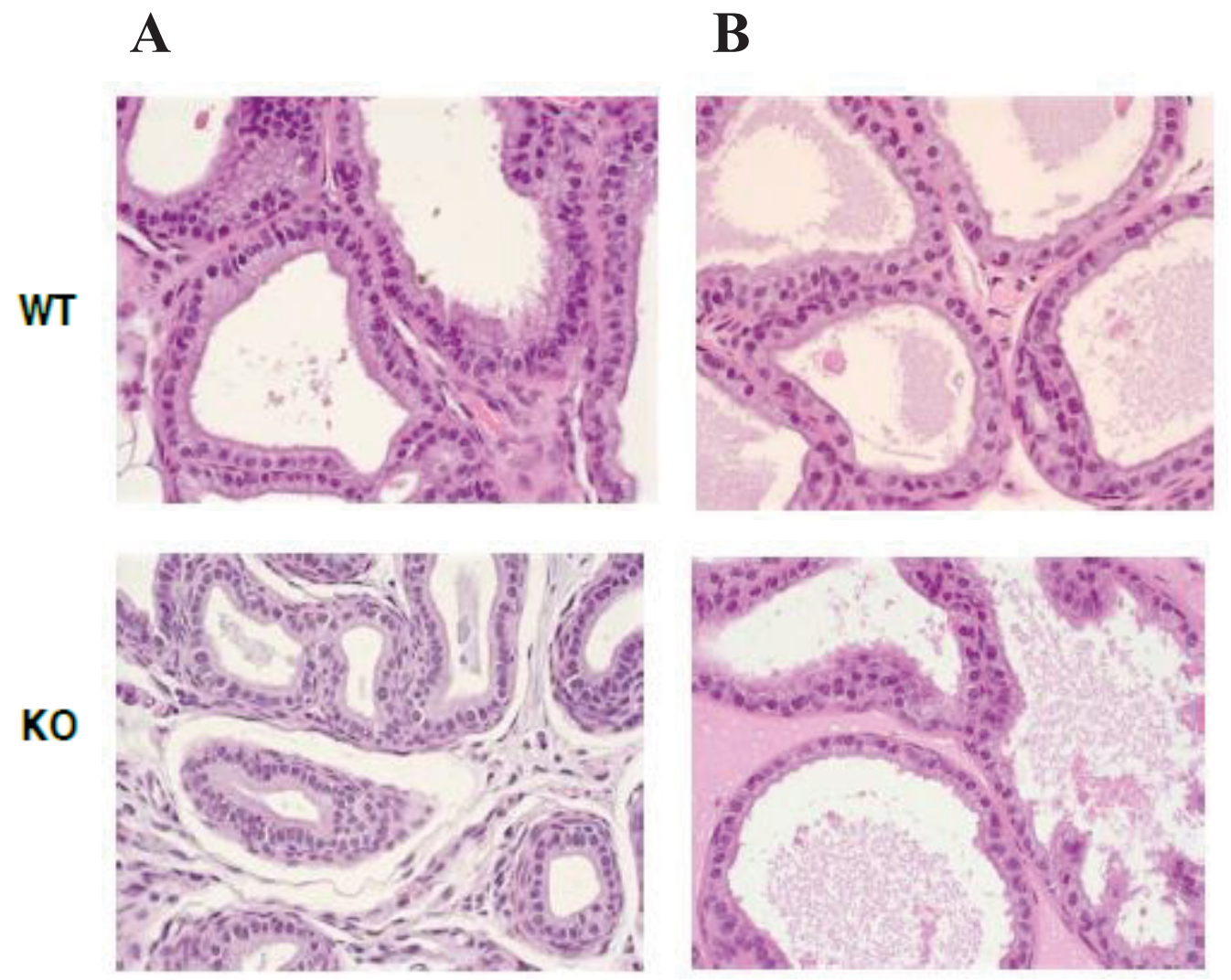

Figure 5-3. Pre-pubertal Mrp4 KO mice exhibit impaired prostate morphology while adult $\mathrm{KO}$ mice are normal. Prostate gland morphology of (A) pre-pubertal and (B) adult Mrp4 mice. (H\&E, 400X magnification) 

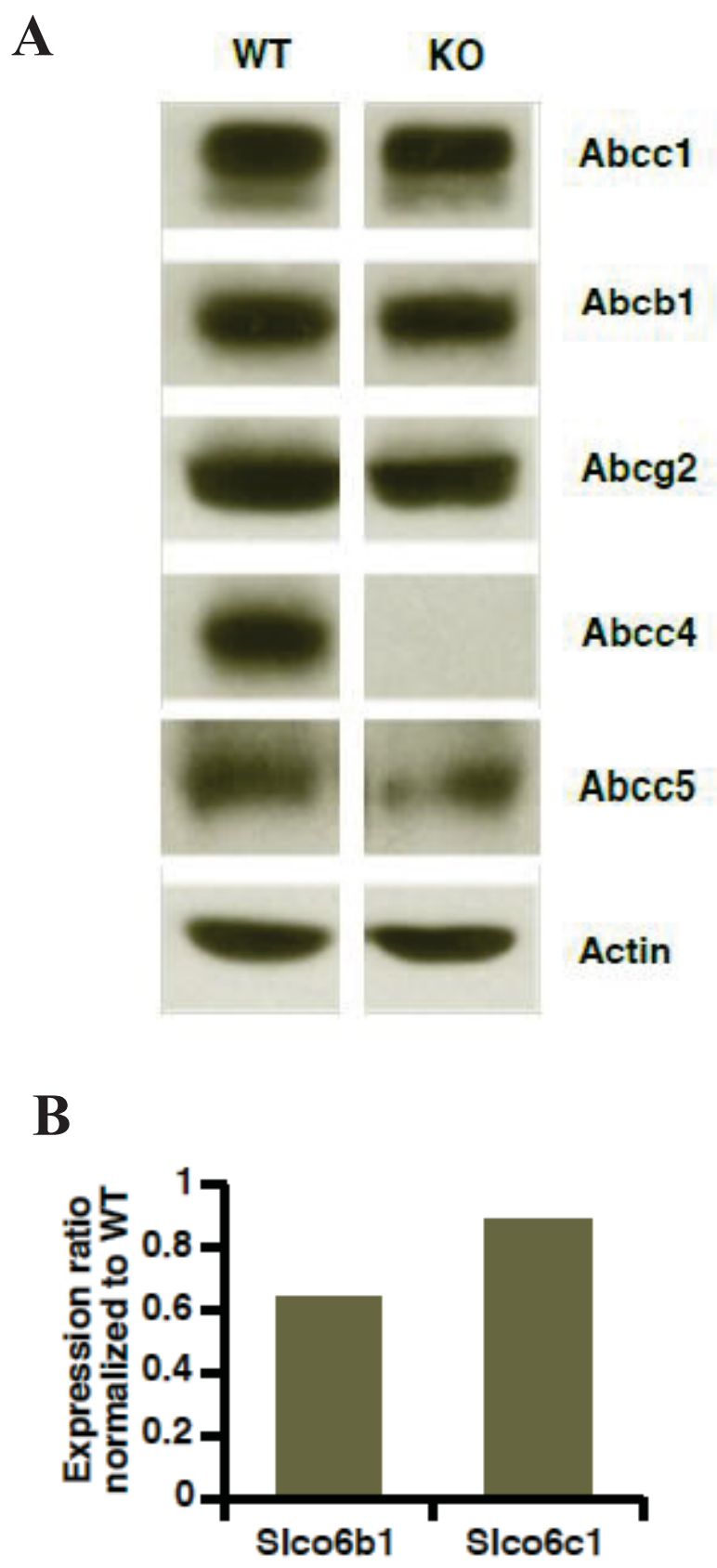

Figure 5-4. Alte rnate $\mathrm{ABC}$ and ste roid trans porters are not upregulated in Mrp4 KO mice. (A) Immunoblot analysis of $A B C$ transporters in adult testes. $\beta$-actin was used as a loading control. (B) mRNA expression of Slco6b1 and Slco6c1 in KO Leydig cells analyzed by real-time PCR, normalized to Rsp16 expression. 
testosterone metabolizing Cyps (Cyp1a2, Cyp2b9, Cyp3a11, Cyp3a13, Cyp7a1 and Cyp7b1) did not exhibit the same pattern of expression as Cyp2b10 (Figure 5-5). In accordance with the microarray data, real-time PCR confirmed Cyp2b10 expression was elevated in pre-pubertal Mrp4 KO liver microsomes but returned to a comparable level with the WT at an adult age (Figure 5-6A). Upregulated liver microsome Cyp2b10 protein expression was observed in individual $\mathrm{KO}$ mice versus expression in WT mice, Cyp2b10 expression was variable in adult animals regardless of genotype. Protein expression of Cyp3a11 increased with age but was not altered between the WT and KO samples in either age group. Cypla2 protein levels were consistent regardless of age or Mrp4 status (Figure 5-6B).

In addition to analyzing Cyp2b10 expression, catalytic activity was also examined. Total Cyp2b activity, as assessed by pentoxyresorufin O-dealkylase (PROD) assay, in pre-pubertal KO samples was elevated when compared to the WT. This was not observed in adult mice (Figure 5-7A). Correspondingly, increased formation of hydroxylated testosterone metabolites was detected with an approximate $60 \%$ increase in metabolites observed in the pre-pubertal Mrp4 KO mice (Figure 5-7B). This data is in accordance with the PROD results.

Liver testosterone concentration was then measured to validate the results seen with increased Cyp2b10 expression and catalytic activity. In accordance with the previous results, testosterone levels in pre-pubertal Mrp4 KO mice were substantially reduced when compared to the corresponding WT animals. No difference in testosterone concentration was observed in adult mice (Figure 5-8).

\section{Elevated Cyp2b10 expression is not a res ult of ge neral CAR activation}

To further verify Cyp2b10 expression was determinant on testosterone concentration and not other regulatory factors that modulate Cyp2b10, several factors were assessed. Real-time PCR analysis revealed similar AR mRNA expression in prepubertal livers (Figure 5-9A); however, expression of AR target genes was largely downregulated in the KO mouse (Figure 5-9B). This decreased activation is consistent with decreased testosterone concentration in these animals.

In vivo studies have shown that testosterone suppresses Cyp2b10, possibly by suppressing CAR activity [163]. Gene expression analysis of CAR target genes in prepubertal mice revealed that only Cyp2b10 is strongly upregulated in Mrp4 KO mice (Figure 5-10) indicating the general de-repression of CAR cannot explain the increased Cyp2b10 upregulation in $\mathrm{KO}$ liver.

\section{Conclusions}

Serum testosterone concentrations were found to be greatly reduced in the prepubertal $\mathrm{KO}$ animal but increased to a more normalized level upon reaching adulthood. 


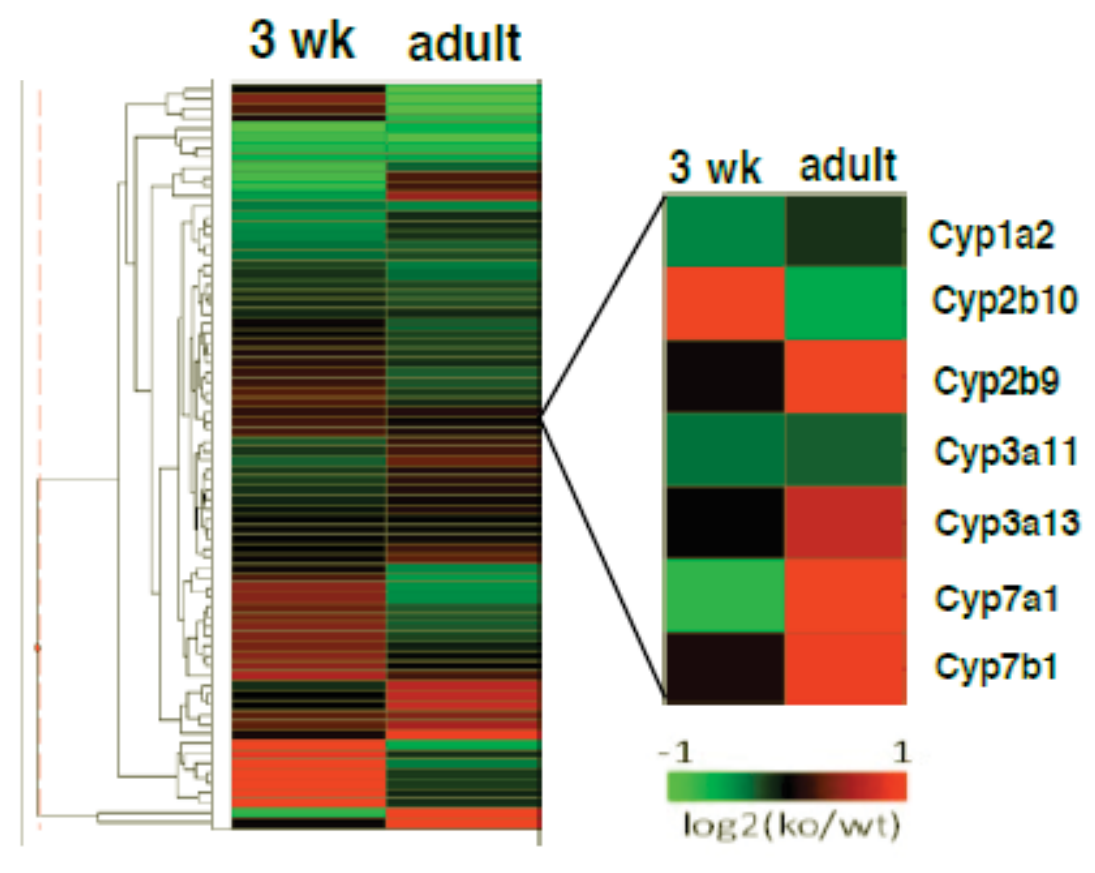

Figure 5-5. Cyp2b10 RNA expression is upregulate din pre-pubertal Mrp4 KO mice but decreases at an adult age. Expression heat map of all Cyp450 genes in the liver. Enlarged map shows testosterone metabolizing Cyp450s only ( $\mathrm{n}=3$ mice per age and genotype). Expressed as change compared to WT values. 

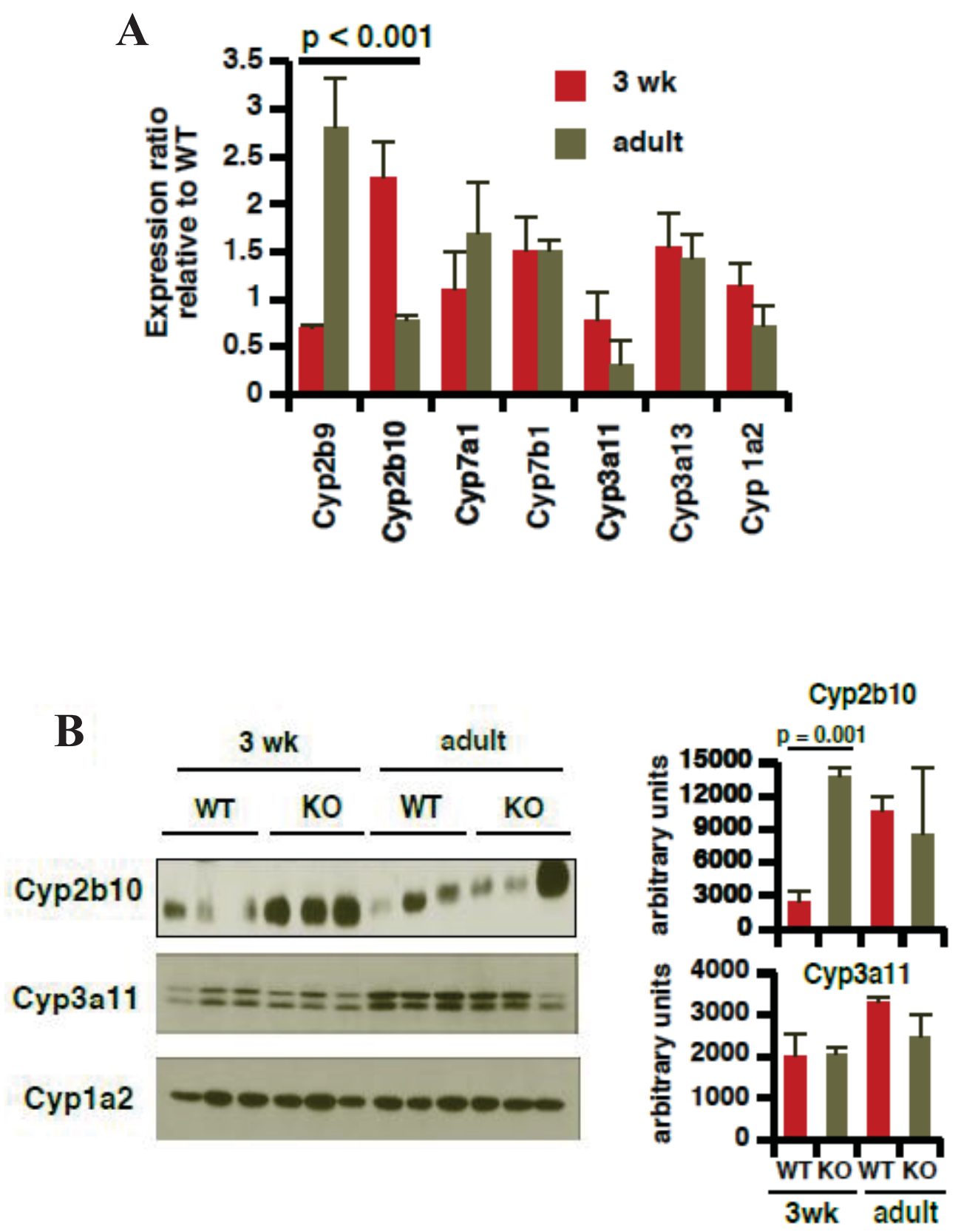

Figure 5-6. Both mRNA and prote in expression of Cyp2b10 are elevated in prepube rtal Mrp4 KO mice but decrease in adulthood. (A) Hepatic expression of testosterone metabolizing enzymes in pre-pubertal and adult Mrp4 KO mice $(\mathrm{n}=3$ mice per age and genotype group). Real time-PCR data is normalized to Gapdh expression and presented as the ratio of expression compared to WT mice. (B) Representative immunoblot analysis of Cyp2b10 and Cyp3a11 proteins in liver microsomes ( $\mathrm{n}=3$ mice per age and genotype.) Cypla2 was used as a loading control. Mean ratios of band intensity from two separate experiments are graphed to the right using ImageJ software. All error bars $=\mathrm{SE}$. 


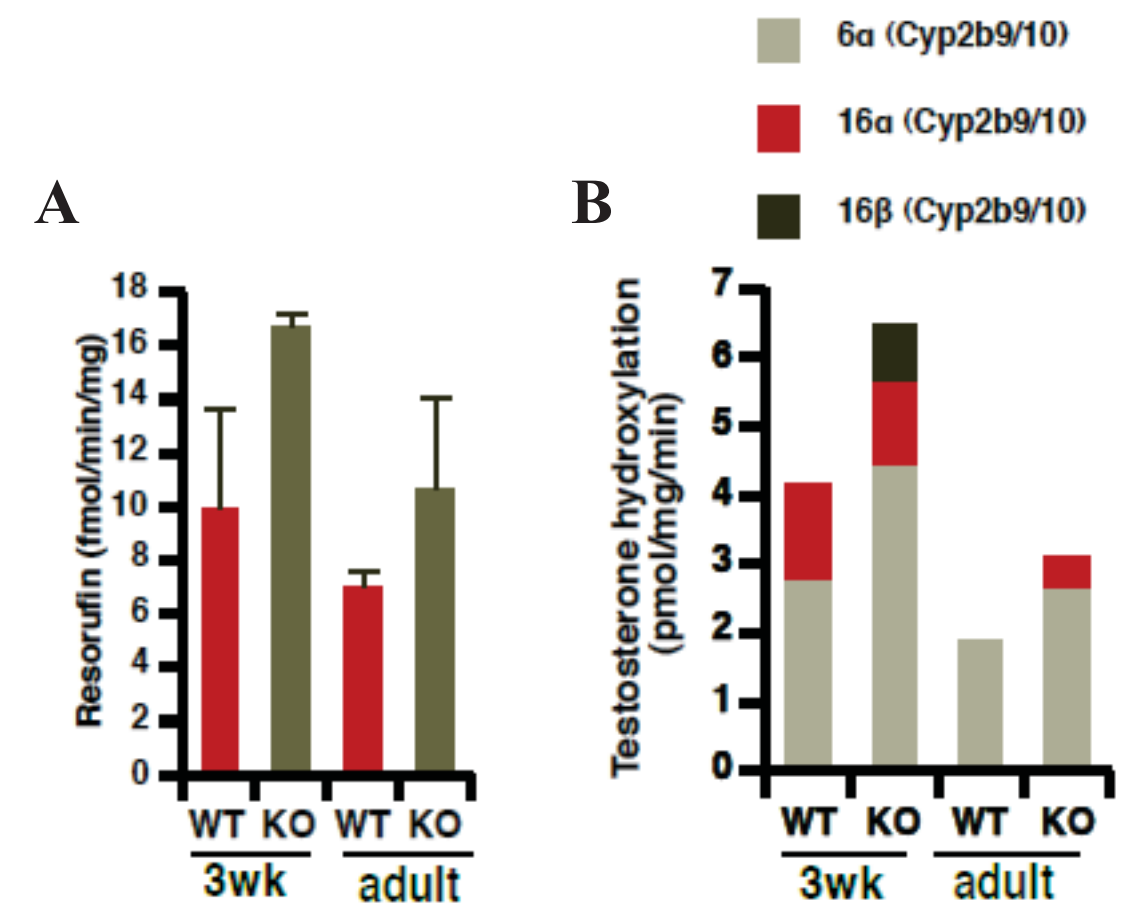

Figure 5-7. Testosterone metabolism is increased in pre-pube rtal Mrp4 KO

animals. (A) Cyp2b enzyme activity in liver microsomes determined by PROD assay. (B) Measurement of hydroxylated testosterone metabolites from liver microsomes using HPLC analysis ( $n=3$ mice per age and genotype). Cyp450s in parenthesis represent the major Cyp responsible for the corresponding metabolite. All error bars $=\mathrm{SE}$. 


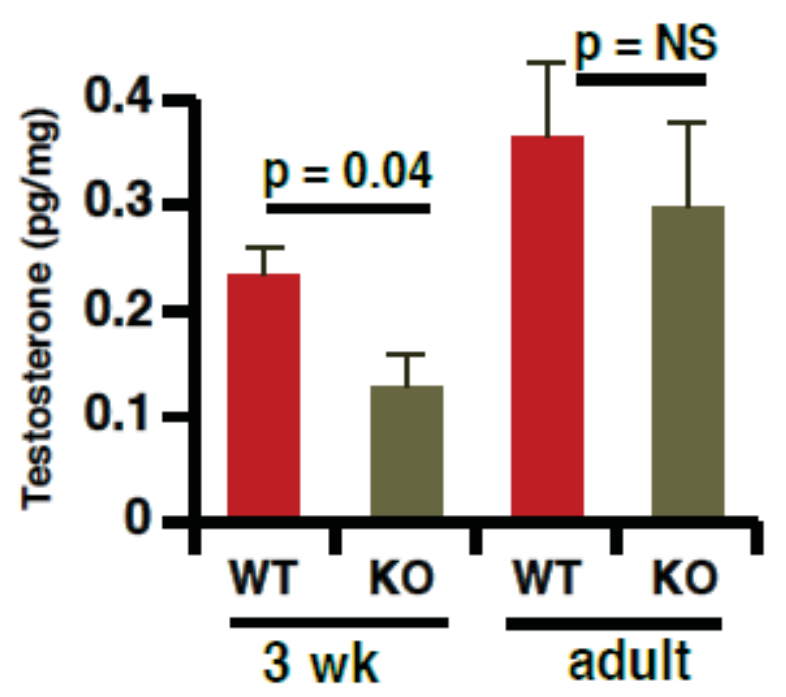

Figure 5-8. Liver tes tosterone concentration is decre ased in pre-pubertal KO mice compare d to WT. Total testosterone concentration in pre-pubertal and adult Mrp4 mouse liver as measured by radioimmunoassay $(n=4$ mice per age and genotype). Error bars $=\mathrm{SE}$. 

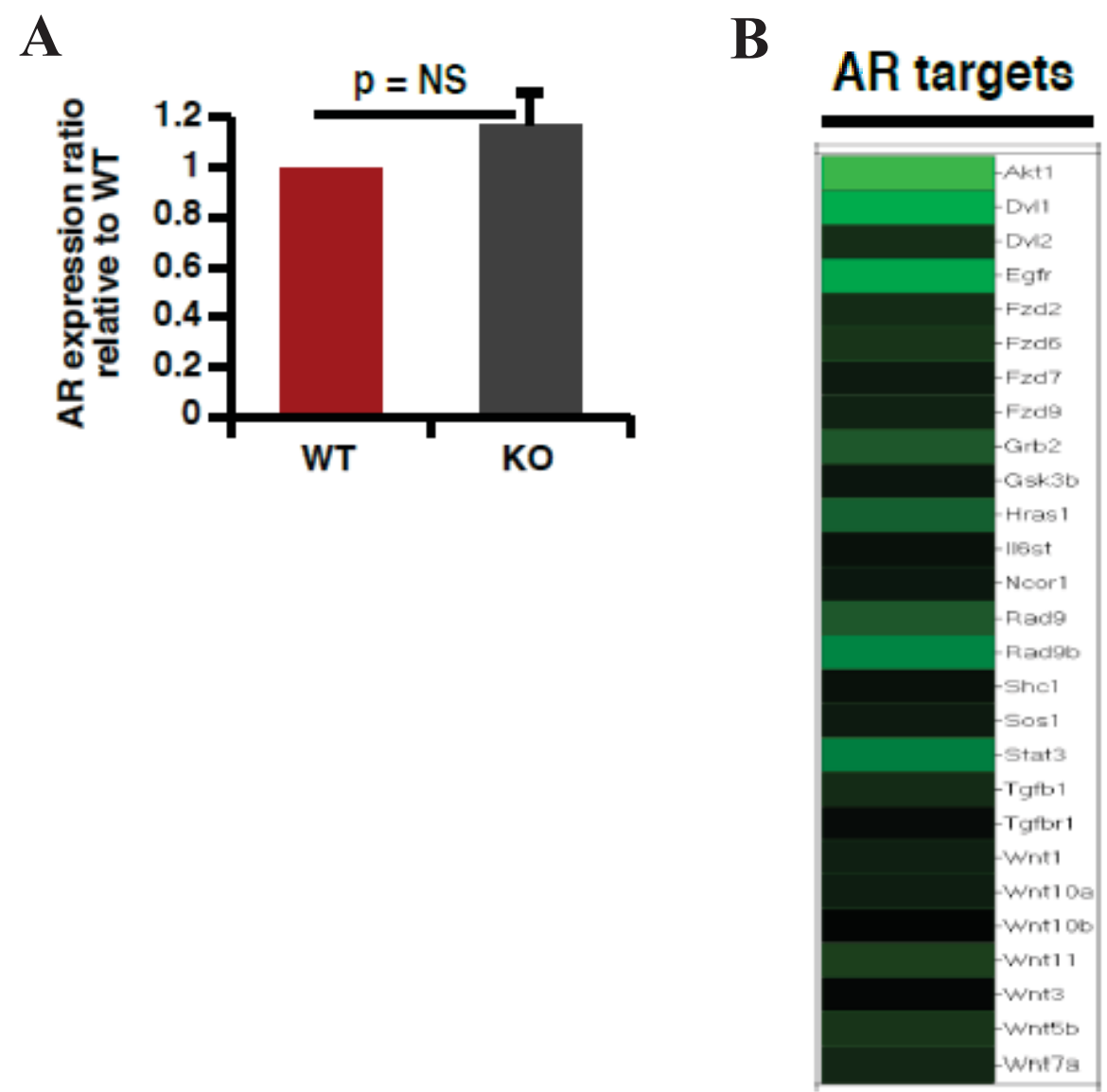

Figure 5-9. Androgen receptor target ge nes are downregulated in pre-pubertal Mrp4 KO mice. (A) Hepatic androgen receptor mRNA expression assessed by realtime PCR normalized to Gapdh expression. (B) Heat map representing the expression of androgen receptor targets in pre-pubertal Mrp4 $\mathrm{KO}$ mice in relation to WT expression levels. 


\section{Car targets}

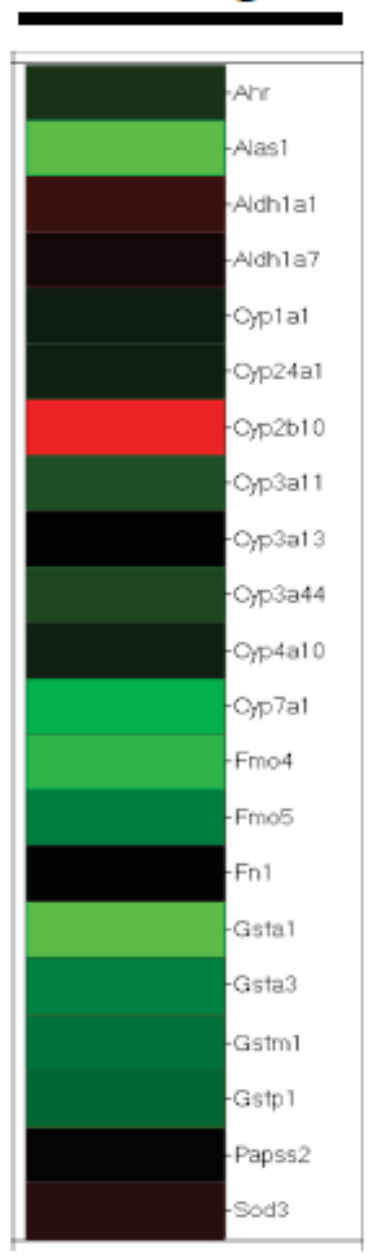

Figure 5-10. A gene ral downre gulation of Car target gene expression is not observed in pre-pubertal Mrp4 KO mice. Heat map representing hepatic gene expression of Car target genes in pre-pubertal $\mathrm{KO}$ mice in relation to WT gene expression. 
Confirmation of these effects was seen upon examination of prostate morphology, an organ which requires circulating testosterone for maturation. Pre-pubertal KO prostate presented with a disorganized structure and excess interstitial space while the adult $\mathrm{KO}$ prostate was identical to the WT. Circulating androstenedione concentrations were not altered between the genotypes, and upregulation of other $\mathrm{ABC}$ transporters present in the testes was not observed.

Increased Cyp2b10 expression and activity was confirmed in the pre-pubertal $\mathrm{KO}$ mice. No other testosterone metabolizing Cyp examined exhibited this increase. Upon reaching an adult age, Cyp2b10 in $\mathrm{KO}$ mice showed a considerable decrease in both expression and activity. This metabolizing effect was also confirmed by liver testosterone levels which showed the same pattern as serum testosterone. Finally, the change in Cyp2b10 expression was not a result of CAR activation as it was the only target gene upregulated in our analysis, confirming its expression levels are dependent on testosterone concentration in this system. 


\section{CHAPTER 6. DISCUSSION}

\section{Mrp4 Is Localized to Leydig Cells}

Prior to our initial experiments, Mrp4 was well reported to have testicular expression; however, its cellular localization and specific role had yet to be determined $[136,137]$. Through the use of immunoblot and immunohistochemical techniques, Mrp4 was discovered to be specifically localized to the Leydig cell compartment. Leydig cells are responsible for the synthesis and release of the primary male sex hormone testosterone [57] which is vital for the maintenance of spermatogenesis [164].

While it has been shown that $\mathrm{ABC}$ transporters expressed in the testes play their expected cytoprotective role in effluxing toxic compounds as indicated by the protective role of Mrp1 at the blood-testes barrier [140], data has also been presented which highlights the importance of these transporters in regulating testosterone levels. In addition to the previously discussed testosterone deficiency observed in Abcc1 KO animals, ABCA1 KO mice also exhibit reduced intratesticular testosterone levels. Primarily expressed in Sertoli cells, the absence of ABCA1 results in abnormal lipid accumulation in Sertoli cells and depletion of lipid droplets from Leydig cells, producing partially compromised Leydig cell function [165]. However, no evidence had been presented directly linking the loss of Mrp4 to testosterone deficiency. Interestingly, substrates of Mrp4 had been implicated in negatively impacting androgen response. In vivo analysis of chronic methotrexate treatment in rats showed decreased testosterone as compared to untreated controls. Two enzymes involved in the steroid biosynthesis

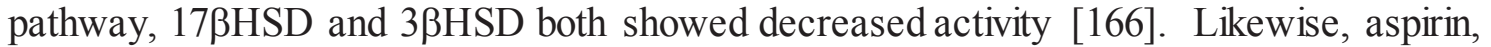
both a substrate and inhibitor of Mrp4 [167, 168] has been reported to impact steroidogenesis. Acute aspirin administration in humans showed impaired steroidogenesis, a phenomenon most likely due to aspirin's interference with LH-hCG action on the plasma membrane of Leydig cells [169]. Aspirin dosing in rodents resulted in decreased spermatid numbers, producing a morphology consistent with impaired germ cell maturation [170, 171]. With initial data confirming the localization of Mrp4 to Leydig cells, coupled with literature evidence supporting that inhibition of Mrp4 impairs steroidogenesis and spermatogenesis, it was hypothesized that Mrp4 deficient mice may possess an inherent defect in testosterone production.

\section{Mrp4 KO Mice Have an Inhe rent Deficiency in Testicular Testosterone Concentration}

Intratesticular testosterone measurements revealed severely impaired levels in Mrp4 KO animals both prior to puberty and at an adult age. To confirm these results, a series of testosterone dependent parameters were observed. Pre-pubertal Mrp4 KO mice

possessed half the number of primary spermatids within the seminiferous tubules than did the WT mouse, consistent with low availability of testosterone [143, 172]. Germ cell maturation is controlled by a balance of cell proliferation and apoptosis [144, 153], and 
pre-pubertal KO mice exhibited decreased germ cell proliferation and increased apoptosis. These findings are consistent with previous studies that illustrate gonadotropin deprivation and/or testosterone withdrawal results in increased apoptosis at multiple stages of germ cell development [173, 174]. However, despite the continued reduction in testicular testosterone concentration in adult Mrp4 $\mathrm{KO}$ mice, proliferation and apoptosis measurements were comparable to those seen in Mrp4 WT animals. We sought an explanation for the restoration of testicular morphology in adult $\mathrm{KO}$ mice despite their sustained testosterone reduction.

It is well documented that testosterone is essential for spermatogenesis, although the absolute levels required are still debatable. In rodents and primates, intratesticular testosterone levels are elevated approximately 100 fold over serum concentrations by virtue of its localized production. These concentrations are in excess if what is required to saturate the AR [175]. Experimental reduction of testicular testosterone levels in rats led to an abolition in sperm production when the concentration was less than $20 \%$ of that of the controls [152]. This proportionate reduction was observed in the pre-pubertal and adult Mrp4 $\mathrm{KO}$ mice, but only the younger animals exhibited signs of impaired spermatogenesis. Critical analysis of testosterone concentration in $\mathrm{KO}$ mice revealed a four-fold increase in testosterone levels as the mice reached adulthood. While the concentration remains decreased in adult $\mathrm{KO}$ mice, it is conceivable that the four fold increase generates enough testicular testosterone to saturate the AR in the testes, thus allowing normal progression of spermatogenesis in these animals.

In conclusion, our initial studies revealed the localization of Mrp4 to the Leydig cells. Additionally, it was observed the loss of Mrp4 resulted in decreased intratesticular testosterone in these animals, but this deficiency negatively impacted mice before puberty. As adult mice possessed normal testicular morphology and were reproductively comparable to the WT animals with respect to litter size, it appeared the loss of Mrp4 did not contribute to an overall detrimental phenotype in the adult KO testes.

\section{Cyclic AMP Is the Regulatory Factor Controlling Decreas ed Testosterone Synthe sis in the Mrp4 KO Mouse}

The data presented in this section provided the first evidence that the absence of Mrp4 in the testes resulted in an inherent defect in Leydig cell testosterone biosynthesis. While prior studies had demonstrated the loss of a testicular transporter resulted in impaired intratesticular testosterone concentration, the mechanism underlying the decrease had failed to be fully characterized or was not dependent on the transporter's expression in the Leydig cells. We provided evidence that the testicular testosterone deficiency characterized in the Mrp4 KO mouse was a product of decreased intracellular cAMP concentration, leading to a downstream cascade of impaired biosynthetic processes, including CREB phosphorylation and diminished testosterone biosynthetic gene expression. 
Proper regulation of cAMP is critical for the maintenance of testosterone biosynthesis, as it is a primary regulator of many steps in testosterone formation. Luteinizing hormone receptor mRNA expression requires basal cAMP expression [99]. However, long-term incubation of the MA-10 Leydig cell line with a cAMP derivative resulted in decreased LHR mRNA [100], presumably due to increased receptor degradation by receptormediated endocytosis. While this may initially appear to be inconsistent with our data showing decreasedcAMP concentration, acute LH stimulation of Leydig cells generated an increase in intracellular cAMP levels in the Mrp4 KO. It can be surmised that this initial accumulation of cAMP potentially triggers receptor internalization, resulting in decreased Lhr expression observed in Mrp4 KO Leydig cells.

Cyclic AMP also modulates a variety of aspects of testosterone biosynthesis through its binding and activation of CREB. CREB mediated gene transcription is achieved by activation of PKA and subsequent phosphorylation of CREB. In turn, CREB binds the conserved cAMP response element TGACGTCA typically found in the promoter of many cAMP responsive genes [102]. Multiple genes in the testosterone biosynthesis pathway contain CREB binding sites in their promoter regions. The activation of the StAR protein, the rate limiting step in steroid biosynthesis, is dependent on cAMP. The StAR promoter does not contain the typical CRE binding motif but instead contains a cAMP responsive region that has functional elements for other transcriptional activities [103]. Despite the absence of a consensus CRE site, studies have shown the classical cAMP-PKA signaling cascade activates CREB and upregulates the transcription of the StAR gene [104, 105]. StAR expression is vital for steroid biosynthesis as shown in cell culture context as well as with a StAR KO mouse model. Mice lacking StAR exhibited Leydig cell hyperplasia and a reduced capacity for spermatogenesis [44], indicating these animals possess insufficient androgen production to maintain optimal spermatogenesis.

Our results in Mrp4 KO mice reveal both a decrease in cAMP concentration as well as lowered StAR mRNA and protein expression. Although the phosphorylation status of StAR has yet to be determined, based on prior reports, the Mrp4 KO animal could potentially possess a deficiency in StAR phosphorylation due to lowered cAMP concentration and possible decreased PKA activation. In addition to CREB binding, cAMP responsiveness of the StAR promoter is also regulated by SF-1 [176] which has been identified as essential to both basal and hormone induced cAMP regulation of StAR $[177,178]$. Microarray analysis of whole testes revealed a slight decrease in SF-1 expression in KO animals (data not shown) thereby adding another factor that could account for the decreased StAR expression observed in these animals.

The concurrent cholesterol importer, $\mathrm{Pbr}$, is not reported to be under CREB activation; however, a cAMP-inducible element that regulates $\mathrm{Pbr}$ structure and function is present as inhibition of PKA results in reduced steroid formation in MA-10 cells [108]. Functionally, Pbr exists in a complex with other proteins including VDAC, ANT, pk10, PRAX-1 and PAP7 [179]. We observed no downregulation of either Pbr or Vdac protein expression in Mrp4 $\mathrm{KO}$ testes in spite of reduced cAMP concentration, indicating the $\mathrm{Pbr}$ complex may be regulated by other crucial factors. It has been suggested that Pbr may 
play a role in controlling the import of StAR into the mitochondria as Leydig cells with knocked down Pbr expression generated low formation of mature StAR protein in response to hormone stimulation, correlating with an absence of steroid formation [95]. For our studies it may be inferred, in the presence of impaired cAMP concentration and StAR expression, the equivalent expression of Pbr in Mrp4 WT and KO testes is responsible for the observed testicular testosterone, albeit minimal, concentration in these mice.

For CREB induced gene expression, the duration of Ser133 phosphorylation has been shown to determine the efficacy of expression. In a subtype of striatal neurons, stimulation with dopamine, a cAMP activating neurotransmitter, involves Ser133 phosphorylation that is maintained 30 minutes after stimulation. In other subtypes of striatal neurons, Ser133 phosphorylation is more transient as dephosphorylation occurs within 15 minutes of the stimulus. In neurons where phosphorylation is sustained, CREB target genes are induced whereas unsustained phosphorylation does not promote gene induction [111]. These results bolster our data that exhibits minimal Ser133 phosphorylation in Mrp4 KO Leydig cells stimulated with LH. After 30 minutes exposure to hormonal stimulation, the phosphorylation state of these cells was barely altered above the basal level. As illustrated with neuronal cells, this non-existent Ser133 phosphorylation in Mrp4 KO Leydig cells produced a host of inactivated downstream gene targets.

The decrease in cAMP concentration measured in Mrp4 KO Leydig cells was initially a puzzling finding as it was anticipated cAMP levels would be elevated as it is a well-established substrate for Mrp4. More detailed analysis revealed, however, that acute inhibition of Mrp4 when stimulated with LH resulted in increased intracellular cAMP accumulation in the WT cells. As the activation of adenylyl cyclase and the formation of cAMP occurs within seconds of receptor activation [180], it can be postulated that the decreased cAMP concentration in KO Leydig cells is not a result of abated formation but instead of increased degradation by PDEs. Phosphodiesterases including PDE4A [181], PDE5A [182], PDE8A [148] and PDE8B [183] have been localized to the testes. Both PDE8A and PDE8B are highly expressed in Leydig cells, and their inhibition increases PKA-dependent phosphorylation and protein expression of components of steroidogenesis [183]. The same experiments have also shown additional inhibition of PDE4 synergize potentiated steroid production, demonstrating these PDEs function to maintain low cAMP levels thereby suppressing steroidogenesis. While PDE status has yet to be clarified in our experiments, based on our data, increased PDE concentrations may be responsible for the long-term depression of cAMP concentration detected in Mrp4 KO Leydig cells. Our future studies aim to examine this more in depth. 


\section{Increased Cyp2b10 Expression and Activity Results in Decreased Serum Testosterone in Pre-pubertal Mrp4 KO Mice}

Our results from these sets of experiments highlight the important relationship between testosterone concentration and Cyp2b10 expression. Initial findings of decreased serum testosterone concentration in pre-pubertal Mrp4 KO mice but normalized adult levels were originally a perplexing result. Although testicular testosterone biosynthesis was reduced regardless of age (refer to chapters 2 and 4), it was not anticipated that its release from the testes impacted circulating concentrations, as testosterone is not a substrate for Mrp4 [54]. While the common route for testosterone release is generally accepted to be passive diffusion [64], androgen efflux proteins have been characterized. The rat gonad specific transporters Slco6a1 and Slco6b1 transport DHEAS [162] while Abcg2 effluxes steroids including estradiol, progesterone, and testosterone [148]. Similarly, ABC transporters ABCG1 and ABCG5 have been implicated in cholesterol transport $[184,185]$. Our samples were evaluated for expression of some of these transporters to determine if increased expression in adult Mrp4 KO mice could be responsible for elevated serum testosterone concentration. As our results revealed that none of the transporters showed upregulation in the $\mathrm{KO}$, it was concluded that increased serum testosterone was not a result of potentially increased transport.

Based on published reports stating testosterone concentration and Cyp2b10 expression have a negative correlation, we proposed decreased serum testosterone in prepubertal KO mice was a result of increased Cyp2b10 expression and catalytic activity. Results from microarray analysis and real-time PCR showed increased Cyp2b10 expression in $\mathrm{KO}$ mice. Likewise, elevated Cyp2b10 protein expression was observed in pre-pubertal Mrp4 KO liver microsomes. Although Cyp3a11 is an important testosterone metabolizing enzymes, no change in expression was ever observed in our samples. Unlike with Cyp2b10, there is no current evidence that Cyp3a11 expression depends on testosterone concentration. The adult samples did show the expected increase in expression regardless of genotype $[113,186]$. Consistent with the expression data, Cyp2b10 catalytic activity was elevated in the pre-pubertal KO mice. Increased $16 \alpha-$ and $16 \beta$-hydroxylated metabolites were consistent with elevated Cyp2b10 activity, as they are primarily metabolized by the enzyme [124, 125].

The actions of testosterone and other androgens are mediated through the AR, a ligand dependent transcription factor. Upon entry into the androgen target cell, testosterone either binds directly to the AR or binds following its conversion to DHT. Following a series of conformational changes, activation or repression of downstream target genes occurs [187]. Our microarray analysis of pre-pubertal Mrp4 KO liver showed AR target genes were largely downregulated in comparison to WT, compatible with reduced liver testosterone concentrations. Based on these results, it is conceivable to speculate DHT concentrations were similarly reduced in these animals although levels were not measured. 
Studies have shown endogenous androgens repress the nuclear orphan receptor CAR, of which Cyp2b10 is a target gene [163]. We aimed to test if general de-repression of CAR target genes was secondary to reduced hepatic testosterone in pre-pubertal KO mice. The gene expression pattern was similar between the genotypes with the exception of strongly induced Cyp2b10 expression in the KO liver. Therefore, general derepression of CAR could not explain the increased hepatic Cyp2b10 in pre-pubertal KO mice.

In conclusion, these studies show reduced systemic testosterone concentration in pre-pubertal Mrp4 KO mice is a result of increased metabolism by Cyp2b10 and decreased testicular testosterone production However, in adult mice, circulating testosterone concentration returns to near normal levels despite a sustained reduction in testicular testosterone due to alleviated testosterone metabolism.

\section{Genetic Variants Highlight the Importance of Proper Functioning Mrp4}

The data shown here provides the first evidence that the absence of Mrp4 in a KO mouse model results in the downregulation of a steroid biosynthetic pathway. However, several human mutations of MRP4 have been identified, with some creating detrimental effects due to lack normal MRP4 function. Studies conducted in Xenopus laevis oocytes expressing the human MRP4 missense mutation V776I revealed a decreased ability of these oocytes to transport 6-mercaptopurine (6MP). In conjunction with decreased transport, the V776I mutation also exhibited reduced protein expression as well as plasma membrane surface expression [188]. Similar types of studies performed in HEK293 cells also reinforced the importance of properly functioning MRP4. For this report, an ethnically diverse population (270 healthy individuals) was used to obtain potential MRP4 variants in the general population. A total of 98 variants were identified, and ten were chosen for analysis based on a frequency of $\geq 5 \%$ in the population studied. While none of the variants were observed to be completely deleterious, both G187W and G487E, both evolutionarily conserved, exhibited significantly reduced ability to transport both azathioprine (AZA) and 9-(2-phosphonyl-methoxyethyl) adenine (PMEA). The P78A and P403L variants, also evolutionarily conserved, showed reduced function when transporting AZT [189]. A single nucleotide polymorphism (rs3765534) found in human MRP4, common in approximately $18 \%$ of the Japanese population, renders cells more susceptible to 6MP toxicity than cells with WT MRP4. This variant allele showed similar protein expression when transfected into HEK293 cells but strongly reduced cell surface expression, a factor that contributes to increased intracellular thioguanine nucleotide concentration [45]. Based on these and other data, it can be hypothesized that naturally occurring MRP4 variants, in addition to contributing to chemotherapeutic toxicity, may also play a role in reducing testosterone concentration in human males. Although this has yet to be examined, it merits investigation in order to fully understand the crucial role of MRP4 in the testes. 


\section{Future Directions}

The complete set of studies presented here show Mrp4 is a crucial factor in regulating normal testosterone biosynthesis. We anticipate future studies based on this work will highlight the importance of Mrp4 expression in Leydig cells as it relates to chemotherapeutic drug induced male sterility. Multiple cancer chemotherapeutic drugs produce detrimental reproductive effects secondary to impaired testosterone production. Chronic administration of azathioprine and methotrexate have been lined to sperm toxicity [190] and decreased testosterone concentration [166], respectively, in rodents. 6mercaptopurine, a routinely administered drug in both childhood [191] and adult [192] acute lymphoblastic leukemia, is reported as a carcinogen [193] that negatively impacts reproductive capabilities [194]. These studies all conclude the adverse reproductive effects are a result of decreased testosterone concentration. We anticipate Mrp4 protects Leydig cells from chemotherapeutic toxicity caused from these agents through its ability to both efflux these substrates as well as maintain normal testosterone biosynthesis. 


\section{LIST OF REFERENCES}

1. Higgins, C.F., ABC transporters: from microorganisms to man. Annu Rev Cell Biol, 1992. 8: p. 67-113.

2. Juliano, R.L. and V. Ling, A surface glycoprotein modulating drug permeability in Chinese hamster ovary cell mutants. Biochim Biophys Acta, 1976. 455(1): p. 152-62.

3. Cole, S.P., et al., Overexpression of a transporter gene in a multidrug-resistant human lung cancer cell line. Science, 1992. 258(5088): p. 1650-4.

4. Doyle, L.A., et al., A multidrug resistance transporter from human MCF-7 breast cancer cells. Proc Natl Acad Sci U S A, 1998. 95(26): p. 15665-70.

5. Allikmets, R., et al., A human placenta-specific ATP-binding cassette gene $(A B C P)$ on chromosome $4 q 22$ that is involved in multidrug resistance. Cancer Res, 1998. 58(23): p. 5337-9.

6. Miyake, K., et al., Molecular cloning of cDNAs which are highly overexpressed in mitoxantrone-resistant cells: demonstration of homology to ABC transport genes. Cancer Res, 1999. 59(1): p. 8-13.

7. Szakacs, G., et al., The role of ABC transporters in drug absorption, distribution, metabolism, excretion and toxicity (ADME-Tox). Drug Discov Today, 2008. 13(910): p. 379-93.

8. Gottesman, M.M., T. Fojo, and S.E. Bates, Multidrug resistance in cancer: role of ATP-dependent transporters. Nat Rev Cancer, 2002. 2(1): p. 48-58.

9. Dean, M., A. Rzhetsky, and R. Allikmets, The human ATP-binding cassette $(A B C)$ transporter superfamily. Genome research, 2001. 11(7): p. 1156-66.

10. Fromm, M.F., Importance of P-glycoprotein at blood-tissue barriers. Trends Pharmacol Sci, 2004. 25(8): p. 423-9.

11. Borst, P. and R.O. Elferink, Mammalian ABC transporters in health and disease. Annu Rev Biochem, 2002. 71: p. 537-92.

12. Takahashi, K., et al., ABC proteins: key molecules for lipid homeostasis. Med Mol Morphol, 2005. 38(1): p. 2-12.

13. Hyde, S.C., et al., Structural model of ATP-binding proteins associated with cystic fibrosis, multidrug resistance and bacterial transport. Nature, 1990. 346(6282): p. 362-5. 
14. Fukuda, Y. and J.D. Schuetz, ABC transporters and their role in nucleoside and nucleotide drug resistance. Biochem Pharmacol, 2012. 83(8): p. 1073-83.

15. Joyce, C., et al., Study of ABCA1 function in transgenic mice. Arterioscler Thromb Vasc Biol, 2003. 23(6): p. 965-71.

16. Kaminski, W.E., et al., ABCA6, a novel a subclass ABC transporter. Biochem Biophys Res Commun, 2001. 285(5): p. 1295-301.

17. Annilo, T., et al., Identification and characterization of a novel ABCA subfamily member, ABCA12, located in the lamellar ichthyosis region on 2q34. Cytogenet Genome Res, 2002. 98(2-3): p. 169-76.

18. Krishnamurthy, P.C., et al., Identification of a mammalian mitochondrial porphyrin transporter. Nature, 2006. 443(7111): p. 586-9.

19. Wolters, J.C., R. Abele, and R. Tampe, Selective and ATP-dependent translocation of peptides by the homodimeric ATP binding cassette transporter TAP-like (ABCB9). J Biol Chem, 2005. 280(25): p. 23631-6.

20. Arrese, M. and M. Ananthanarayanan, The bile salt export pump: molecular properties, function and regulation. Pflugers Arch, 2004. 449(2): p. 123-31.

21. Bakos, E. and L. Homolya, Portrait of multifaceted transporter, the multidrug resistance-associated protein 1 (MRP1/ABCC1). Pflugers Arch, 2007. 453(5): p. 621-41.

22. Mennone, A., et al., Mrp4-/- mice have an impaired cytoprotective response in obstructive cholestasis. Hepatology, 2006. 43(5): p. 1013-21.

23. van Aubel, R.A., et al., The MRP4/ABCC4 gene encodes a novel apical organic anion transporter in human kidney proximal tubules: putative efflux pump for urinary cAMP and cGMP. J Am Soc Nephrol, 2002. 13(3): p. 595-603.

24. Aleksandrov, A.A., L.A. Aleksandrov, and J.R. Riordan, CFTR (ABCC7) is a hydrolyzable-ligand-gated channel. Pflugers Arch, 2007. 453(5): p. 693-702.

25. Bryan, J., et al., ABCC8 and ABCC9: ABC transporters that regulate $K+$ channels. Pflugers Arch, 2007. 453(5): p. 703-18.

26. Imanaka, T., et al., Characterization of the 70-kDa peroxisomal membrane protein, an ATP binding cassette transporter. J Biol Chem, 1999. 274(17): p. 11968-76.

27. van Herwaarden, A.E., et al., Multidrug transporter ABCG2/breast cancer resistance protein secretes riboflavin (vitamin B2) into milk. Mol Cell Biol, 2007. 27(4): p. 1247-53. 
28. Krishnamurthy, P. and J.D. Schuetz, The ABC transporter Abcg2/Bcrp: role in hypoxia mediated survival. Biometals, 2005. 18(4): p. 349-58.

29. Yu, L., et al., Expression of $A B C G 5$ and $A B C G 8$ is required for regulation of biliary cholesterol secretion. J Biol Chem, 2005. 280(10): p. 8742-7.

30. Schuetz, J.D., et al., MRP4: A previously unidentified factor in resistance to nucleoside-based antiviral drugs. Nat Med, 1999. 5(9): p. 1048-51.

31. Ritter, C.A., et al., Cellular export of drugs and signaling molecules by the ATPbinding cassette transporters MRP4 (ABCC4) and MRP5 (ABCC5). Drug Metab Rev, 2005. 37(1): p. 253-78.

32. Zelcer, N., et al., Transport of bile acids in multidrug-resistance-protein 3overexpressing cells co-transfected with the ileal $\mathrm{Na}+$-dependent bile-acid transporter. Biochem J, 2003. 369(Pt 1): p. 23-30.

33. Chen, Z.S., et al., Analysis of methotrexate and folate transport by multidrug resistance protein 4 (ABCC4): MRP4 is a component of the methotrexate efflux system. Cancer Res, 2002. 62(11): p. 3144-50.

34. Rius, M., et al., Cotransport of reduced glutathione with bile salts by MRP4 (ABCC4) localized to the basolateral hepatocyte membrane. Hepatology, 2003. 38(2): p. 374-84.

35. Imaoka, T., et al., Functional involvement of multidrug resistance-associated protein 4 (MRP4/ABCC4) in the renal elimination of the antiviral drugs adefovir and tenofovir. Mol Pharmacol, 2007. 71(2): p. 619-27.

36. Ray, A.S., et al., Mechanism of active renal tubular efflux of tenofovir. Antimicrob Agents Chemother, 2006. 50(10): p. 3297-304.

37. $\mathrm{Ci}, \mathrm{L}$., et al., Involvement of MRP4 (ABCC4) in the luminal efflux of ceftizoxime and cefazolin in the kidney. Mol Pharmacol, 2007. 71(6): p. 1591-7.

38. Leggas, M., et al., Mrp4 confers resistance to topotecan and protects the brain from chemotherapy. Mol Cell Biol, 2004. 24(17): p. 7612-21.

39. Chen, Z.S., K. Lee, and G.D. Kruh, Transport of cyclic nucleotides and estradiol 17-beta-D-glucuronide by multidrug resistance protein 4. Resistance to 6mercaptopurine and 6-thioguanine. J Biol Chem, 2001. 276(36): p. 33747-54.

40. Rius, M., et al., Prostanoid transport by multidrug resistance protein 4 (MRP4/ABCC4) localized in tissues of the human urogenital tract. J Urol, 2005. 174(6): p. 2409-14.

41. Li, C., et al., Spatiotemporal coupling of cAMP transporter to CFTR chloride channel function in the gut epithelia. Cell, 2007. 131(5): p. 940-51. 
42. Nies, A.T., et al., Expression and immunolocalization of the multidrug resistance proteins, MRP1-MRP6 (ABCC1-ABCC6), in human brain. Neuroscience, 2004. 129(2): p. 349-60.

43. Belinsky, M.G., et al., Multidrug resistance protein 4 protects bone marrow, thymus, spleen, and intestine from nucleotide analogue-induced damage. Cancer Res, 2007. 67(1): p. 262-8.

44. Hasegawa, T., et al., Developmental roles of the steroidogenic acute regulatory protein (StAR) as revealed by StAR knockout mice. Mol Endocrinol, 2000. 14(9): p. $1462-71$.

45. Krishnamurthy, P., et al., Transporter-mediated protection against thiopurineinduced hematopoietic toxicity. Cancer Res, 2008. 68(13): p. 4983-9.

46. Sutherland, E.W. and T.W. Rall, Fractionation and characterization of a cyclic adenine ribonucleotide formed by tissue particles. J Biol Chem, 1958. 232(2): p. 1077-91.

47. Blumenthal, S.A., Earl Sutherland (1915-1975) and the discovery of cyclic AMP. Perspect Biol Med, 2012. 55(2): p. 236-49.

48. Jedlitschky, G., B. Burchell, and D. Keppler, The multidrug resistance protein 5 functions as an ATP-dependent export pump for cyclic nucleotides. J Biol Chem, 2000. 275(39): p. 30069-74.

49. Sellers, Z.M., et al., MRP4 and CFTR in the regulation of CAMP and betaadrenergic contraction in cardiac myocytes. Eur J Pharmacol, 2012. 681(1-3): p. 80-7.

50. Loe, D.W., et al., ATP-dependent 17 beta-estradiol 17-(beta-D-glucuronide) transport by multidrug resistance protein (MRP). Inhibition bycholestatic steroids. J Biol Chem, 1996. 271(16): p. 9683-9.

51. van Aubel, R.A., et al., Adenosine triphosphate-dependent transport of anionic conjugates by the rabbit multidrug resistance-associated protein Mrp2 expressed in insect cells. Mol Pharmacol, 1998. 53(6): p. 1062-7.

52. Zeng, H., et al., Transport of amphipathic anions by human multidrug resistance protein 3. Cancer Res, 2000. 60(17): p. 4779-84.

53. Zelcer, N., et al., Steroid and bile acid conjugates are substrates of human multidrug-resistance protein (MRP) 4 (ATP-binding cassette C4). Biochem J, 2003. 371(Pt 2): p. 361-7.

54. Ho, L.L., et al., Androgen regulation of multidrug resistance-associated protein 4 (MRP4/ABCC4) in prostate cancer. Prostate, 2008. 68(13): p. 1421-9. 
55. Cai, C., et al., Androgen induces expression of the multidrug resistance protein gene MRP4 in prostate cancer cells. Prostate Cancer Prostatic Dis, 2007. 10(1): p. $39-45$.

56. Griswold, M.D., The central role of Sertoli cells in spermatogenesis. Semin Cell Dev Biol, 1998. 9(4): p. 411-6.

57. Shalet, S.M., Normal testicular function and spermatogenesis. Pediatr Blood Cancer, 2009. 53(2): p. 285-8.

58. Neaves, W.B., et al., Leydig cell numbers, daily sperm production, and serum gonadotropin levels in aging men. J Clin Endocrinol Metab, 1984. 59(4): p. 75663.

59. Huhtaniemi, I. and L.J. Pelliniemi, Fetal Leydig cells: cellular origin, morphology, life span, and special functionalfeatures. Proc Soc Exp Biol Med, 1992. 201(2): p. 125-40.

60. Baird, D.T., et al., The concentration of oestrone and oestradiol-17 in spermatic venous blood in man. J Endocrinol, 1973. 57(2): p. 285-8.

61. Dufau, M.L., Endocrine regulation and communicating functions of the Leydig cell. Annu Rev Physiol, 1988. 50: p. 483-508.

62. Johnson, L.R. and J.H. Byrne, Essential medical physiology. 2nd ed1998, Philadelphia: Lippincott-Raven. xii, 858 p.

63. Payne, A.H. and G.L. Youngblood, Regulation of expression of steroidogenic enzymes in Leydig cells. Biol Reprod, 1995. 52(2): p. 217-25.

64. Nieschlag, E., H.M. Behre, and S. Nieschlag, Andrology : male reproductive health and dysfunction. 3rd ed2010, Heidelberg ; New York: Springer. xvii, p.629

65. Sherins, R.J. and D.L. Loriaux, Studies of the role of sex steroids in the feedback control of FSH concentrations in men. J Clin Endocrinol Metab, 1973. 36(5): p. 886-93.

66. Mooradian, A.D., J.E. Morley, and S.G. Korenman, Biological actions of androgens. Endocr Rev, 1987. 8(1): p. 1-28.

67. O'Donnell, L., et al., Testosterone promotes the conversion of round spermatids between stages VII and VIII of the rat spermatogenic cycle. Endocrinology, 1994. 135(6): p. 2608-14.

68. McLachlan, R.I., et al., Testosterone effects on spermatogenesis in the gonadotropin-releasing hormone-immunized rat. Biol Reprod, 1994. 50(2): p. 271-80. 
69. Ghosh, S., A.P. Sinha-Hikim, and L.D. Russell, Further observations of stagespecific effects seen after short-term hypophysectomy in the rat. Tissue Cell, 1991. 23(5): p. 613-30.

70. Franca, L.R., et al., Hormonal regulation of spermatogenesis in the hypophysectomized rat: quantitation of germ-cell population and effect of elimination of residual testosterone after long-term hypophysectomy. J Androl, 1998. 19(3): p. 335-40; discussion 341-2.

71. Cattanach, B.M., et al., Gonadotrophin-releasing hormone deficiency in a mutant mouse with hypogonadism. Nature, 1977. 269(5626): p. 338-40.

72. O'Shaughnessy, P.J., et al., Fetal development of Leydig cell activity in the mouse is independent of pituitary gonadotroph function. Endocrinology, 1998. 139(3): p. 1141-6.

73. Singh, J., C. O'Neill, and D.J. Handelsman, Induction of spermatogenesis by androgens in gonadotropin-deficient (hpg) mice. Endocrinology, 1995. 136(12): p. 5311-21.

74. Lei, Z.M., et al., Targeted disruption of luteinizing hormone/human chorionic gonadotropin receptor gene. Mol Endocrinol, 2001. 15(1): p. 184-200.

75. Vanderschueren, D., et al., Androgens and bone. Endocr Rev, 2004. 25(3): p. 389425.

76. Ren, S.G., et al., Direct administration of testosterone increases rat tibial epiphyseal growth plate width. Acta Endocrinol (Copenh), 1989. 121(3): p. 401-5.

77. Ray, R., et al., Sex steroids and stem cell function. Mol Med, 2008. 14(7-8): p. 493-501.

78. Liu, X.H., et al., Androgens promote preosteoblast differentiation via activation of the canonical Wnt signaling pathway. Ann N Y Acad Sci, 2007. 1116: p. 42331.

79. Tenover, J.S., Effects of testosterone supplementation in the aging male. J Clin Endocrinol Metab, 1992. 75(4): p. 1092-8.

80. Ferrando, A.A., et al., Testosterone administration to older men improves muscle function: molecular and physiological mechanisms. Am J Physiol Endocrinol Metab, 2002. 282(3): p. E601-7.

81. Kenny, A.M., et al., Effects of transdermal testosterone on bone and muscle in older men with low bioavailable testosterone levels. J Gerontol A Biol Sci Med Sci, 2001. 56(5): p. M266-72. 
82. Urban, R.J., et al., Testosterone administration to elderly men increases skeletal muscle strength and protein synthesis. Am J Physiol, 1995. 269(5 Pt 1): p. E8206.

83. Saad, F. and L. Gooren, The role of testosterone in the metabolic syndrome: a review. J Steroid Biochem Mol Biol, 2009. 114(1-2): p. 40-3.

84. Allan, C.A., et al., Testosterone therapy prevents gain in visceral adipose tissue and loss of skeletal muscle in nonobese aging men. J Clin Endocrinol Metab, 2008. 93(1): p. 139-46.

85. Schroeder, E.T., et al., Effects of androgen therapy on adipose tissue and metabolism in older men. J Clin Endocrinol Metab, 2004. 89(10): p. 4863-72.

86. Simon, D., et al., Association between plasma total testosterone and cardiovascular risk factors in healthy adult men: The Telecom Study. J Clin Endocrinol Metab, 1997. 82(2): p. 682-5.

87. Svartberg, J., et al., Association of endogenous testosterone with blood pressure and left ventricular mass in men. The Tromso Study. Eur J Endocrinol, 2004. 150(1): p. 65-71.

88. Marin, P., et al., Androgen treatment of abdominally obese men. Obes Res, 1993. 1(4): p. 245-51.

89. Arakane, F., et al., Phosphorylation of steroidogenic acute regulatory protein (StAR) modulates its steroidogenic activity. J Biol Chem, 1997. 272(51): p. 32656-62.

90. Calle, R.A., et al., ANPs effect on MARCKS and StAR phosphorylation in agoniststimulated glomerulosa cells. Mol Cell Endocrinol, 2001. 177(1-2): p. 71-9.

91. Baker, B.Y., et al., Cholesterol binding does not predict activity of the steroidogenic acute regulatory protein, StAR. J Biol Chem, 2007. 282(14): p. 10223-32.

92. Bose, H.S., V.R. Lingappa, and W.L. Miller, Rapid regulation of steroidogenesis by mitochondrial protein import. Nature, 2002. 417(6884): p. 87-91.

93. Katsumata, N., et al., Adrenal gland. Significance of new StAR gene mutation of S195A-StAR phosphorylation found in congenital adrenal lipoid hyperplasia. Clin Endocrinol, 2000. 48: p. 141-143.

94. Lacapere, J.J. and V. Papadopoulos, Peripheral-type benzodiazepine receptor: structure and function of a cholesterol-binding protein in steroid and bile acid biosynthesis. Steroids, 2003. 68(7-8): p. 569-85. 
95. Hauet, T., et al, Peripheral-type benzodiazepine receptor-mediated action of steroidogenic acute regulatory protein on cholesterol entry into leydig cell mitochondria. Mol Endocrinol, 2005. 19(2): p. 540-54.

96. Papadopoulos, V., et al., Targeted disruption of the peripheral-type benzodiazepine receptor gene inhibits steroidogenesis in the R2C Leydig tumor cell line. J Biol Chem, 1997. 272(51): p. 32129-35.

97. Papadopoulos, V., et al., Peripheral benzodiazepine receptor in cholesterol ransport and steroidogenesis. Steroids, 1997. 62(1): p. 21-8.

98. West, L.A., et al., Steroidogenic acute regulatory protein and peripheral-type benzodiazepine receptor associate at the mitochondrial membrane. Endocrinology, 2001. 142(1): p. 502-5.

99. Kishi, H., et al., Down-regulation of $L H / h C G$ receptor in rat cultured granulosa cells. FEBS letters, 1997. 402(2-3): p. 198-202.

100. Wang, H., D.L. Segaloff, and M. Ascoli, Lutropin/choriogonadotropin downregulates its receptor by both receptor-mediated endocytosis and a cAMPdependent reduction in receptor mRNA. J Biol Chem, 1991. 266(2): p. 780-5.

101. Nelson, S. and M. Ascoli, Epidermal growth factor, a phorbol ester, and 3',5'cyclic adenosine monophosphate decrease the transcription of the luteinizing hormone/chorionic gonadotropin receptor gene in MA-10 Leydig tumor cells. Endocrinology, 1992. 131(2): p. 615-20.

102. Mayr, B. and M. Montminy, Transcriptional regulation by the phosphorylationdependent factor CREB. Nat Rev Mol Cell Biol, 2001. 2(8): p. 599-609.

103. Manna, P.R., M.T. Dyson, and D.M. Stocco, Regulation of the steroidogenic acute regulatory protein gene expression: present and future perspectives. Mol Hum Reprod, 2009. 15(6): p. 321-33.

104. Clem, B.F., E.A. Hudson, and B.J. Clark, Cyclic adenosine 3',5'-monophosphate (cAMP) enhances $c A M P$-responsive element binding (CREB) protein phosphorylation and phospho-CREB interaction with the mouse steroidogenic acute regulatory protein gene promoter. Endocrinology, 2005. 146(3): p. 134856.

105. Sugawara, T., N. Sakuragi, and H. Minakami, CREM confers cAMP responsiveness in human steroidogenic acute regulatory protein expression in NCI-H295R cells rather than SF-1/Ad4BP. J Endocrinol, 2006. 191(1): p. 327-37.

106. Stocco, D.M., et al., Elements involved in the regulation of the StAR gene. Mol Cell Endocrinol, 2001. 177(1-2): p. 55-9. 
107. Clark, B.J., V. Ranganathan, and R. Combs, Post-translational regulation of steroidogenic acute regulatory protein by cAMP-dependent protein kinase A. Endocr Res, 2000. 26(4): p. 681-9.

108. Boujrad, N., et al., Acute action of choriogonadotropin on Leydig tumor cells: induction of a higher affinity benzodiazepine-binding site related to steroid biosynthesis. Endocrinology, 1994. 135(4): p. 1576-83.

109. Zhang, X., et al., Genome-wide analysis of cAMP-response element binding protein occupancy, phosphorylation, and target gene activation in human tissues. Proc Natl Acad Sci U S A, 2005. 102(12): p. 4459-64.

110. Anakwe, O.O. and A.H. Payne, Noncoordinate regulation of de novo synthesis of cytochrome P-450 cholesterol side-chain cleavage and cytochrome P-450 17 alpha-hydroxylase/C17-20 lyase in mouse Leydig cell cultures: relation to steroid production. Mol Endocrinol, 1987. 1(9): p. 595-603.

111. Liu, F.C. and A.M. Graybiel, Spatiotemporal dynamics of CREB phosphorylation: transient versus sustained phosphorylation in the developing striatum. Neuron, 1996. 17(6): p. 1133-44.

112. You, L., Steroid hormone biotransformation andxenobiotic induction of hepatic steroid metabolizing enzymes. Chem Biol Interact, 2004. 147(3): p. 233-46.

113. Zhang, Y.Y. and L. Yang, Interactions between human cytochrome P450 enzymes and steroids: physiological and pharmacological implications. Expert Opin Drug Metab Toxicol, 2009. 5(6): p. 621-9.

114. Guengerich, F.P., Cytochrome P450s and other enzymes in drug metabolism and toxicity. AAPS J, 2006. 8(1): p. E101-11.

115. Turgeon, D., et al., Relative enzymatic activity, protein stability, and tissue distribution of human steroid-metabolizing UGT2B subfamily members. Endocrinology, 2001. 142(2): p. 778-87.

116. Strott, C.A., Sulfonation and molecular action. Endocr Rev, 2002. 23(5): p. 70332.

117. Ball, P. and R. Knuppen, Catecholoestrogens (2-and 4-hydroxyoestrogens): chemistry, biogenesis, metabolism, occurrence and physiological significance. Acta Endocrinol Suppl (Copenh), 1980. 232: p. 1-127.

118. Witt, B.R. and I.H. Thorneycroft, Reproductive steroid hormones: generation, degradation, reception, and action. Clin Obstet Gynecol, 1990. 33(3): p. 563-75.

119. Nelson, D.R., The cytochrome 450 homepage. Hum Genomics, 2009. 4(1): p. 59-65. 
120. Arlotto, M.P., J.M. Trant, and R.W. Estabrook, Measurement of steroid hydroxylation reactions by high-performance liquid chromatography as indicator of P450 identity and function. Methods Enzymol, 1991. 206: p. 454-62.

121. Domanski, T.L., et al., Dual role of human cytochrome P450 3 A4 residue Phe304 in substrate specificity and cooperativity. J Pharmacol Exp Ther, 2000. 293(2): p. 585-91.

122. Choi, M.H., et al., Characterization of testosterone 11 beta-hydroxylation catalyzed by human liver microsomal cytochromes P450. Drug Metab Dispos, 2005. 33(6): p. 714-8.

123. Shimada, T., et al., Interindividual variations in human liver cytochrome P-450 enzymes involved in the oxidation of drugs, carcinogens and toxic chemicals: studies with liver microsomes of 30 Japanese and 30 Caucasians. J Pharmacol Exp Ther, 1994. 270(1): p. 414-23.

124. Imaoka, S., et al,, Multiple forms of human P450 expressed in Saccharomyces cerevisiae. Systematic characterization and comparison with those of the rat. Biochem Pharmacol, 1996. 51(8): p. 1041-50.

125. Ekins, S., et al., Further characterization of the expression in liver and catalytic activity of CYP2B6. J Pharmacol Exp Ther, 1998. 286(3): p. 1253-9.

126. Yamazaki, H. and T. Shimada, Progesterone and testosterone hydroxylation by cytochromes P450 2C19,2C9, and $3 \mathrm{~A} 4$ in human liver microsomes. Arch Biochem Biophys, 1997. 346(1): p. 161-9.

127. Payne, A.H. and D.B. Hales, Overview of steroidogenic enzymes in the pathway from cholesterol to active steroid hormones. Endocr Rev, 2004. 25(6): p. 947-70.

128. Honkakoski, P., A. Kojo, and M.A. Lang, Regulation of the mouse liver cytochrome P450 2B subfamily by sex hormones and phenobarbital. Biochem J, 1992. 285 ( Pt 3): p. 979-83.

129. Honkakoski, P., et al., The nuclear orphan receptor CAR-retinoid X receptor heterodimer activates the phenobarbital-responsive enhancer module of the CYP2B gene. Mol Cell Biol, 1998. 18(10): p. 5652-8.

130. Kawamoto, T., et al., Estrogen activation of the nuclear orphan receptor CAR (constitutive active receptor) in induction of the mouse Cyp2b10 gene. Mol Endocrinol, 2000. 14(11): p. 1897-905.

131. Petry, F., et al., Subcellular localization of rat Abca5, a rat ATP-binding-cassette transporter expressed in Leydig cells, and characterization of its splice variant apparently encoding a half-transporter. Biochem J, 2006. 393(Pt 1): p. 79-87. 
132. Melaine, N., et al., Molecular cloning of several rat $A B C$ transporters including a new $A B C$ transporter, $A b c b 8$, and their expression in rat testis. Int J Androl, 2006. 29(3): p. 392-9.

133. Bart, J., et al., The distribution of drug-efflux pumps, P-gp, BCRP, MRP1 and $M R P 2$, in the normal blood-testis barrier and in primary testicular tumours. Eur $\mathrm{J}$ Cancer, 2004. 40(14): p. 2064-70.

134. Fatima, S., S. Zhou, and B.P. Sorrentino, Abcg2 expression marks tissue-specific stem cells in multiple organs in a mouse progeny tracking model. Stem Cells, 2012. 30(2): p. 210-21.

135. Sivils, J.C., I. Gonzalez, and L.J. Bain, Mice lacking Mrp1 have reduced testicular steroid hormone levels and alterations in steroid biosynthetic enzymes. Gen Comp Endocrinol, 2010. 167(1): p. 51-9.

136. Lee, $\mathrm{K}$., et al., Isolation of MOAT-B, a widely expressed multidrug resistanceassociated protein/canalicular multispecific organic anion transporter-related transporter. Cancer Res, 1998. 58(13): p. 2741-7.

137. Maher, J.M., et al., Tissue distribution and hepatic and renal ontogeny of the multidrug resistance-associated protein (Mrp) family in mice. Drug Metab Dispos, 2005. 33(7): p. 947-55.

138. Morgan, J.A., et al., Deregulated hepatic metabolism exacerbates impaired testosterone production in Mrp4-deficient mice. J Biol Chem, 2012. 287(18): p. 14456-66.

139. Bradford, M.M., A rapid and sensitive method for the quantitation of microgram quantities of protein utilizing the principle of protein-dye binding. Anal Biochem, 1976. 72: p. 248-54.

140. Wijnholds, J., et al., Multidrug resistance protein 1 protects the oropharyngeal mucosal layer and the testicular tubules against drug-induced damage. J Exp Med, 1998. 188(5): p. 797-808.

141. O'Shaughnessy, P.J., L. Willerton, and P.J. Baker, Changes in Leydig cell gene expression during development in the mouse. Biol Reprod, 2002. 66(4): p. 966-75.

142. Ge, R.S., et al., Gene expression in rat leydig cells during development from the progenitor to adult stage: a cluster analysis. Biol Reprod, 2005. 72(6): p. 140515.

143. McLachlan, R.I., et al., Effects of testosterone on spermatogenic cell populations in the adult rat. Biol Reprod, 1994. 51(5): p. 945-55. 
144. Wolgemuth, D.J., E. Laurion, and K.M. Lele, Regulation of the mitotic and meiotic cell cycles in the male germ line. Recent Prog Horm Res, 2002. 57: p. 75101.

145. Huhtaniemi, I., Mutations along the pituitary-gonadal axis affecting sexual maturation: novel information from transgenic and knockout mice. Mol Cell Endocrinol, 2006. 254-255: p. 84-90.

146. Ahtiainen, P., et al., Phenotypic characterisation of mice with exaggerated and missing LH/hCG action. Mol Cell Endocrinol, 2007. 260-262: p. 255-63.

147. Clark, B.J. and R.K. Cochrum, The steroidogenic acute regulatory protein as a target of endocrine disruption in male reproduction. Drug Metab Rev, 2007. 39(2-3): p. 353-70.

148. Vasta, V., M. Shimizu-A lbergine, and J.A. Beavo, Modulation of Leydig cell function by cyclic nucleotide phosphodiesterase 8A. Proc Natl Acad Sci U S A, 2006. 103(52): p. 19925-30.

149. Nikolsky, Y., et al., Functional analysis of OMICs data and small molecule compounds in an integrated "knowledge-based" platform. Methods Mol Biol, 2009. 563: p. 177-96.

150. Eacker, S.M., et al., Hormonal regulation of testicular steroid and cholesterol homeostasis. Mol Endocrinol, 2008. 22(3): p. 623-35.

151. Shaywitz, A.J. and M.E. Greenberg, CREB: a stimulus-induced transcription factor activated by a diverse array of extracellular signals. Annu Rev Biochem, 1999. 68: p. 821-61.

152. Awoniyi, C.A., et al., Quantitative restoration of advanced spermatogenic cells in adult male rats made azoospermic by active immunization against luteinizing hormone or gonadotropin-releasing hormone. Endocrinology, 1989. 125(3): p. 1303-9.

153. Sofikitis, N., et al., Hormonal regulation of spermatogenesis and spermiogenesis. J Steroid Biochem Mol Biol, 2008. 109(3-5): p. 323-30.

154. Pareek, T.K., et al., Insights into male germ cell apoptosis due to depletion of gonadotropins caused by GnRH antagonists. Apoptosis, 2007. 12(6): p. 1085100.

155. McLachlan, R.I., et al., The effects of recombinant follicle-stimulating hormone on the restoration of spermatogenesis in the gonadotropin-releasing hormoneimmunized adult rat. Endocrinology, 1995. 136(9): p. 4035-43.

156. Nebert, D.W. and D.W. Russell, Clinical importance of the cytochromes P450. Lancet, 2002. 360(9340): p. 1155-62. 
157. Waxman, D.J., Interactions of hepatic cytochromes P-450 with steroid hormones. Regioselectivity and stereospecificity of steroid metabolism and hormonal regulation of rat P-450 enzyme expression. Biochem Pharmacol, 1988. 37(1): p. 71-84.

158. Sih, C.J., Enzymatic mechanism of steroid hydroxylation. Science, 1969. 163(3873): p. 1297-300.

159. Waxman, D.J., et al., Human liver microsomal steroid metabolism: identification of the major microsomal steroid hormone 6 beta-hydroxylase cytochrome P-450 enzyme. Arch Biochem Biophys, 1988. 263(2): p. 424-36.

160. Marker, P.C., et al., Hormonal, cellular, and molecular control of prostatic development. Dev Biol, 2003. 253(2): p. 165-74.

161. Janvilisri, T., et al., Sterol transport by the human breast cancer resistance protein (ABCG2) expressed in Lactococcus lactis. J Biol Chem, 2003. 278(23): p. 20645-51.

162. Suzuki, T., et al., Identification and characterization of novel rat and human gonad-specific organic anion transporters. Mol Endocrinol, 2003. 17(7): p. 120315.

163. Kawamoto, T., et al., Estrogen activation of the nuclearorphan receptor CAR (constitutive active receptor) in induction of the mouse Cyp $2 b 10$ gene. Molecular endocrinology, 2000. 14(11): p. 1897-905.

164. Walker, W.H., Molecular mechanisms of testosterone action in spermatogenesis. Steroids, 2009. 74(7): p. 602-7.

165. Selva, D.M., et al., The ATP-binding cassette transporter 1 mediates lipid efflux from Sertoli cells and influences male fertility. J Lipid Res, 2004. 45(6): p. 104050 .

166. Badri, S.N., G. Vanithakumari, and T. Malini, Studies on methotrexate effects on testicular steroidogenesis in rats. Endocr Res, 2000. 26(2): p. 247-62.

167. El-Sheikh, A.A., et al., Interaction of nonsteroidal anti-inflammatory drugs with multidrug resistance protein (MRP) 2/ABCC2- and MRP4/ABCC4-mediated methotrexate transport. J Pharmacol Exp Ther, 2007. 320(1): p. 229-35.

168. Nozaki, Y., et al., Species difference in the inhibitory effect of nonsteroidal antiinflammatory drugs on the uptake of methotrexate by human kidney slices. $\mathrm{J}$ Pharmacol Exp Ther, 2007. 322(3): p. 1162-70.

169. Conte, D., et al., Aspirin inhibits androgen response to chorionic gonadotropin in humans. Am J Physiol, 1999. 277(6 Pt 1): p. E1032-7. 
170. Didolkar, A.K., P.B. Patel, and D. Roychowdhury, Effect of aspirin on spermatogenesis in mature and immature rats. Int J Androl, 1980. 3(5): p. 58593.

171. Biswas, N.M., et al., Andrenogonadal interactions in nicotine-induced alteration of steroidogenesis in male rat. Andrologia, 1979. 11(3): p. 227-33.

172. Awoniyi, C.A., et al., Exogenously administered testosterone maintains spermatogenesis quantitatively in adult rats actively immunized against gonadotropin-releasing hormone. Endocrinology, 1992. 130(6): p. 3283-8.

173. Sinha, Y.N., et al., Gonadal regulation of prolactin and growth hormone secretion in the mouse. Biol Reprod, 1979. 21(2): p. 473-81.

174. Henriksen, K., H. Hakovirta, and M. Parvinen, Testosterone inhibits and induces apoptosis in rat seminiferous tubules in a stage-specific manner: in situ quantification in squash preparations after administration of ethane dimethane sulfonate. Endocrinology, 1995. 136(8): p. 3285-91.

175. McLachlan, R.I., et al., Hormonal regulation of spermatogenesis in primates and man: insights for development of the male hormonal contraceptive. J Androl, 2002. 23(2): p. 149-62.

176. Sugawara, T., et al., Regulation of expression of the steroidogenic acute regulatory protein (StAR) gene: a central role for steroidogenic factor 1. Steroids, 1997. 62(1): p. 5-9.

177. Sugawara, T., et al., Multiple steroidogenic factor 1 binding elements in the human steroidogenic acute regulatory protein gene 5'-flanking region are required for maximal promoter activity and cyclic AMP responsiveness. Biochemistry, 1997. 36(23): p. 7249-55.

178. Sandhoff, T.W., et al., Transcriptional regulation of the rat steroidogenic acute regulatory protein gene by steroidogenic factor 1 . Endocrinology, 1998. 139(12): p. $4820-31$.

179. Papadopoulos, V., J. Liu, and M. Culty, Is there a mitochondrial signaling complex facilitating cholesterol import? Mol Cell Endocrinol, 2007. 265-266: p. 59-64.

180. Lodish, H.F., Molecular cell biology. 4th ed2000, New York: W.H. Freeman. xxxvi, 1084, G-17, I-36 p.

181. Conti, M., et al., Cyclic AMP-specific PDE4 phosphodiesterases as critical components of cyclic AMP signaling. J Biol Chem, 2003. 278(8): p. 5493-6.

182. Andric, S.A., et al., Protein kinase G-mediated stimulation of basal Leydig cell steroidogenesis. Am J Physiol Endocrinol Metab, 2007. 293(5): p. E1399-408. 
183. Shimizu-Albergine, M., et al., cAMP-specific phosphodiesterases $8 A$ and $8 B$, essential regulators of Leydig cell steroidogenesis. Mol Pharmacol, 2012. 81(4): p. 556-66.

184. Klucken, J., et al., ABCG1 (ABC8), the human homolog of the Drosophila white gene, is a regulator of macrophage cholesterol and phospholipid transport. Proc Natl Acad Sci U S A, 2000. 97(2): p. 817-22.

185. Yu, L., et al., Overexpression of ABCG5 and ABCG8 promotes biliary cholesterol secretion and reduces fractional absorption of dietary cholesterol. J Clin Invest, 2002. 110(5): p. 671-80.

186. Sakuma, T., et al., A novel female-specific member of the CYP3A gene subfamily in the mouse liver. Arch Biochem Biophys, 2000. 377(1): p. 153-62.

187. Brinkmann, A.O., Molecular mechanisms of androgen action--a historical perspective. Methods Mol Biol, 2011. 776: p. 3-24.

188. Janke, D., et al., 6-mercaptopurine and 9-(2-phosphonyl-methoxyethyl) adenine (PMEA) transport altered by two missense mutations in the drug transporter gene ABCC4. Hum Mutat, 2008. 29(5): p. 659-69.

189. Abla, N., et al., The human multidrug resistance protein 4 (MRP4, ABCC4): functional analysis of a highly polymorphic gene. J Pharmacol Exp Ther, 2008. 325(3): p. 859-68.

190. Bendre, S.V., et al., Lymphocyte Hprt mutant frequency and sperm toxicity in C57BL/6 mice treated chronically with Azathioprine. Mutat Res, 2005. 578(1-2): p. $1-14$.

191. Seibel, N.L., Treatment of acute lymphoblastic leukemia in children and adolescents: peaks and pitfalls. Hematology Am Soc Hematol Educ Program, 2008: p. 374-80.

192. Hoelzer, D. and N. Gokbuget, New approaches to acute lymphoblastic leukemia in adults: where do we go? Semin Oncol, 2000. 27(5): p. 540-59.

193. Polifka, J.E. and J.M. Friedman, Teratogen update: azathioprine and 6mercaptopurine. Teratology, 2002. 65(5): p. 240-61.

194. Ligumsky, M., et al., Effects of 6-mercaptopurine treatment on sperm production and reproductive performance: a study in male mice. Scand J Gastroenterol, 2005. 40(4): p. 444-9. 


\section{VITA}

Jessica Ann Morgan was born in Memphis, TN, in 1979. Raised in Atoka, TN, she graduated from Munford High School in 1997. Upon completion of high school, she attended Christian Brothers University in Memphis, TN, where she graduated in 2001 with a Bachelor of Science Degree in Biology. In 2006, she entered the IPBS program at the University of Tennessee Health Science Center in the track of Molecular Therapeutics and Cell Signaling. She is expected to graduate in December 2012. 